\title{
The Design of Aromatic Ring-Based Polyphosphonium Salts Synthesized via ROMP and the Investigation into Their Antibacterial and Hemolytic
}

\section{Activities}

Hilal Kuday ${ }^{a} \dagger ;$ N. Ceren Süer ${ }^{b} ;$ Ali Bayır ${ }^{b}$; Burak Aksu ${ }^{c}$; Arzu Hatipoğlu ${ }^{b}$; Mehmet Mücahit Güncü̈ ; İlayda Acaroğlu Degitz ${ }^{b}$, Markus Gallei $^{d}$, Tarik Eren ${ }^{b *}$

†: Contributed equally

Authors' affiliation

aDepartment of Pharmacy, Istanbul Yeni Yuzyil University, Topkapi Azmi Ofluoglu Campus, Zeytinburnu 34010, Istanbul, Turkey.

${ }^{b}$ Department of Chemistry, Faculty of Science and Arts, Yildiz Technical University, Davutpasa Campus, 34220 Esenler, Istanbul, Turkey.

${ }^{\mathrm{c}}$ Department of Medical Microbiology, Faculty of Medicine, Marmara University, Basibuyuk Campus, 34854 Maltepe, Istanbul, Turkey.

${ }^{\mathrm{d} O r g a n i c ~ M a c r o m o l e c u l a r ~ C h e m i s t r y, ~ S a a r l a n d ~ U n i v e r s i t y, ~ C a m p u s ~ S a a r b r u ̈ c k e n ~ C 4 ~ 2, ~} 66123$ Saarbrücken, Germany

Tarik Eren (corresponding author). Department of Chemistry, Faculty of Science and Arts, Yildiz Technical University, Davutpasa Campus, 34220 Esenler, Istanbul, Turkey.

*e-mail: teren@yildiz.edu.tr 


\section{Table of Contents}

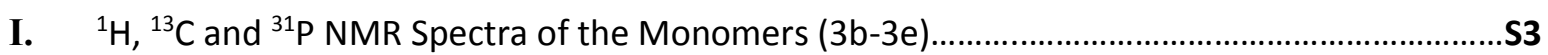

II. ${ }^{1} \mathrm{H}$ and ${ }^{13} \mathrm{C}$ NMR Spectra and SEC and Zeta Size Graph of the Homopolymers (4b-4e)............S9

III. A Molecular Electrostatic Potential (MEP) Analysis of Monomers ........................................S19

IV. Antibacterial and Hemolytic Activity and Zeta Size and Potential Properties of the Homopolymers.

V. ${ }^{1} \mathrm{H}$ and ${ }^{13} \mathrm{C}$ Spectra and SEC Graph of the Copolymers (5a-5r)........ S23

VI. Antibacterial and Hemolytic Activity of the Copolymers. 
I. ${ }^{1} \mathrm{H},{ }^{13} \mathrm{C}$ and ${ }^{31} \mathrm{P}$ NMR Spectra of the Monomers (3b-3e)
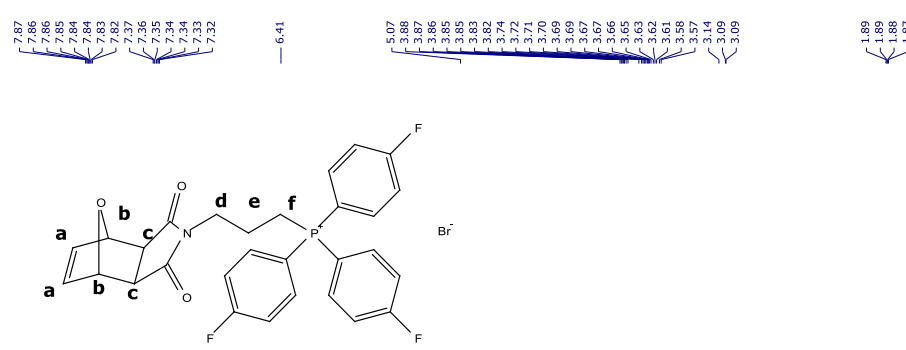

Phenyl rings

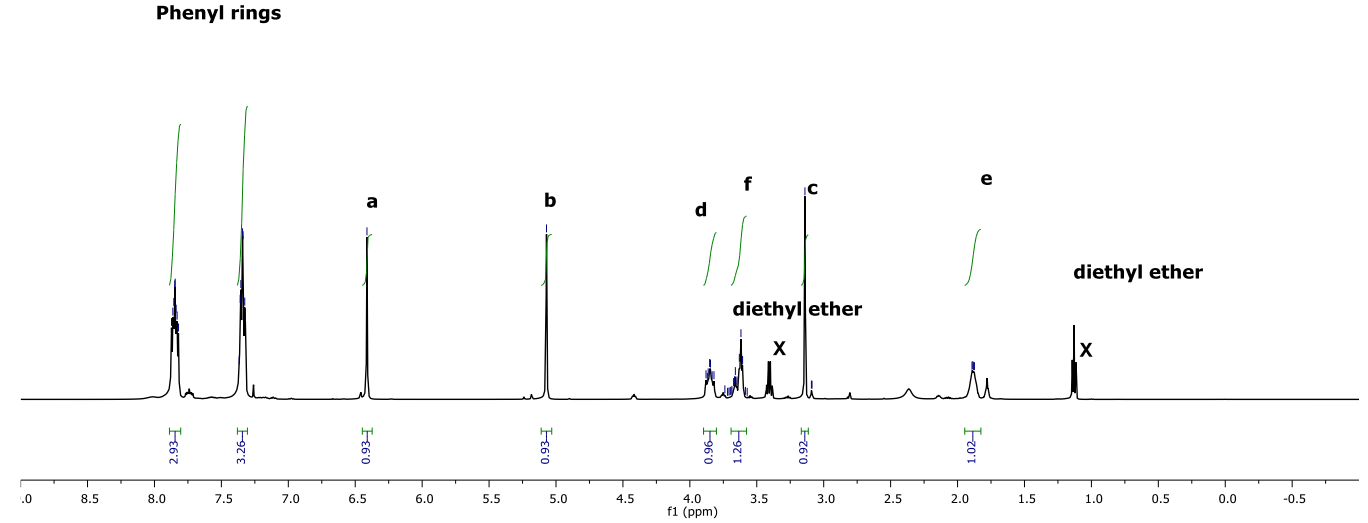

Figure S1. ${ }^{1} \mathrm{H}$ NMR spectrum of tris (4-fluorophenyl) phosphine monomer in $\mathrm{CDCl}_{3}$. (3b)

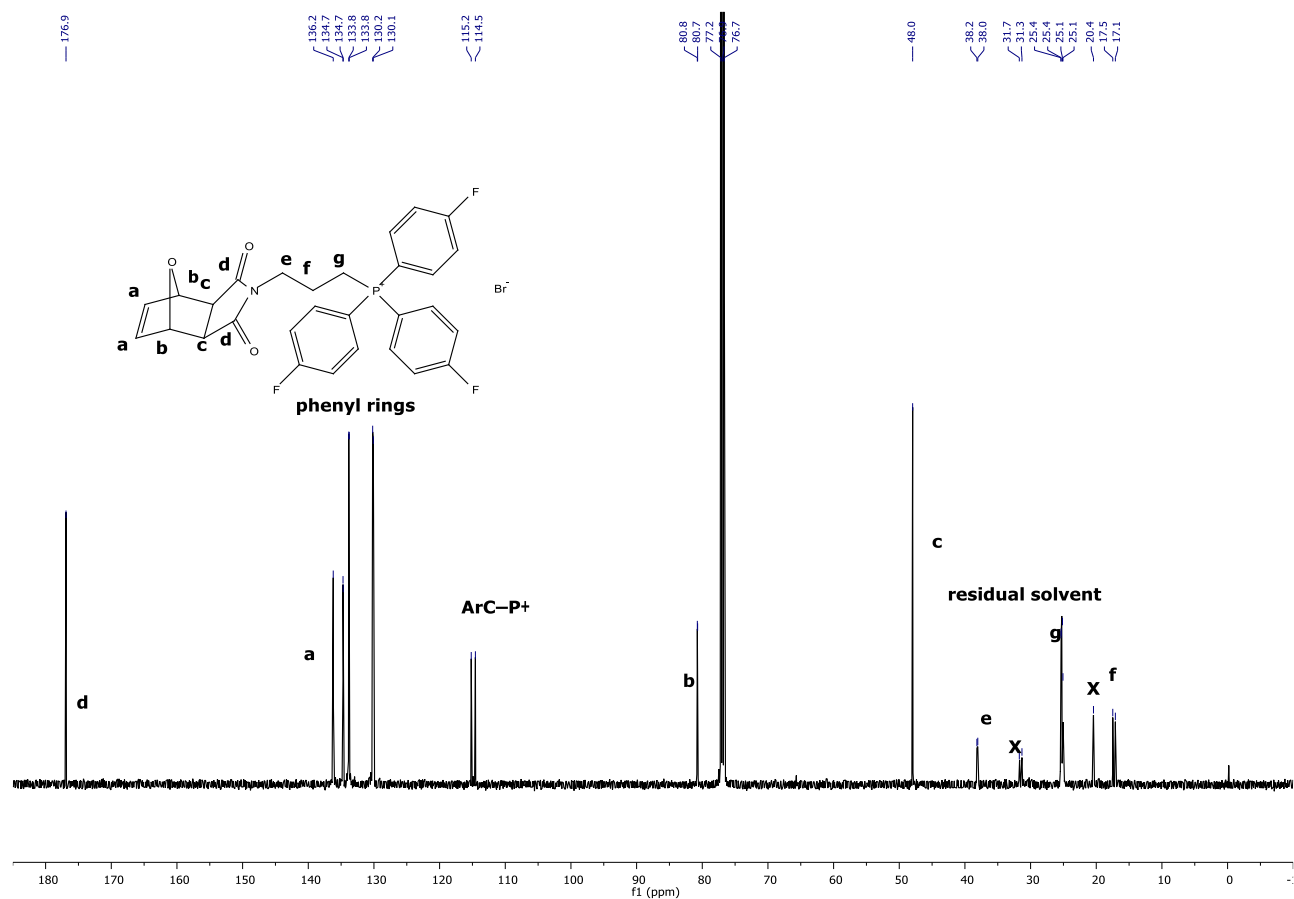

Figure S2. ${ }^{13} \mathrm{C}$ NMR spectrum of tris (4-fluorophenyl) phosphine monomer in $\mathrm{CDCl}_{3}$. (3b) 


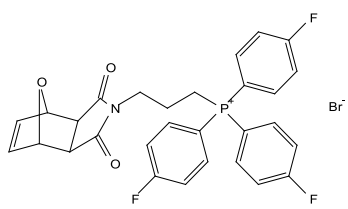

$31 \mathrm{P} \mathrm{NMR} \mathrm{(} 200 \mathrm{MHz}, \mathrm{CDCl}_{3}$ )

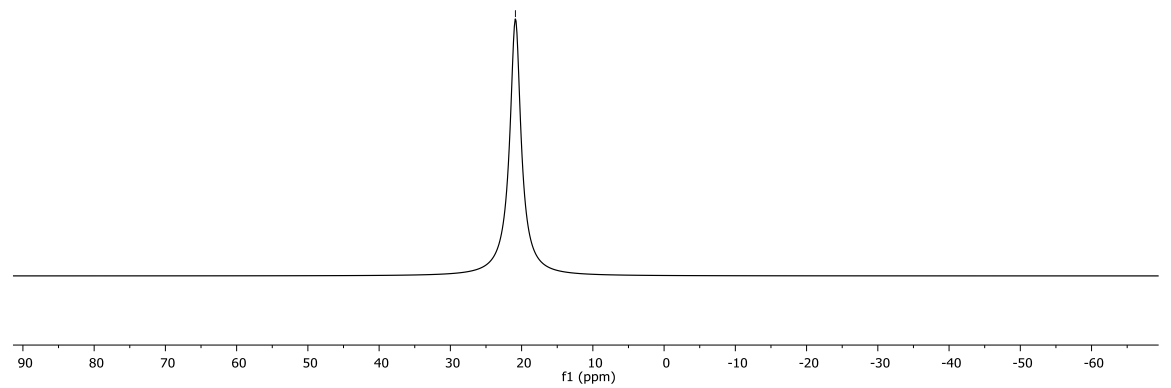

Figure S3. ${ }^{31} \mathrm{P}$ NMR spectrum of tris (4-fluorophenyl) phosphine monomer in $\mathrm{CDCl}_{3}$. (3b)

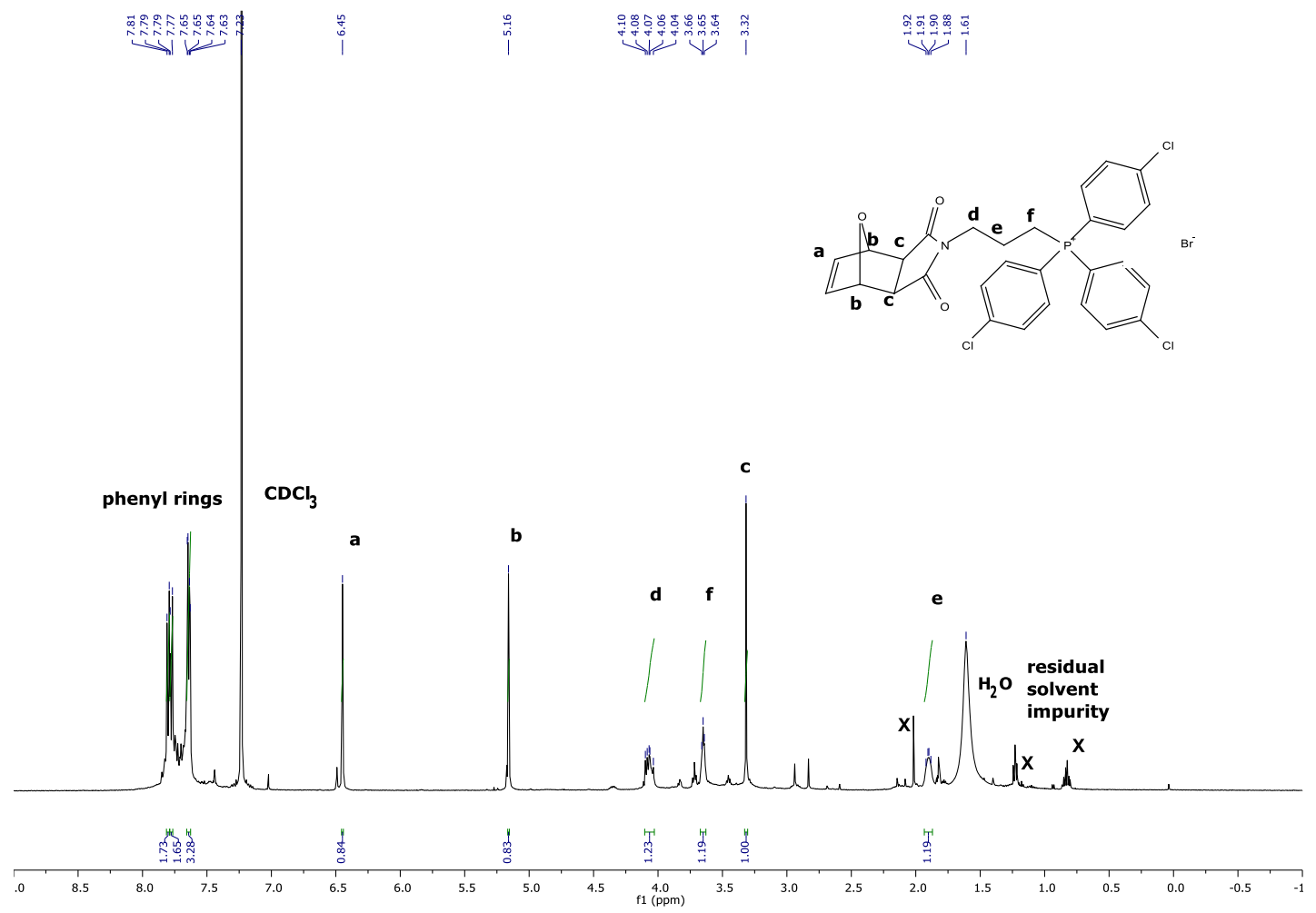

Figure S4. ${ }^{1} \mathrm{H}$ NMR spectrum of tris (4-chlorophenyl) phosphine based monomer in $\mathrm{CDCl}_{3}$. 


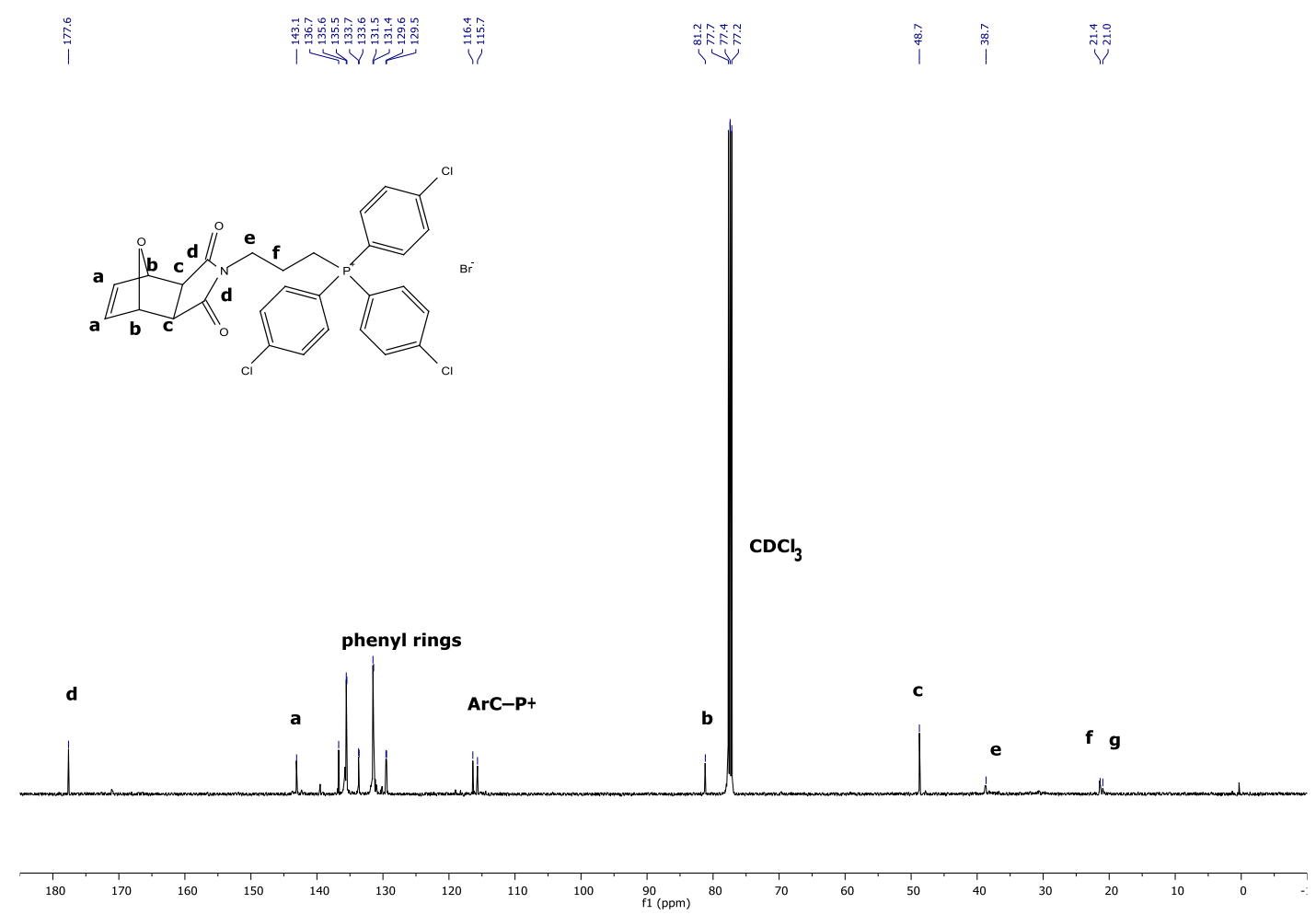

Figure S5. ${ }^{13} \mathrm{C}$ NMR spectrum of tris (4-chlorophenyl) phosphine based monomer in $\mathrm{CDCl}_{3}$.

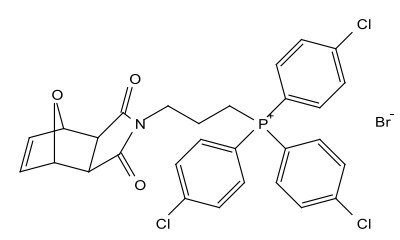

31P NMR (200 MHz, CDÇ)

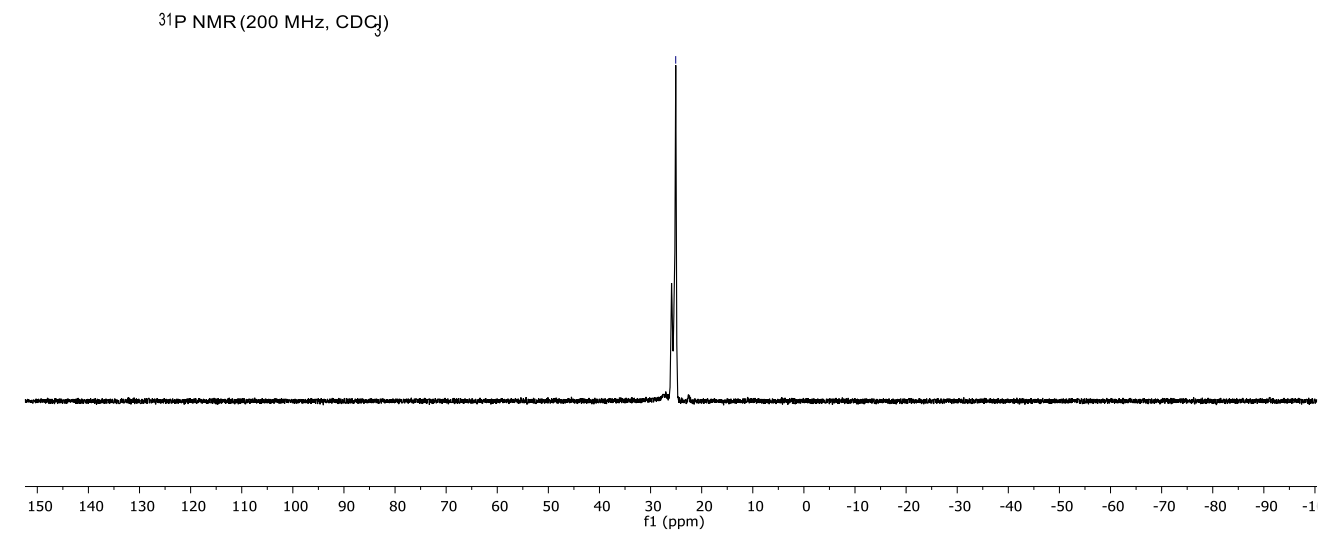

Figure S6. ${ }^{31} \mathrm{P}$ NMR spectrum of tris (4-chlorophenyl) phosphine based monomer in $\mathrm{CDCl}_{3}$.

(3c) 

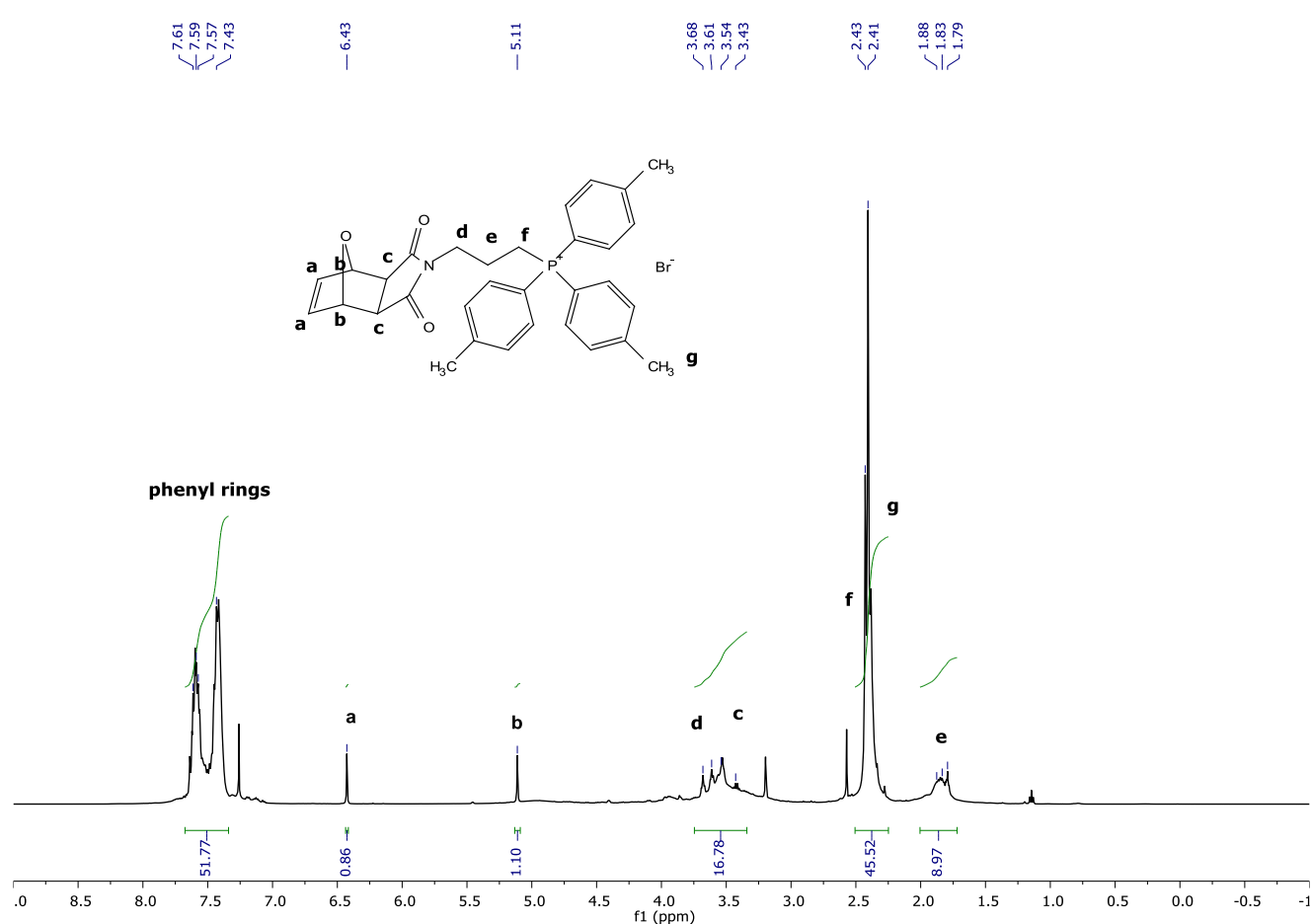

Figure S7. ${ }^{1} \mathrm{H}$ NMR spectrum of tris (4-methylphenyl) phosphine based monomer in $\mathrm{CDCl}_{3}$.

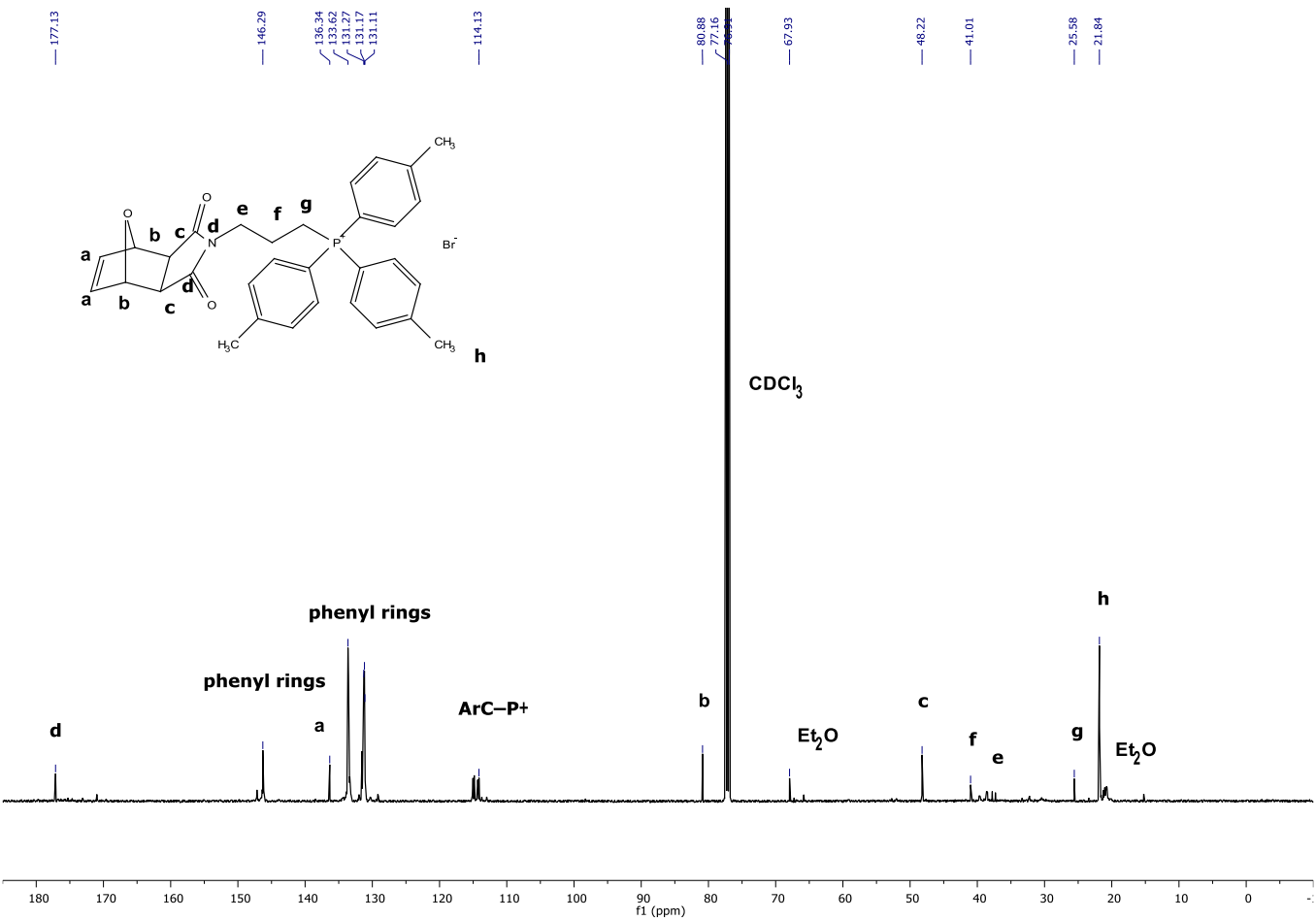

Figure S8. ${ }^{13} \mathrm{C}$ NMR spectrum of tris (4-methylphenyl) phosphine based monomer in $\mathrm{CDCl}_{3}$. 


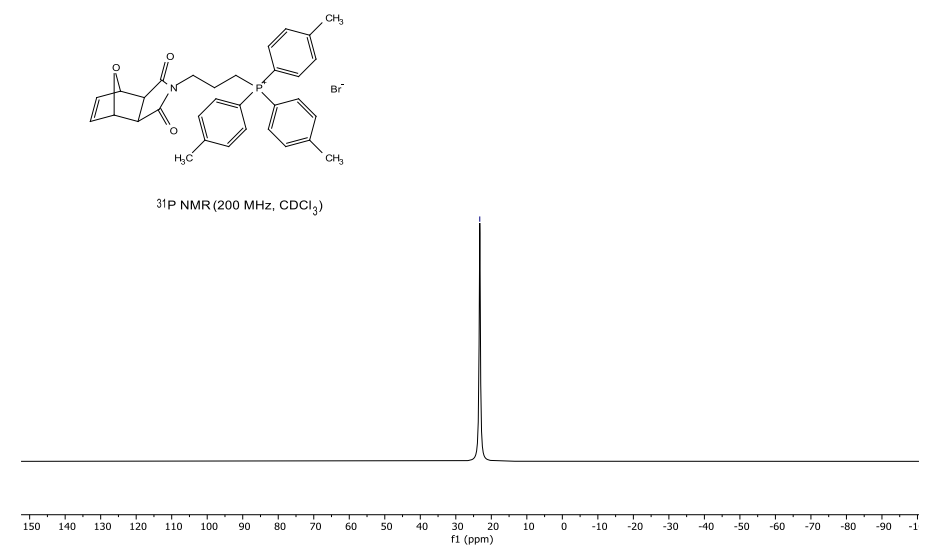

Figure S9. ${ }^{31} \mathrm{P}$ NMR spectrum of tris (4-methylphenyl) phosphine based monomer in $\mathrm{CDCl}_{3}$.

(3d)
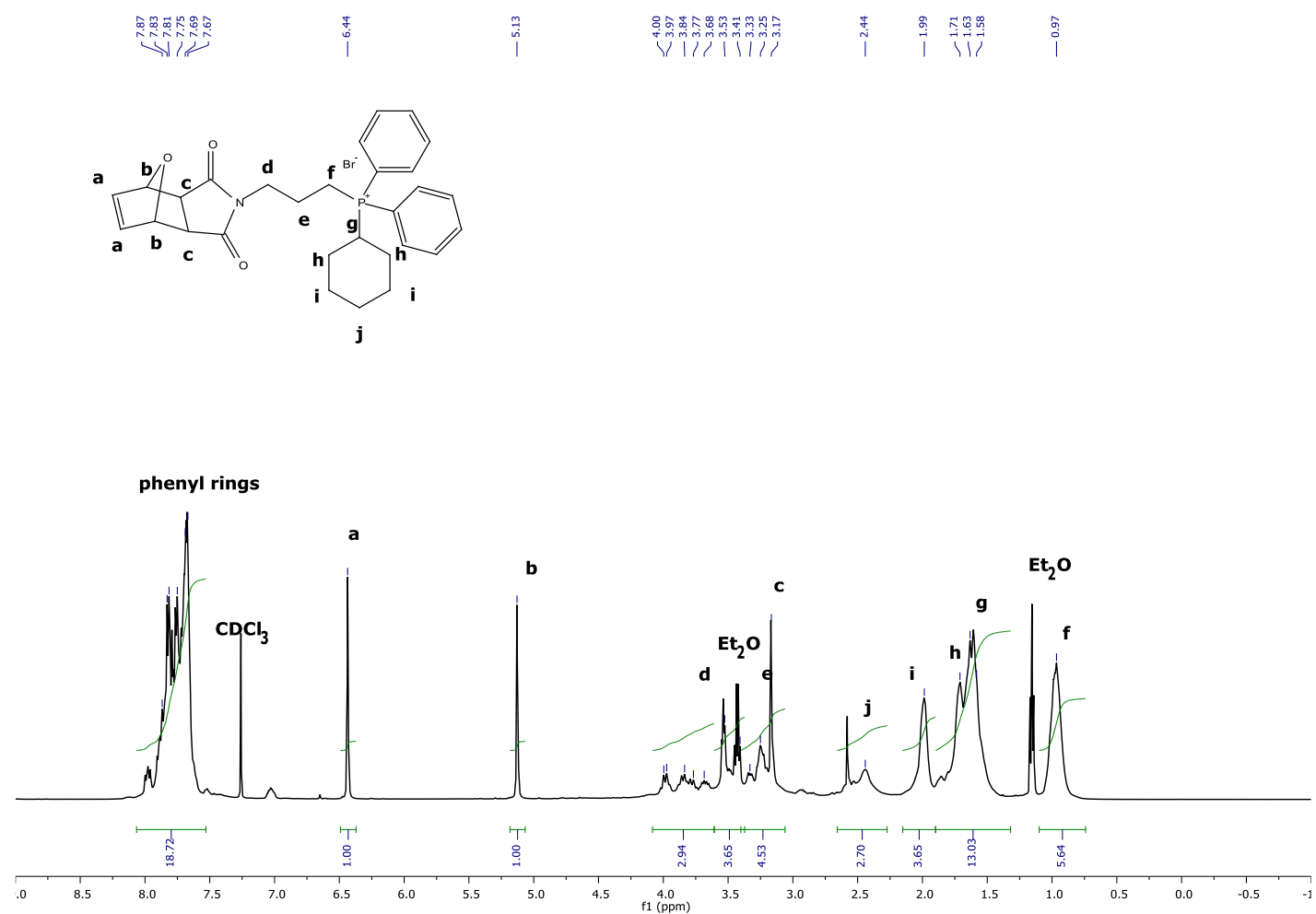

Figure S10. ${ }^{1} \mathrm{H}$ NMR spectrum of cyclohexyl diphenylphosphine based monomer in $\mathrm{CDCl}_{3}$. (3e) 


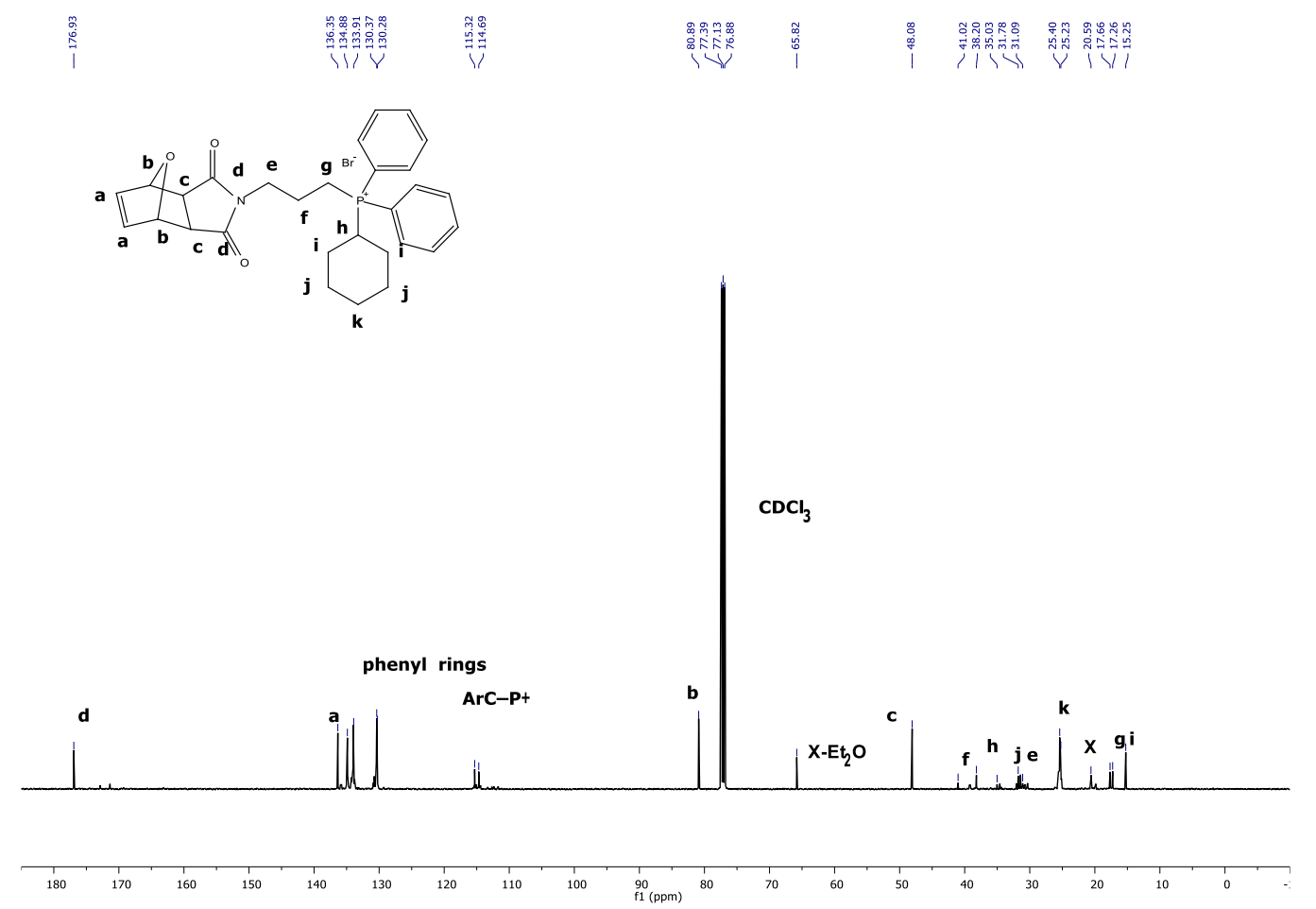

Figure S11. ${ }^{13} \mathrm{C}$ NMR spectrum of cyclohexyl diphenylphosphine based monomer in $\mathrm{CDCl}_{3}$.

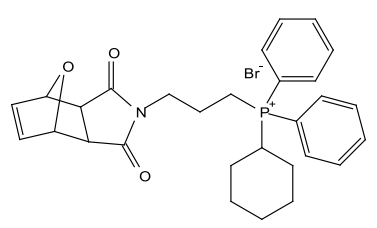

31P NMR (200 MHz, CDCl)

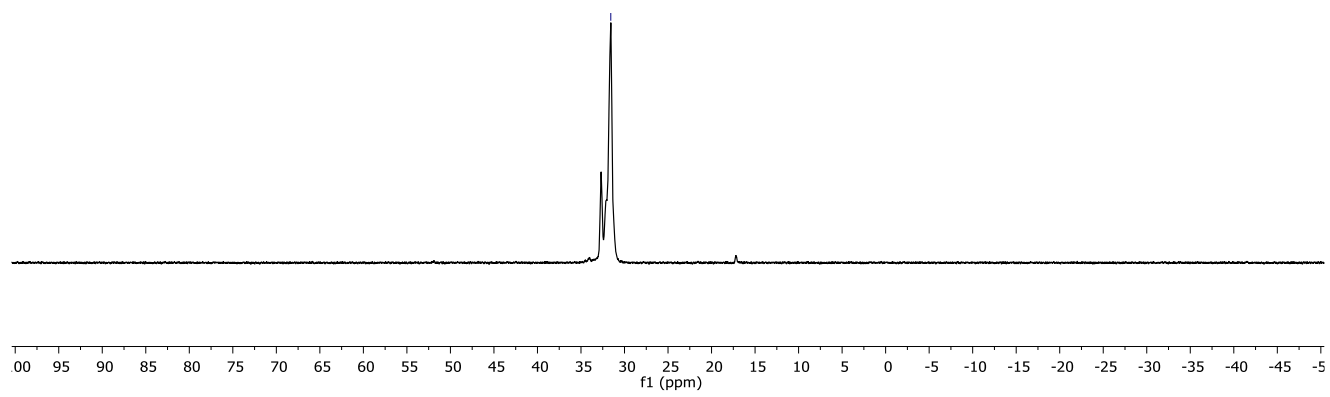

Figure S12. ${ }^{31} \mathrm{P}$ NMR spectrum of cyclohexyl diphenylphosphine based monomer in $\mathrm{CDCl}_{3}$. 
II. ${ }^{1} \mathrm{H}$ NMR Spectra of the Homopolymers (4b-4e)

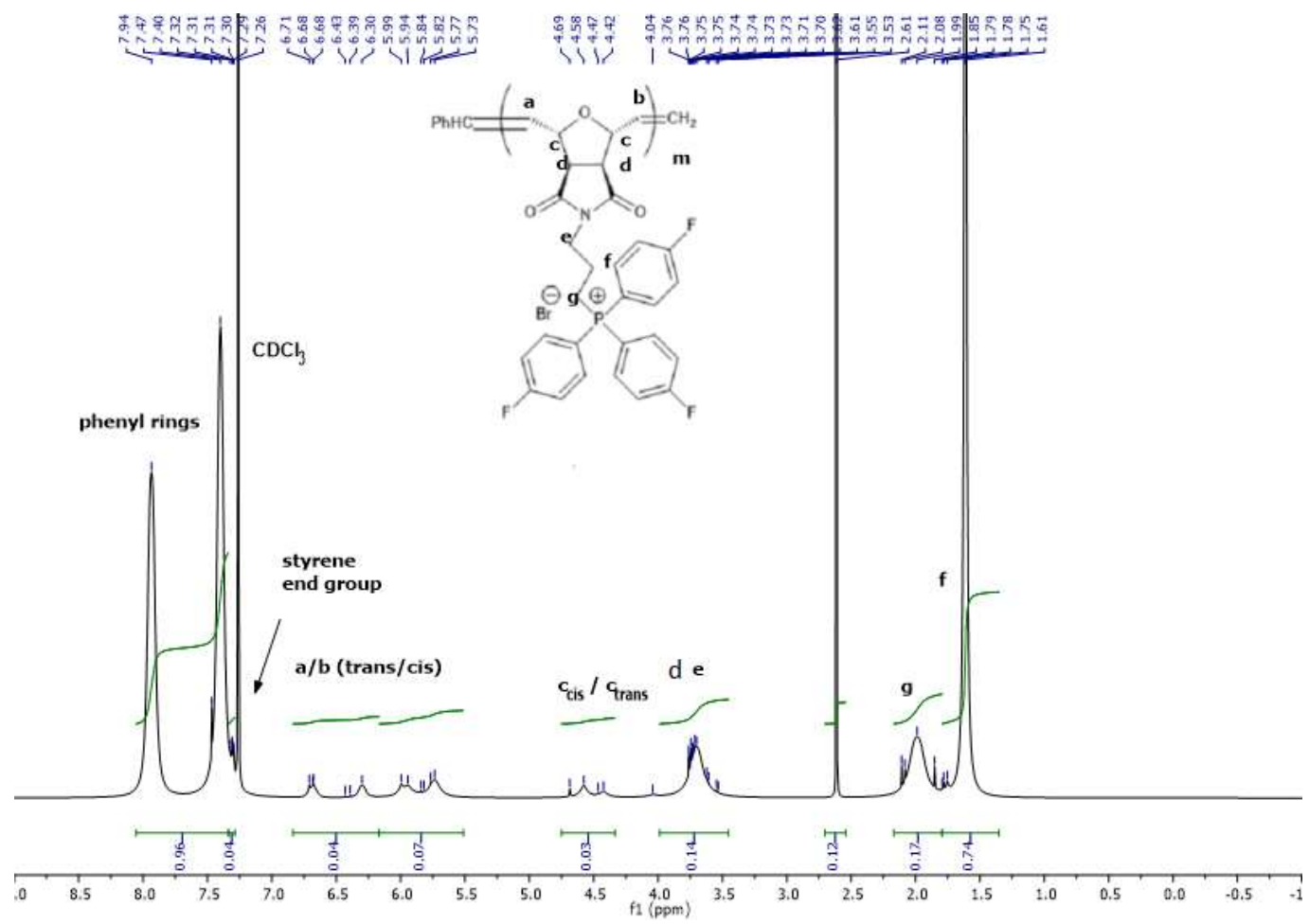

Figure S13. ${ }^{1} \mathrm{H}$ NMR spectrum of tris (4-florophenyl) phosphine based homopolymer in $\mathrm{CDCl}_{3} \cdot(\mathbf{4 b - 3 k})$

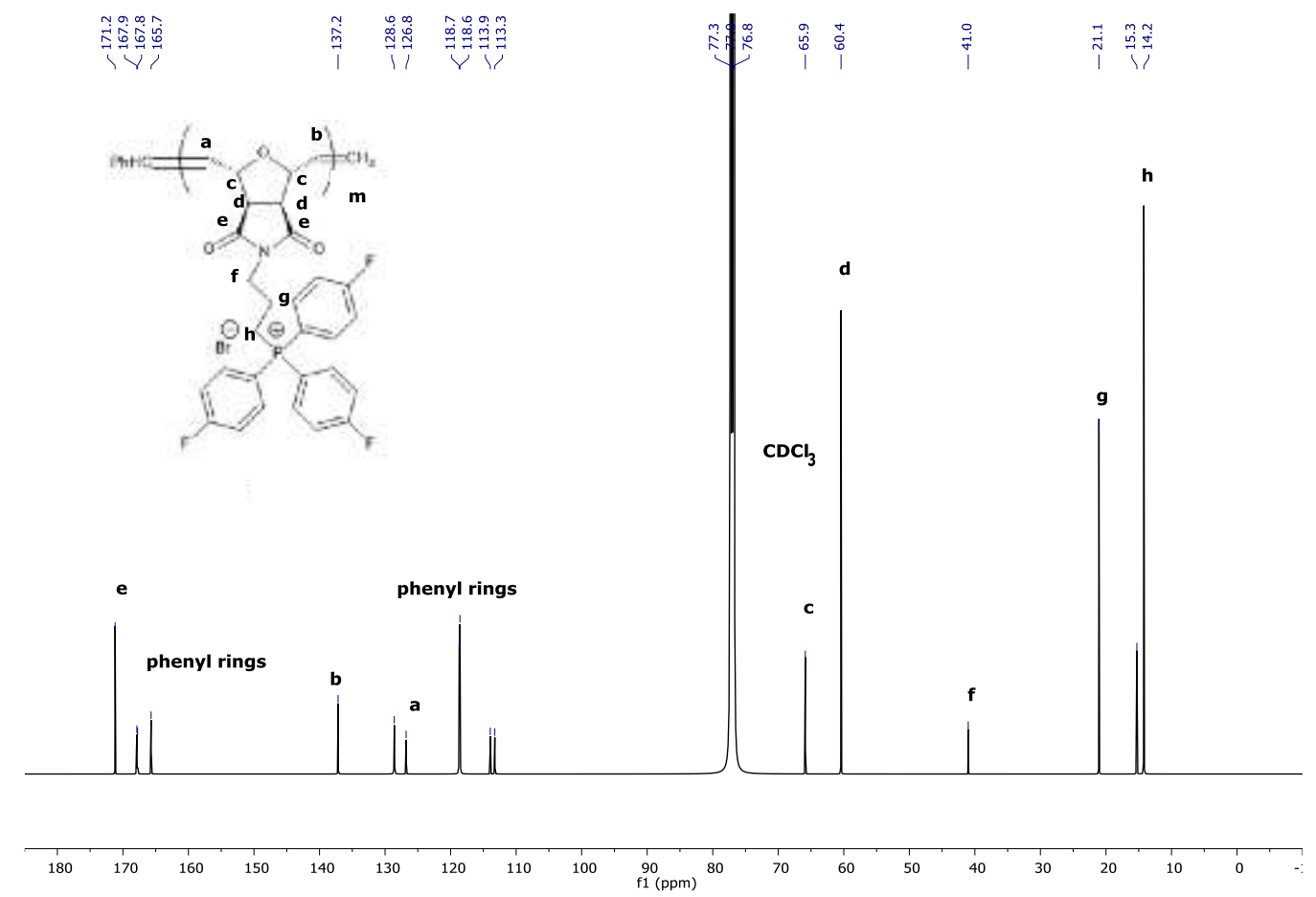

Figure S14. ${ }^{13} \mathrm{C}$ NMR spectrum of tris (4-florophenyl) phosphine based homopolymer in $\mathrm{CDCl}_{3} \cdot(\mathbf{4 b - 3 k})$ 


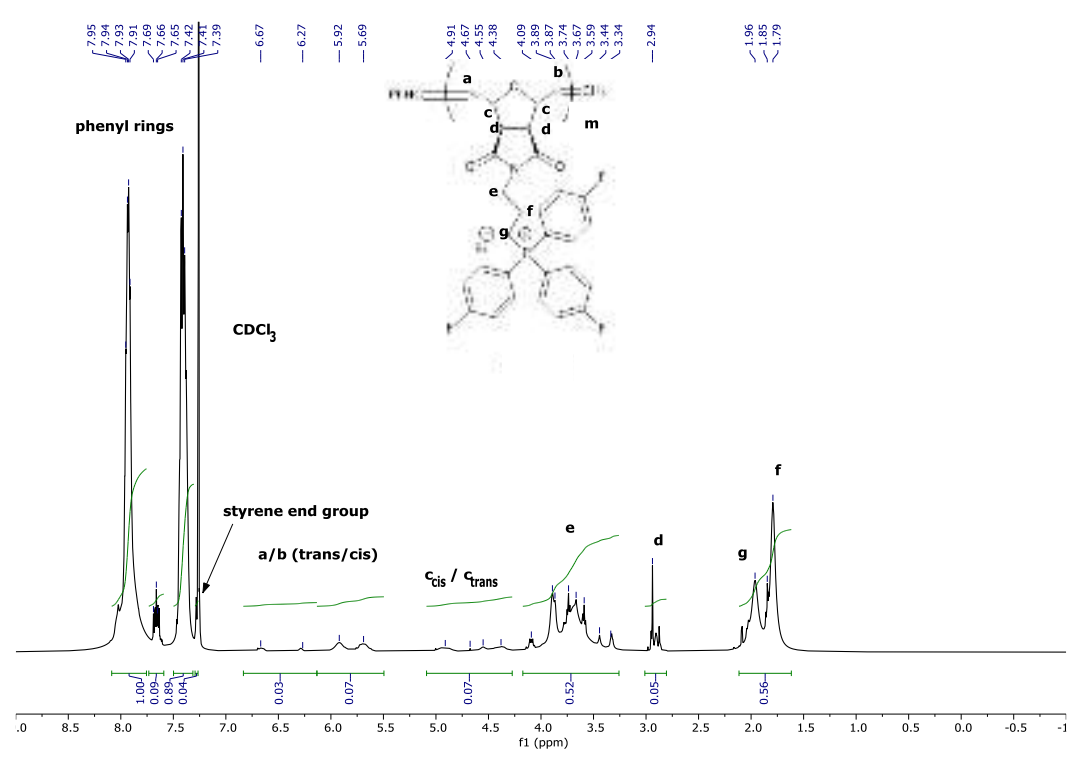

Figure S15. ${ }^{1} \mathrm{H}$ NMR spectrum of tris (4-florophenyl) phosphine based homopolymer in $\mathrm{CDCl}_{3 .} .(4 \mathbf{b}-\mathbf{1 0 k})$

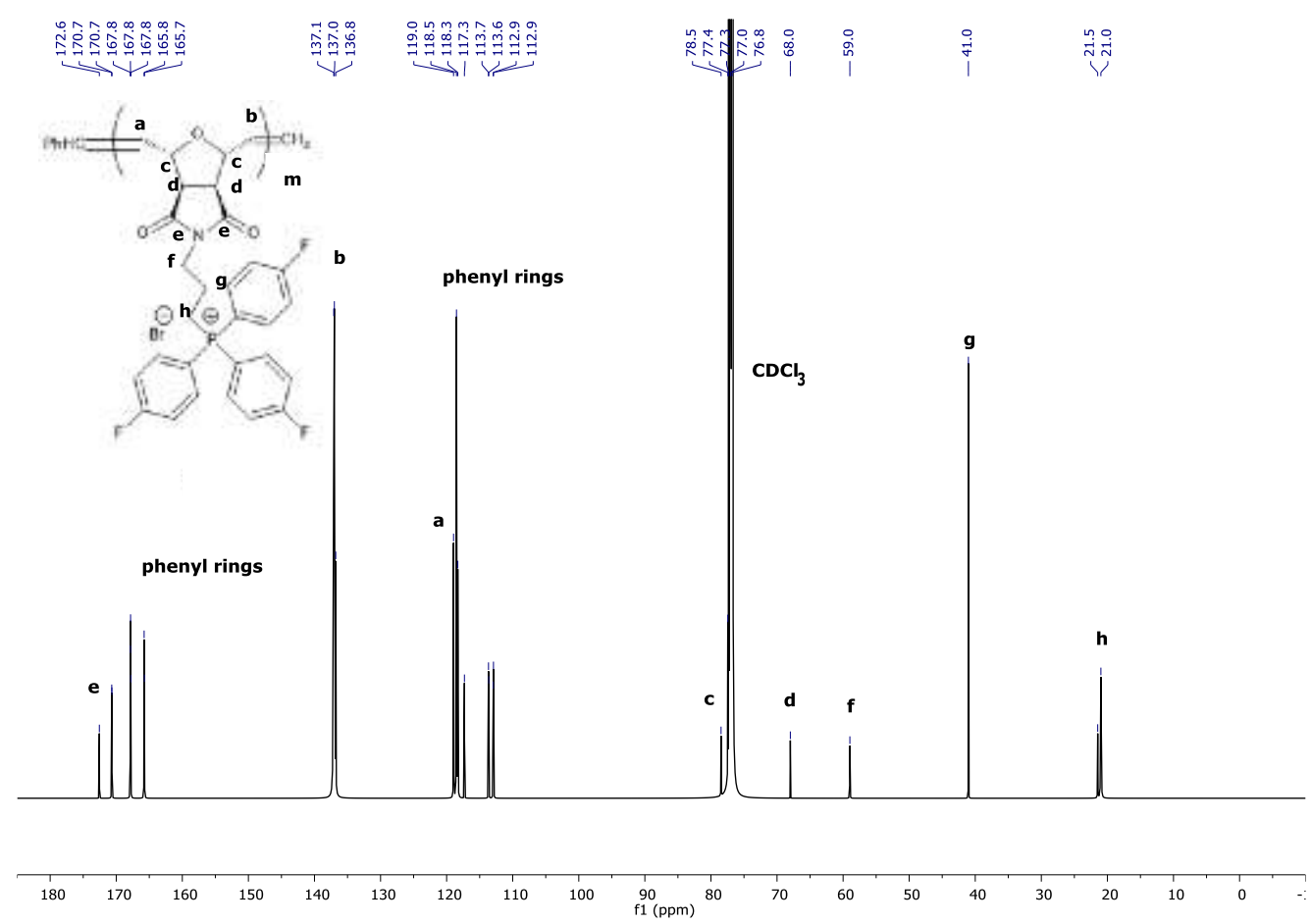

Figure S16. ${ }^{13} \mathrm{C}$ NMR spectrum of tris (4-flourophenyl) phosphine based homopolymer in $\mathrm{CDCl}_{3 \cdot} \cdot(\mathbf{4 b - 1 0 k )}$ 


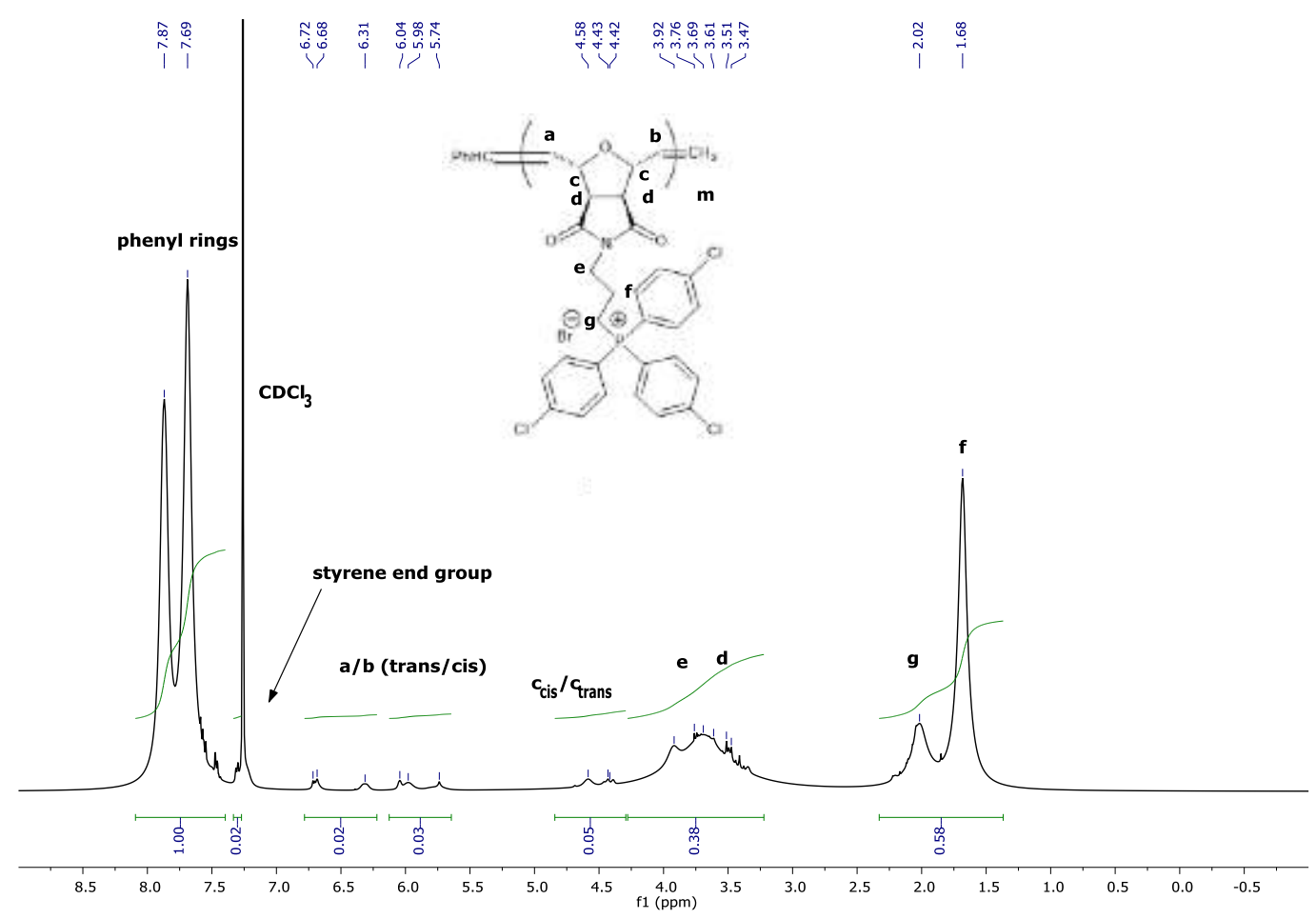

Figure S17. ${ }^{1} \mathrm{H}$ NMR spectrum of tris (4-chlorophenyl) phosphine based homopolymer in $\mathrm{CDCl}_{3 .} .(4 \mathrm{c}-3 \mathrm{k})$

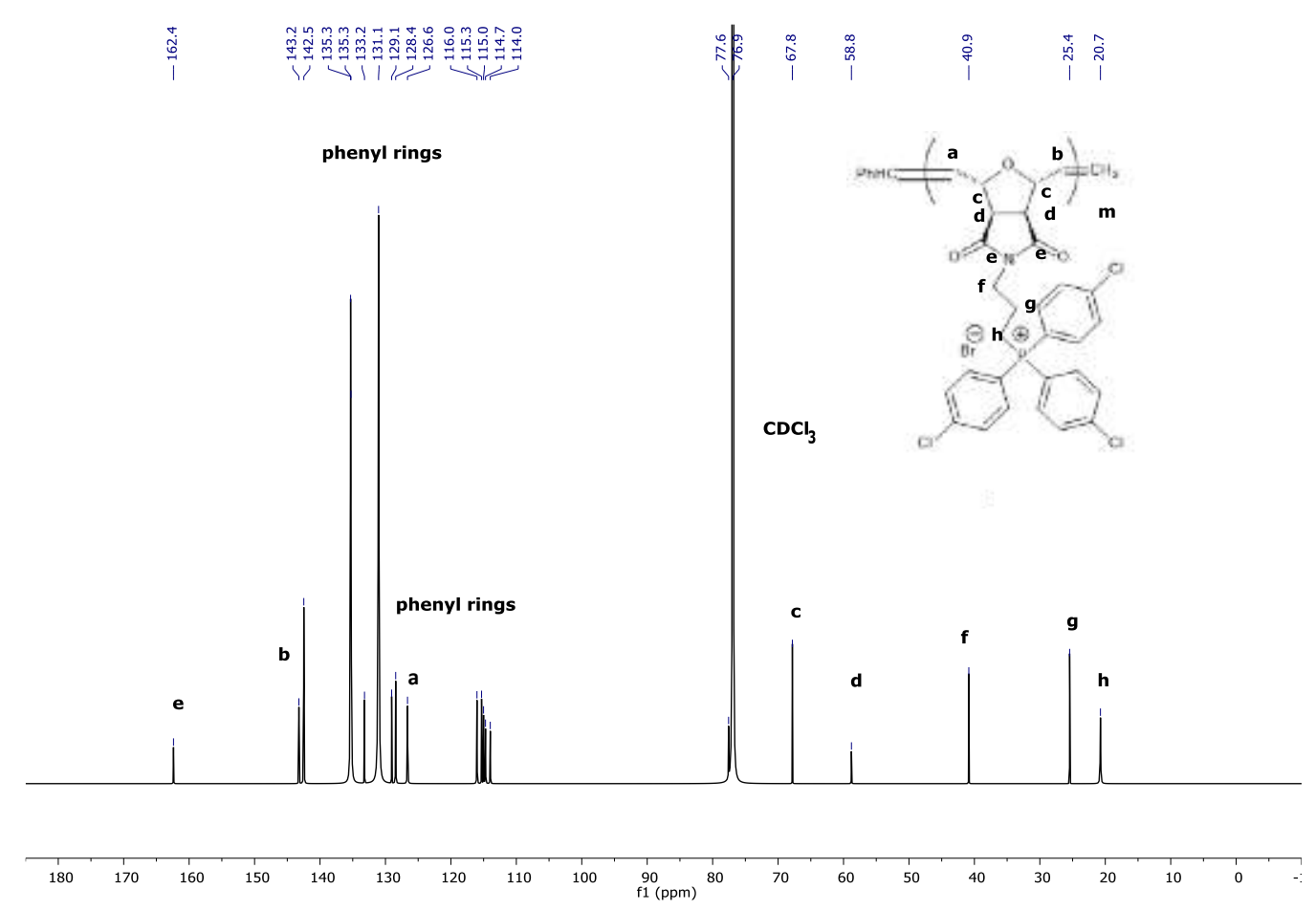

Figure S18. ${ }^{13} \mathrm{C}$ NMR spectrum of tris (4-chlorophenyl) phosphine based homopolymer in $\mathrm{CDCl}_{3 .}$ (4c-3k) 


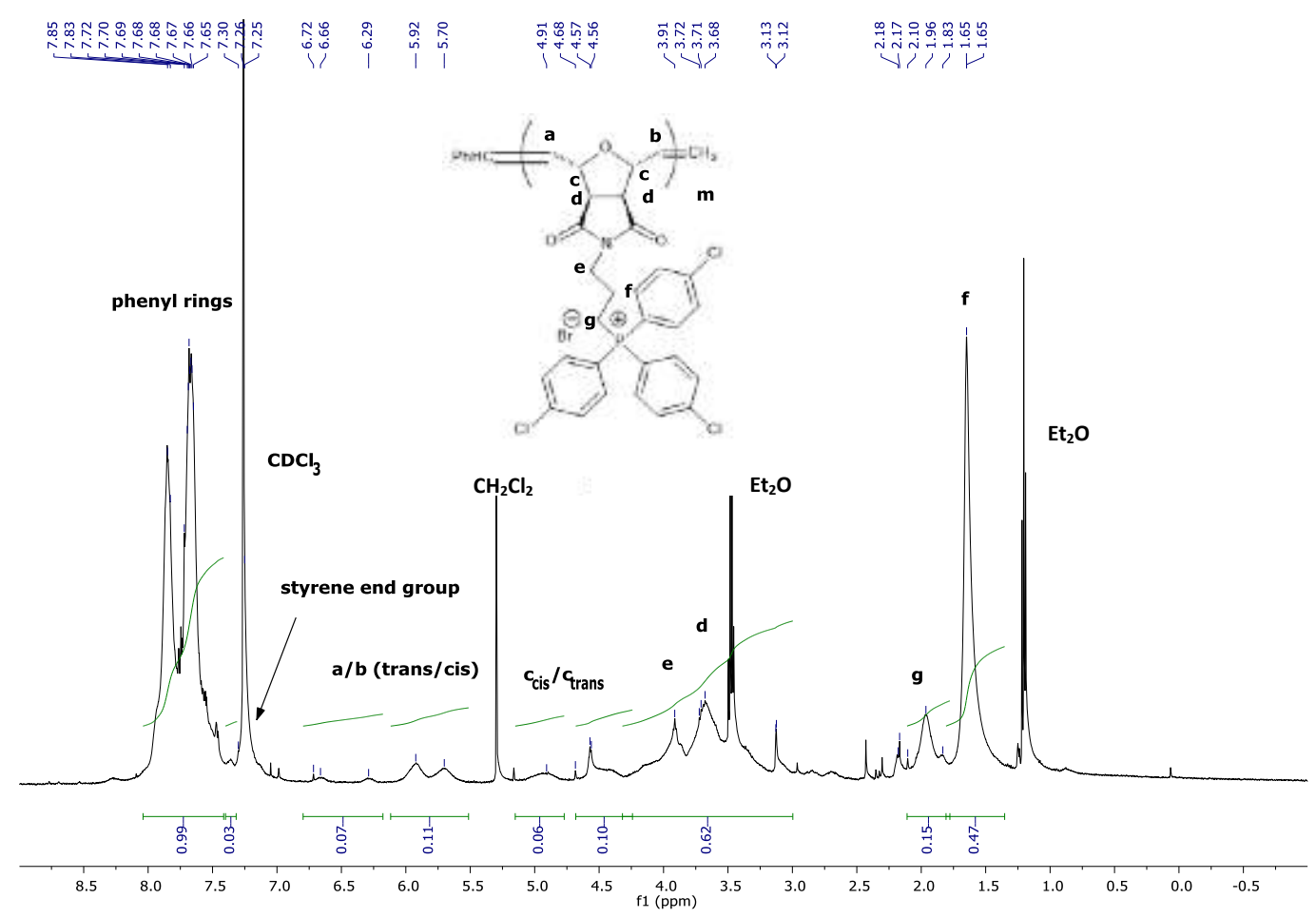

Figure S19. ${ }^{1} \mathrm{H}$ NMR spectrum of tris (4-chlorophenyl) phosphine based homopolymer in $\mathrm{CDCl}_{3} .(4 \mathrm{c}-10 \mathrm{k})$

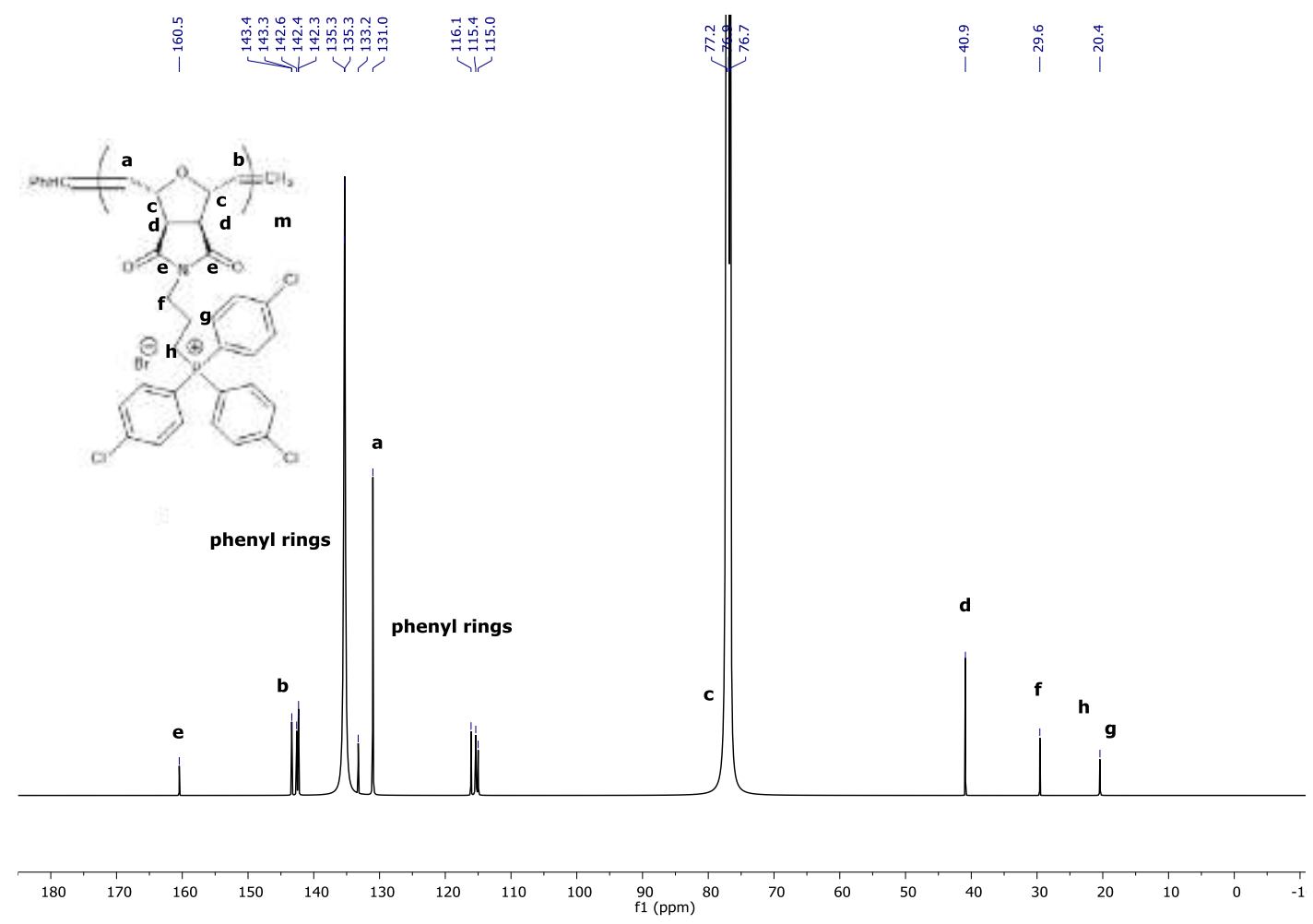

Figure S20. ${ }^{13} \mathrm{C}$ NMR spectrum of tris (4-chlorophenyl) phosphine based homopolymer in $\mathrm{CDCl}_{3} .(4 \mathrm{c}-10 \mathrm{k})$ 


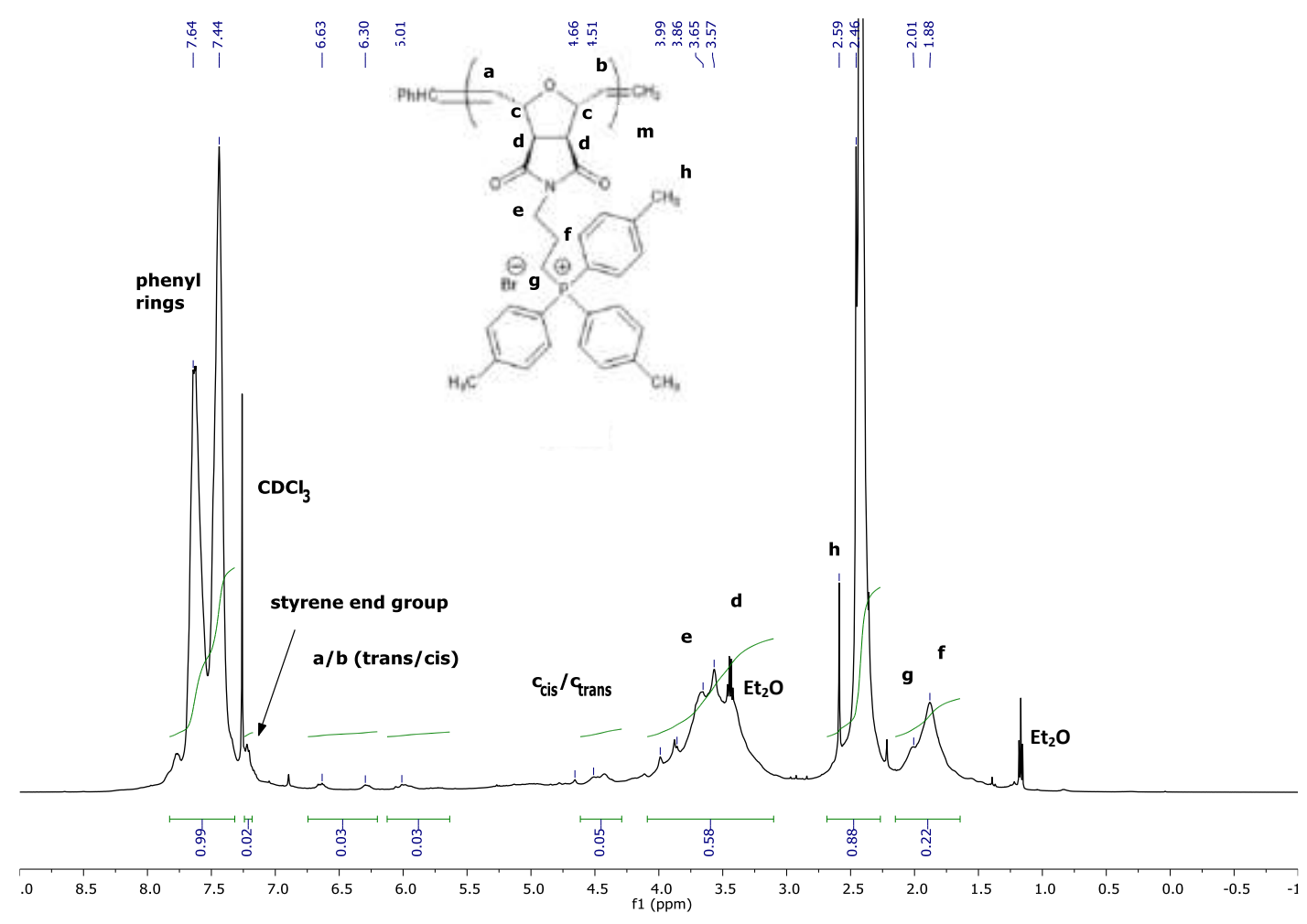

Figure S21. ${ }^{1} \mathrm{H}$ NMR spectrum of tris(4-methylphenyl) phosphine based homopolymer in $\mathrm{CDCl}_{3} \cdot(\mathbf{4 d - 3 k})$

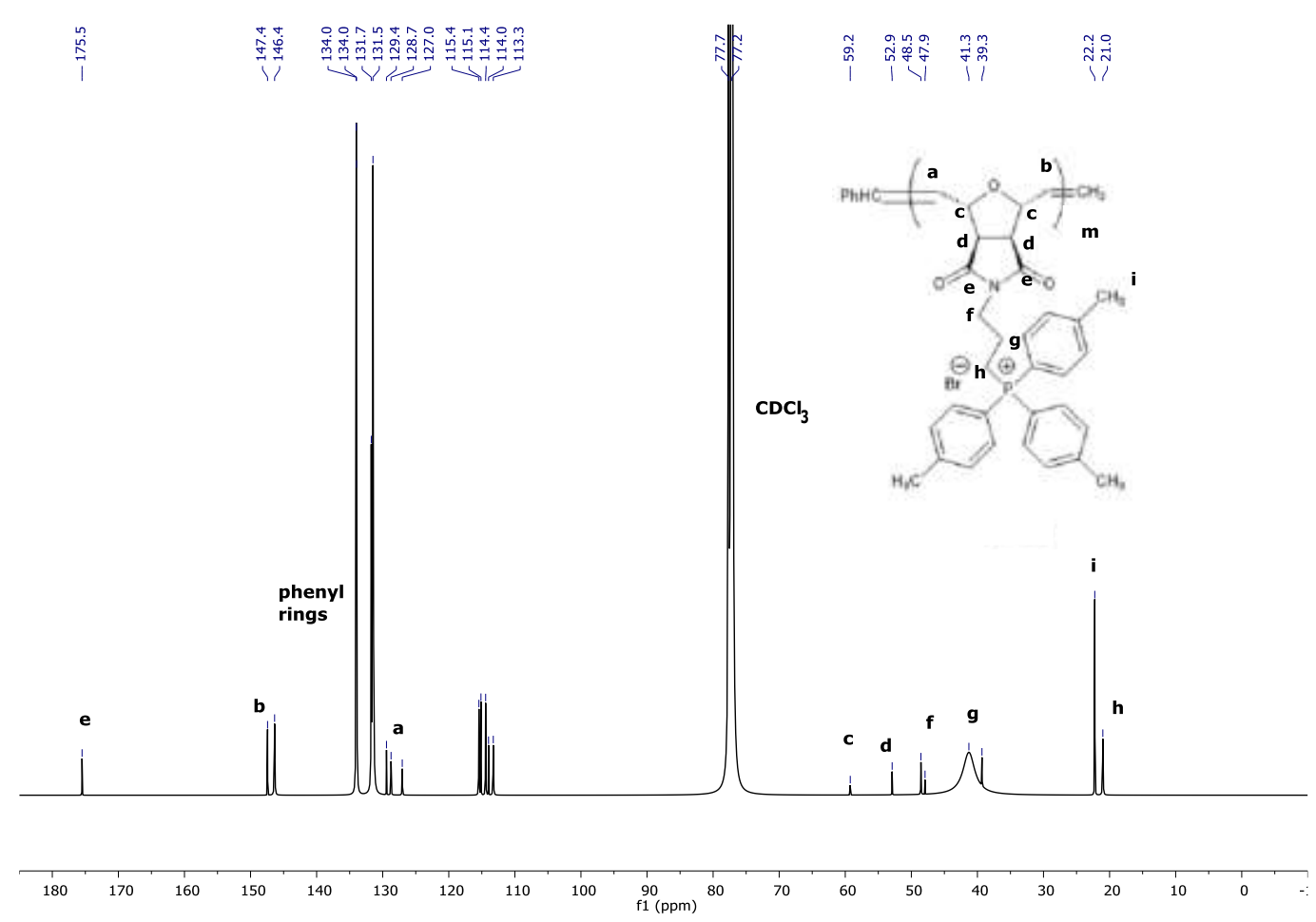

Figure S22. ${ }^{13} \mathrm{C}$ NMR spectrum of tris(4-methylphenyl) phosphine based homopolymer in $\mathrm{CDCl}_{3 .}(\mathbf{4 d - 3 k})$ 


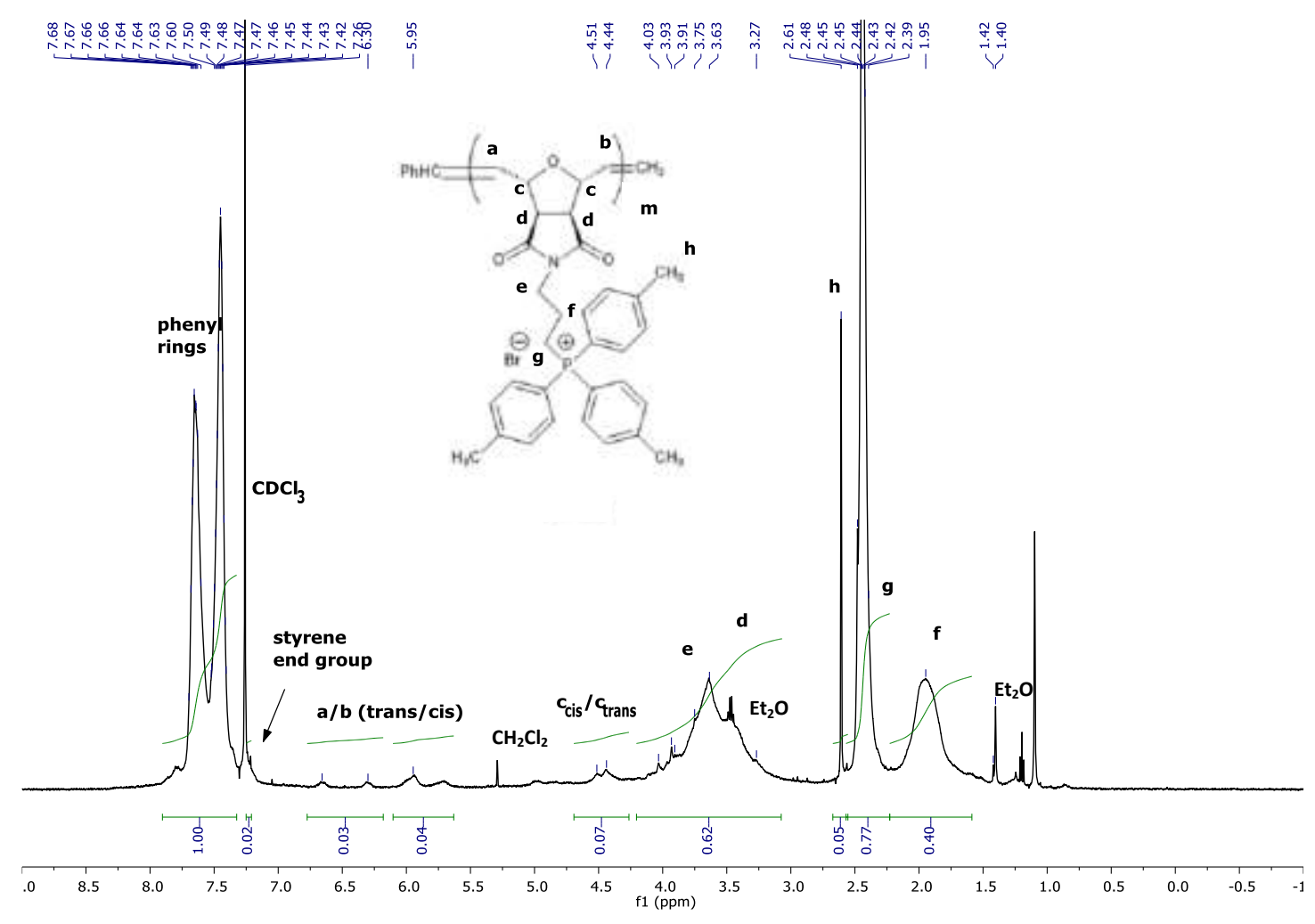

Figure S23. ${ }^{1} \mathrm{H}$ NMR spectrum of tris(4-methylphenyl) phosphine based homopolymer in
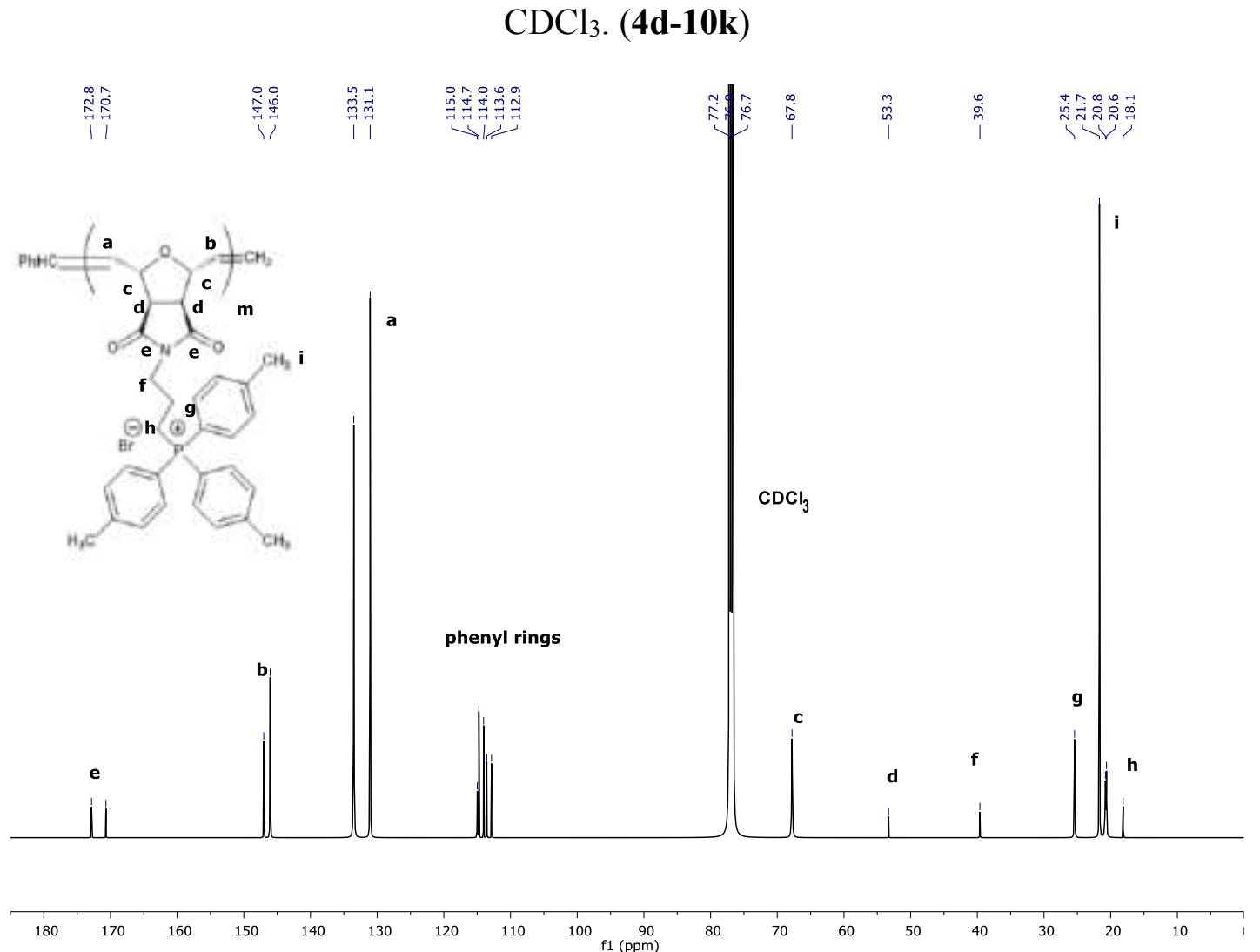

Figure S24. ${ }^{13} \mathrm{C}$ NMR spectrum of tris(4-methylphenyl) phosphine based homopolymer in $\mathrm{CDCl}_{3 .} .(4 d-10 k)$ 


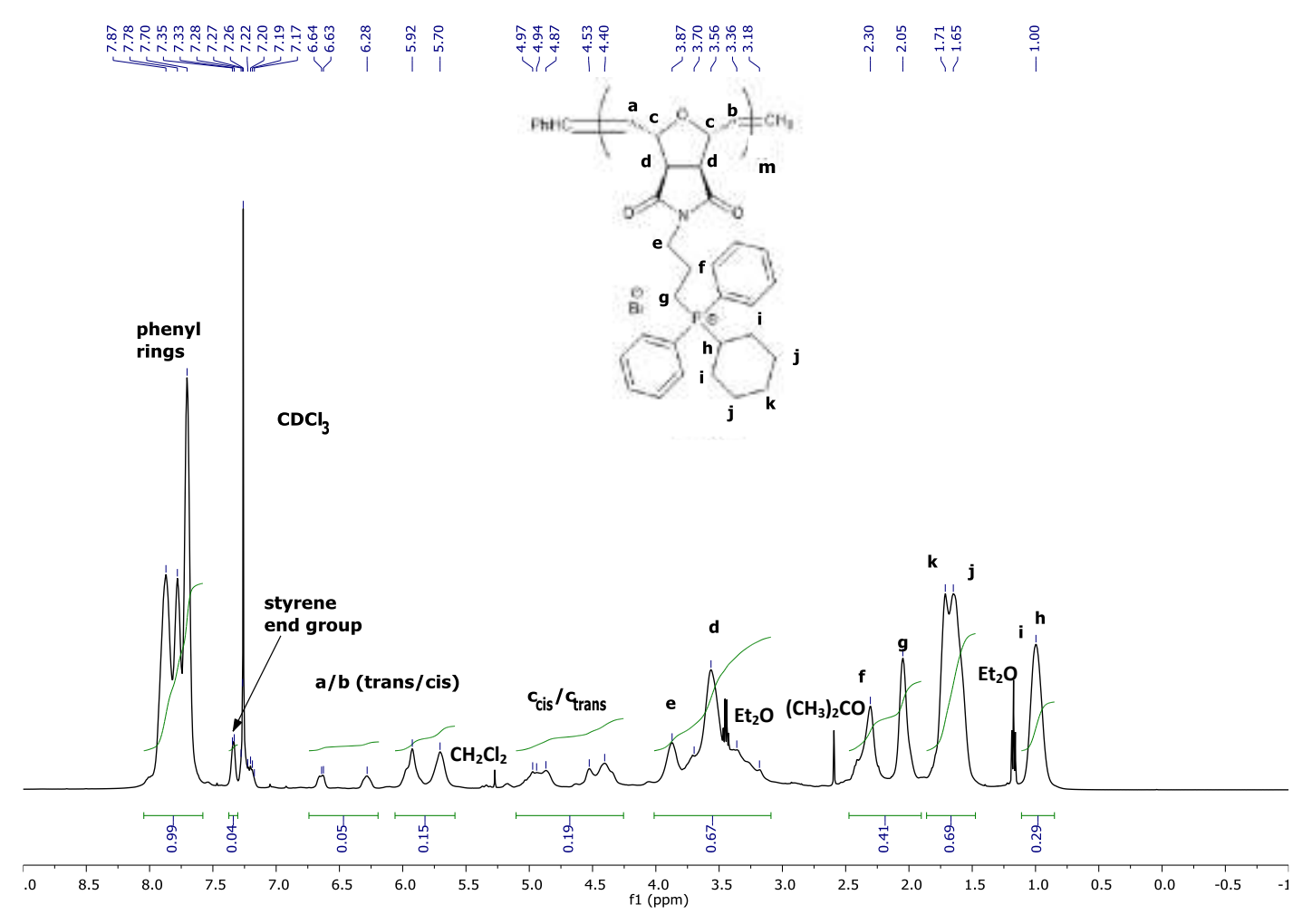

Figure S25. ${ }^{1} \mathrm{H}$ NMR spectrum of cyclohexyl diphenyl phosphine based homopolymer in $\mathrm{CDCl}_{3 .} \cdot(4 \mathbf{e}-3 \mathbf{k})$

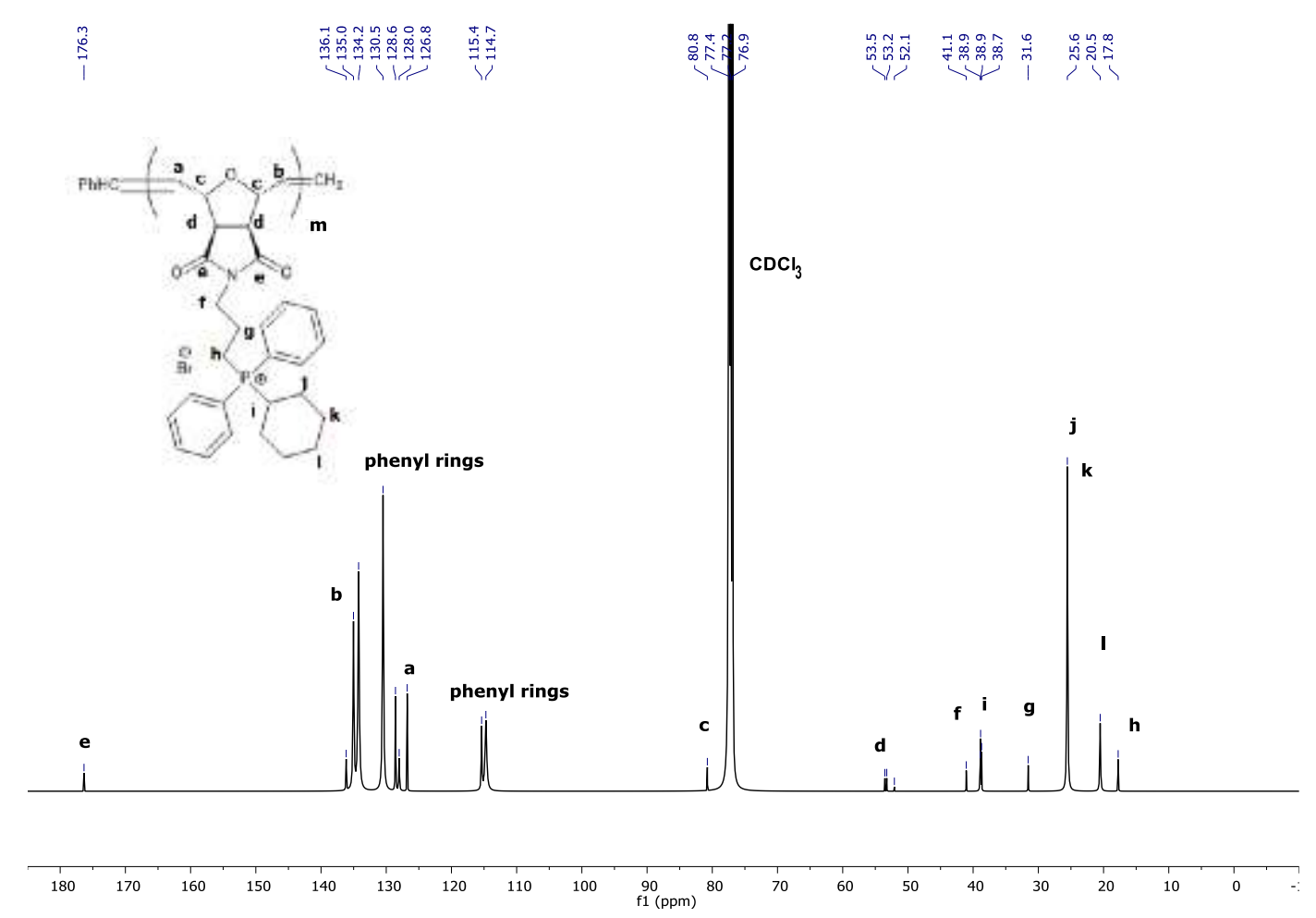

Figure S26. ${ }^{13} \mathrm{C}$ NMR spectrum of cyclohexyl diphenyl phosphine based homopolymer in $\mathrm{CDCl}_{3 .}(4 \mathbf{e}-3 \mathbf{k})$ 


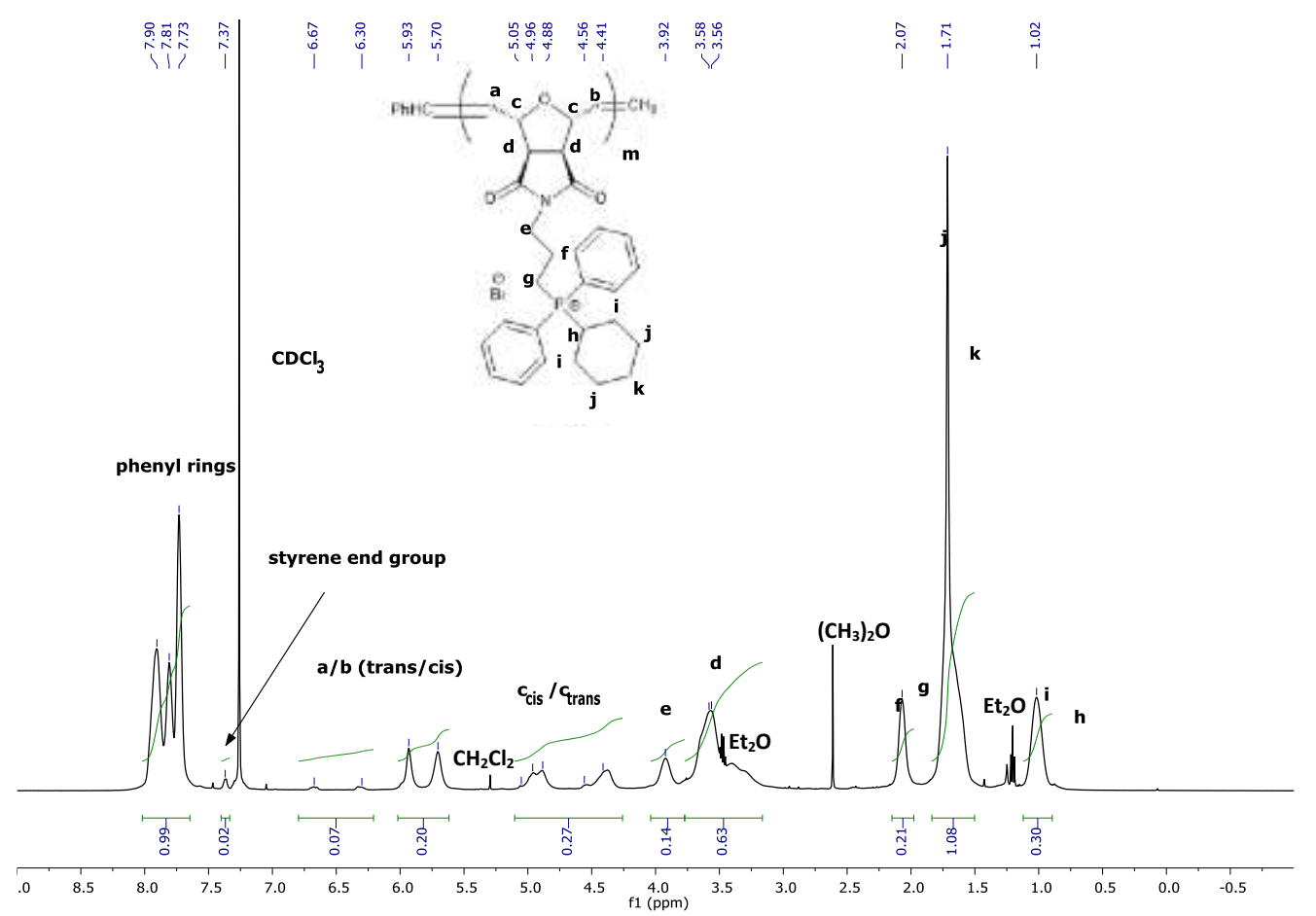

Figure S27. ${ }^{1} \mathrm{H}$ NMR spectrum of cyclohexyl diphenyl phosphine based homopolymer in $\mathrm{CDCl}_{3} .(4 \mathrm{e}-10 \mathrm{k})$

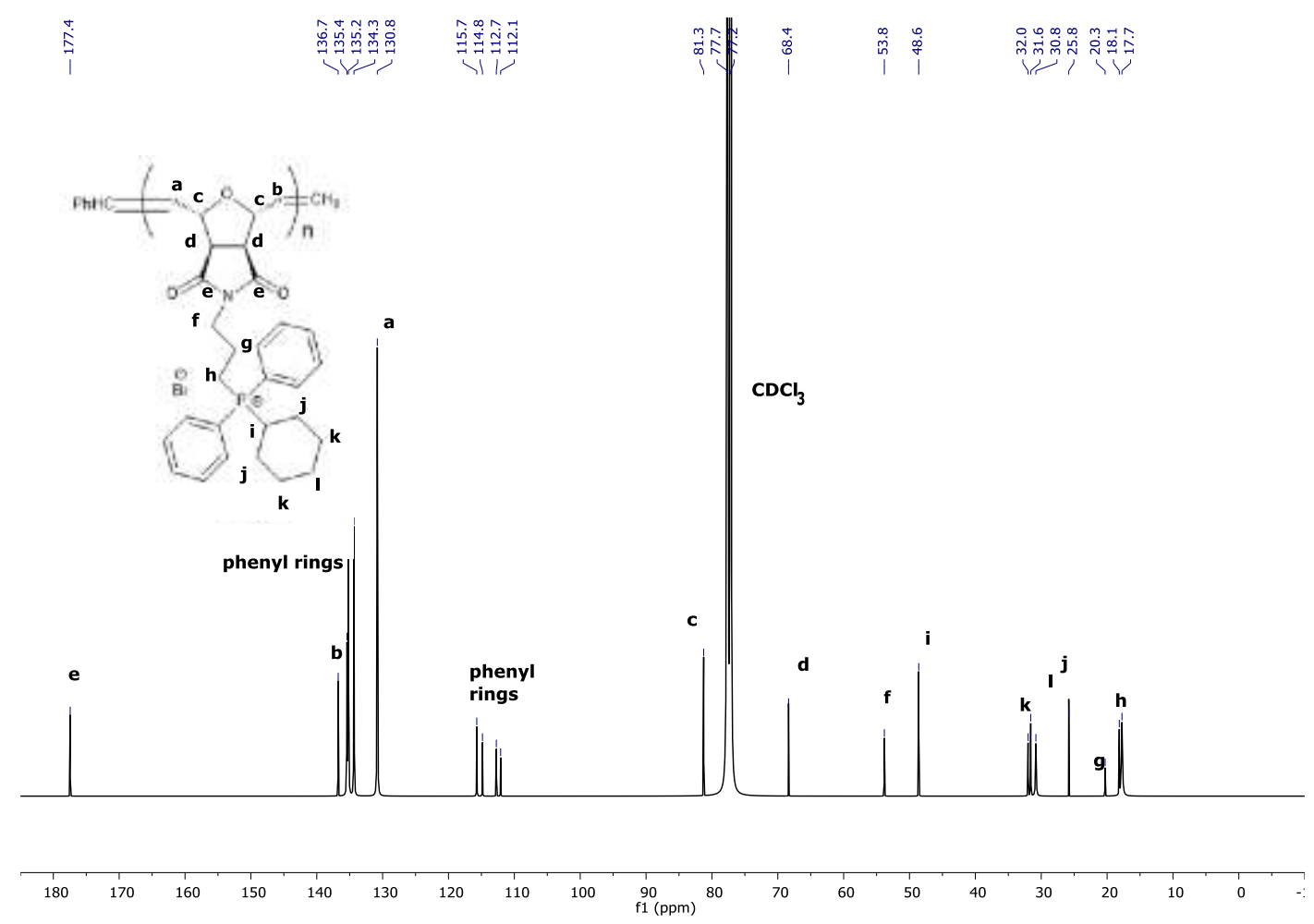

Figure S28. ${ }^{1} \mathrm{H}$ NMR spectrum of cyclohexyl diphenyl phosphine based homopolymer in $\mathrm{CDCl}_{3} \cdot(4 \mathrm{e}-10 \mathrm{k})$ 


\section{Equation 1}

$M_{n}=\frac{[(\text { Integral of the ole finic region } / 2 \text { protons })]}{[(\text { Integral } / 5 \text { protons }, \text { styrene end group })]} * M W_{\text {monomer }}$

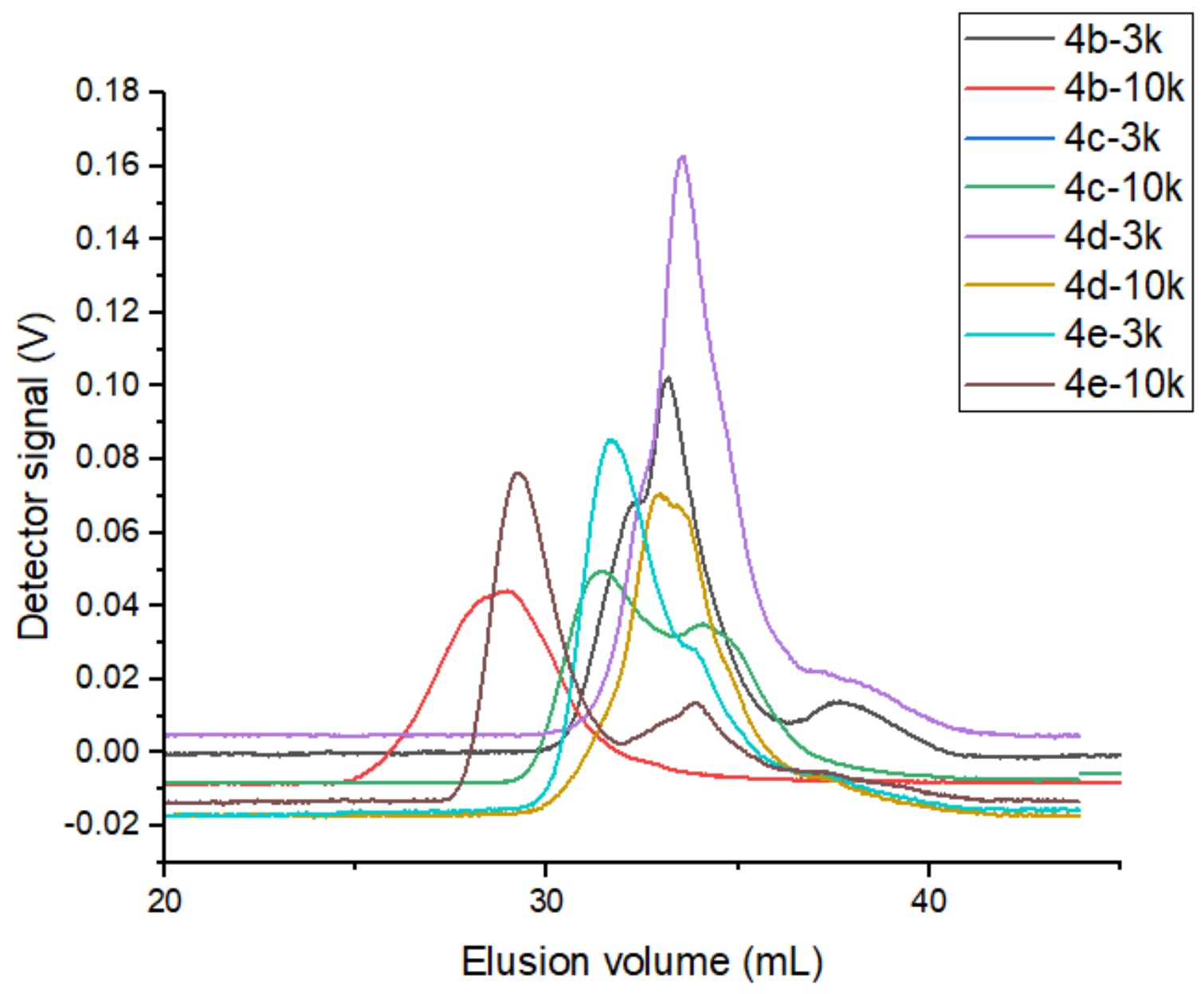

Figure S29. SEC spectra of homopolymers 

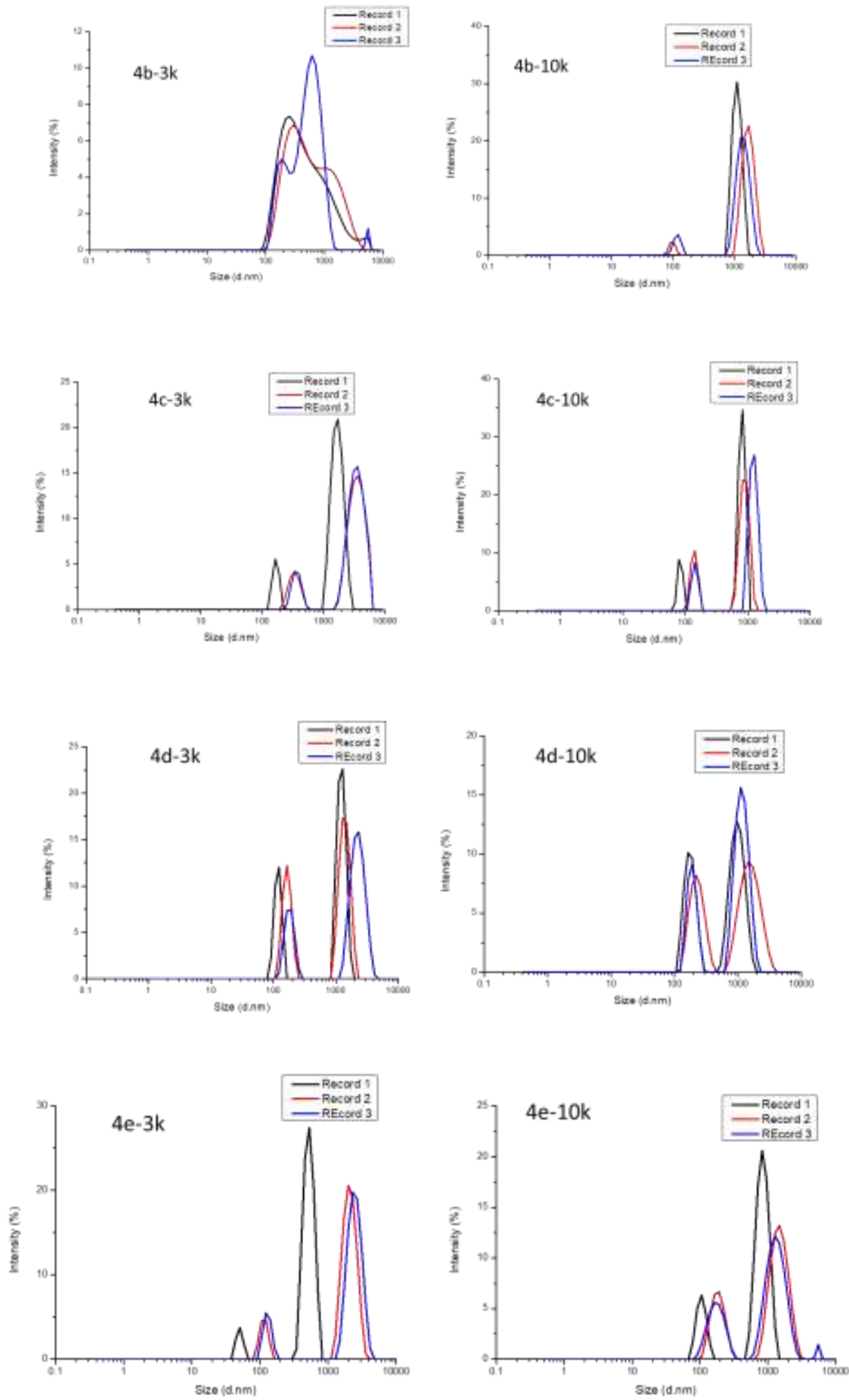

Figure S30. Zeta potential sizer graph for homopolymers $4 \mathrm{~b}, 4 \mathrm{c}, 4 \mathrm{~d}$ and $4 \mathrm{e}$ series 


\section{A Molecular Electrostatic Potential (MEP) Analysis of Monomers}

On the MEP surfaces, different colors are used to depict different values of electrostatic potential. Red indicates negative regions while blue indicates positive regions, and electrostatic potential increases in the following color sequence: red $<$ orange $<$ yellow $<$ green $<$ blue. These surface models helped to understand the size, shape and variation of electron density and to predict the chemical reactivity sites of the molecule. The MEP surfaces of the monomers bearing aromatic rings and substituted with electron donating and electron withdrawing groups are shown in Figure S39 and electstatic potential values are shown in Table S2.

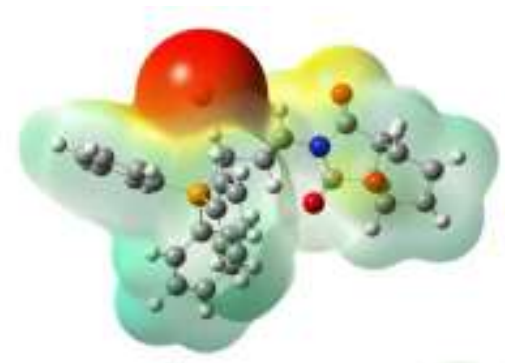

$3 a$

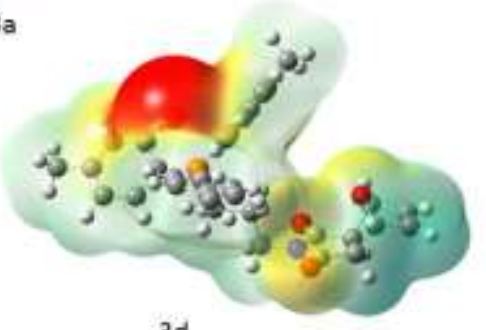

$3 d$

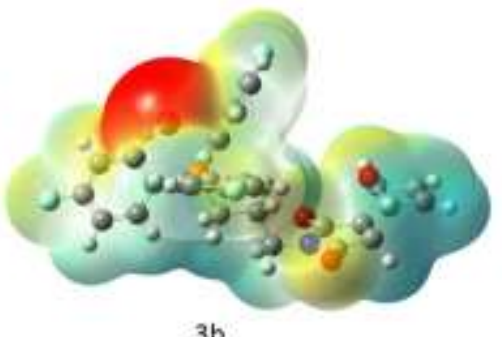

$3 \mathrm{~b}$

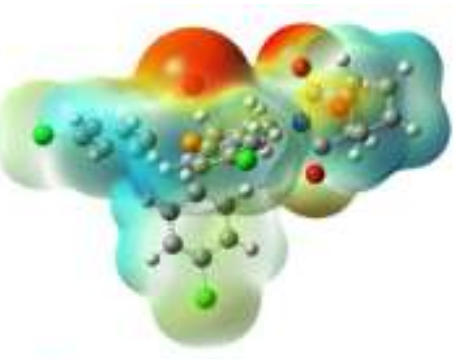

$3 \mathrm{c}$

36

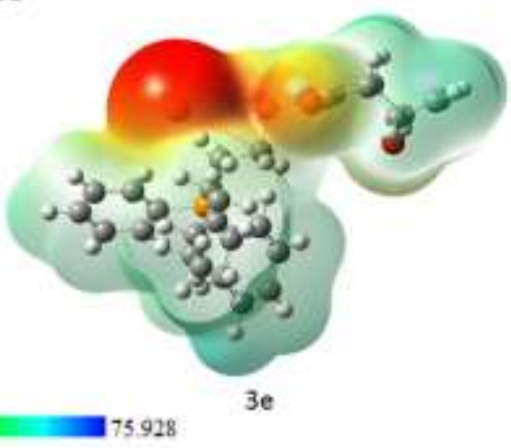

75.928

Figure S31. MEP surfaces were calculated at the B3LYP / 6-31G* level with Density Functional Theory (DFT) using Gaussian 03 software. The conductor-like polarizable continuum model (CPCM) was used to model solvent effects where the solvent was water ( $\varepsilon$ $=78.39$ ). The structural visualizations of the molecules were prepared using Gauss View 5.0 software. 
Table S1. Electrostatic Potential Values for R-groups

\begin{tabular}{|l|c|}
\hline Aromatic Ring & $\begin{array}{c}\text { Electrostatic Potential } \\
\left(\text { kcal mol }^{-1}\right)\end{array}$ \\
\hline $3 a$ \\
\hline 36
\end{tabular}




\section{Antibacterial and Hemolytic Activity and Zeta Size and Potential Properties of the Homopolymers}

Table S2. Antibacterial and hemolytic activities of the homopolymers

\begin{tabular}{|c|c|c|c|c|c|c|c|}
\hline \multirow[t]{2}{*}{ Polymers } & \multicolumn{2}{|c|}{$\begin{array}{c}E . c o l i \\
(\text { ATCC25922) }\end{array}$} & \multicolumn{2}{|c|}{$\begin{array}{c}\text { S. aureus } \\
\text { (ATCC29213) }\end{array}$} & \multirow{2}{*}{$\begin{array}{c}\text { Hemolytic } \\
\text { Activity } \\
\mathrm{HC}_{50}{ }^{[\mathrm{c}]} \\
\left(\mu \mathrm{g} \mathrm{mL}^{-1}\right)\end{array}$} & \multicolumn{2}{|c|}{$\begin{array}{c}\mathrm{SI}^{[\mathrm{d}]} \\
\left(\mathrm{HC}_{50} / \mathrm{MIC}\right)\end{array}$} \\
\hline & $\begin{array}{c}\mathrm{MIC}^{[\mathrm{a}]} \\
\left(\mu \mathrm{g} \mathrm{mL}^{-1}\right)\end{array}$ & $\begin{array}{c}\mathrm{MBC}^{[\mathrm{b}]} \\
\left(\mu \mathrm{g} \mathrm{mL}^{-1}\right)\end{array}$ & $\begin{array}{c}\mathrm{MIC}^{[\mathrm{a}]} \\
\left(\mu \mathrm{g} \mathrm{mL}^{-1}\right)\end{array}$ & $\begin{array}{c}\mathrm{MBC}^{[\mathrm{b}]} \\
\left(\mu \mathrm{g} \mathrm{mL}^{-1}\right)\end{array}$ & & E.coli & S.aureus \\
\hline $4 a-3 k$ & 16 & 256 & 8 & 32 & 256 & 16 & 32 \\
\hline $4 a_{-} \_10 \mathrm{k}$ & $32^{16}$ & 64 & $16^{16}$ & 32 & $<512^{16}$ & $<16$ & $<32$ \\
\hline $4 b-3 k$ & 8 & 256 & 8 & 16 & 256 & 32 & 32 \\
\hline $4 \mathrm{~b}-10 \mathrm{k}$ & 64 & 128 & 8 & 16 & 32 & 0.5 & 4 \\
\hline $4 c-3 k$ & 16 & 32 & 8 & 32 & 8 & 0.5 & 1 \\
\hline $4 c-10 k$ & 32 & 512 & 32 & 512 & $<1$ & $<0.002$ & $<0.002$ \\
\hline $4 d-3 k$ & 8 & 256 & 2 & 32 & 4 & 0.03 & 0.25 \\
\hline $4 d-10 k$ & 16 & 512 & 4 & 4 & 32 & 0.5 & 2 \\
\hline $4 e-3 k$ & 8 & 16 & 2 & 4 & 8 & 1 & 4 \\
\hline $4 \mathrm{e}-10 \mathrm{k}$ & 16 & 512 & 16 & 64 & $<1$ & $<0.06$ & $<0.06$ \\
\hline
\end{tabular}

[a] MIC is the minimum polymer concentration at which $90-100 \%$ of the bacteria in solution can be inhibited. The lower the MIC value, the more active the polymer. [b] MBC is the minimum bactericidal concentration of the polymers. [c] $\mathrm{HC}_{50}$ : Hemolytic concentration of the polymers at which $50 \%$ of human red blood cells are lysed; the higher the $\mathrm{HC}_{50}$, the less hemolytic the polymer. [d] SI: selectivity index of the polymers. 
Table S3. Zeta size and potential properties of the homopolymers and Zeta potential values of $S$. aureus after treatment with polymers $4 \mathbf{c} \_3 \mathbf{k}\left(\mathrm{MIC}=8 \mu \mathrm{g} \mathrm{mL} \mathrm{mL}^{-1}\right)$ and $\mathbf{4} \mathbf{c} \_\mathbf{1 0 k}(\mathrm{MIC}=$ $\left.32 \mu \mathrm{g} \mathrm{mL} L^{-1}\right)$

\begin{tabular}{|c|c|c|}
\hline Polymers & Z-Ave (d.nm) & $\begin{array}{c}\text { Zeta Potential } \\
(\mathbf{m V})\end{array}$ \\
\hline 4a_3k & $591 \pm 19.7$ & $4.1 \pm 1.2$ \\
\hline 4a_10k & $825 \pm 39.2$ & $1.8 \pm 1.1$ \\
\hline 4b_3k & $402 \pm 44.8$ & $5.4 \pm 2.5$ \\
\hline 4b_10k & $1182 \pm 91.6$ & $9.2 \pm 1.3$ \\
\hline 4c_3k & $1696 \pm 198$ & $8.4 \pm 1.9$ \\
\hline 4c_10k & $1127 \pm 250$ & $11 \pm 0.63$ \\
\hline 4d_3k & $831 \pm 115$ & $9.7 \pm 0.72$ \\
\hline 4d_10k & $549 \pm 101$ & $7.8 \pm 0.22$ \\
\hline 4e_3k & $893 \pm 247$ & $9.7 \pm 0.64$ \\
\hline 4e_10k & $613 \pm 23.7$ & $10 \pm 6.7$ \\
\hline S. aureus & n.d & $-2.2 \pm 0.52$ \\
\hline S. aureus /4c_3k & n.d & $-5.3 \pm 0.73$ \\
\hline S. aureus/4c_10k & n.d & $-1.1 \pm 1.2$ \\
\hline a & & \\
\hline & & \\
\hline & & \\
\hline
\end{tabular}

n.d. means not determined 


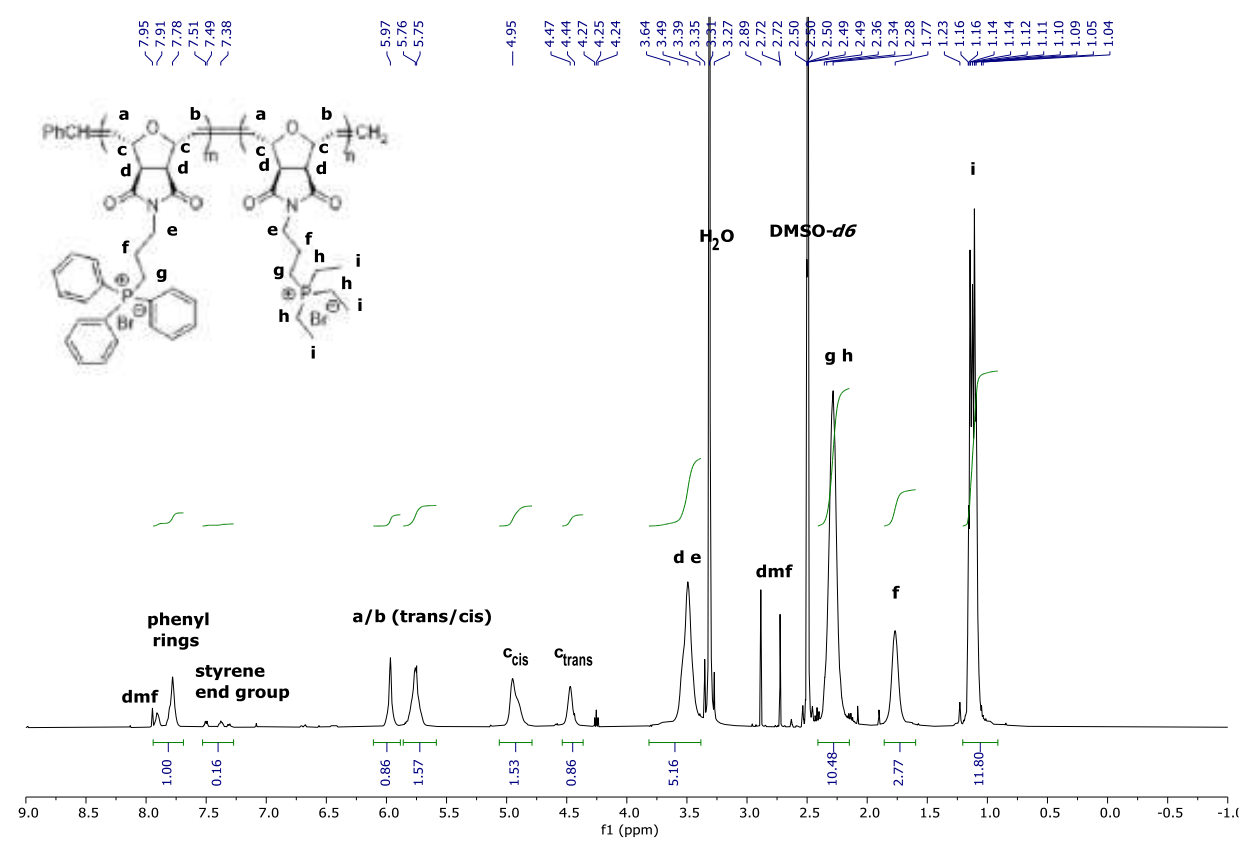

Figure S32. ${ }^{1} \mathrm{H}$ NMR spectrum of phenyl and ethyl based copolymer with a theoretical ratio m:n (1:9, by weight) in DMSO- $d_{6 .}$ (5a)

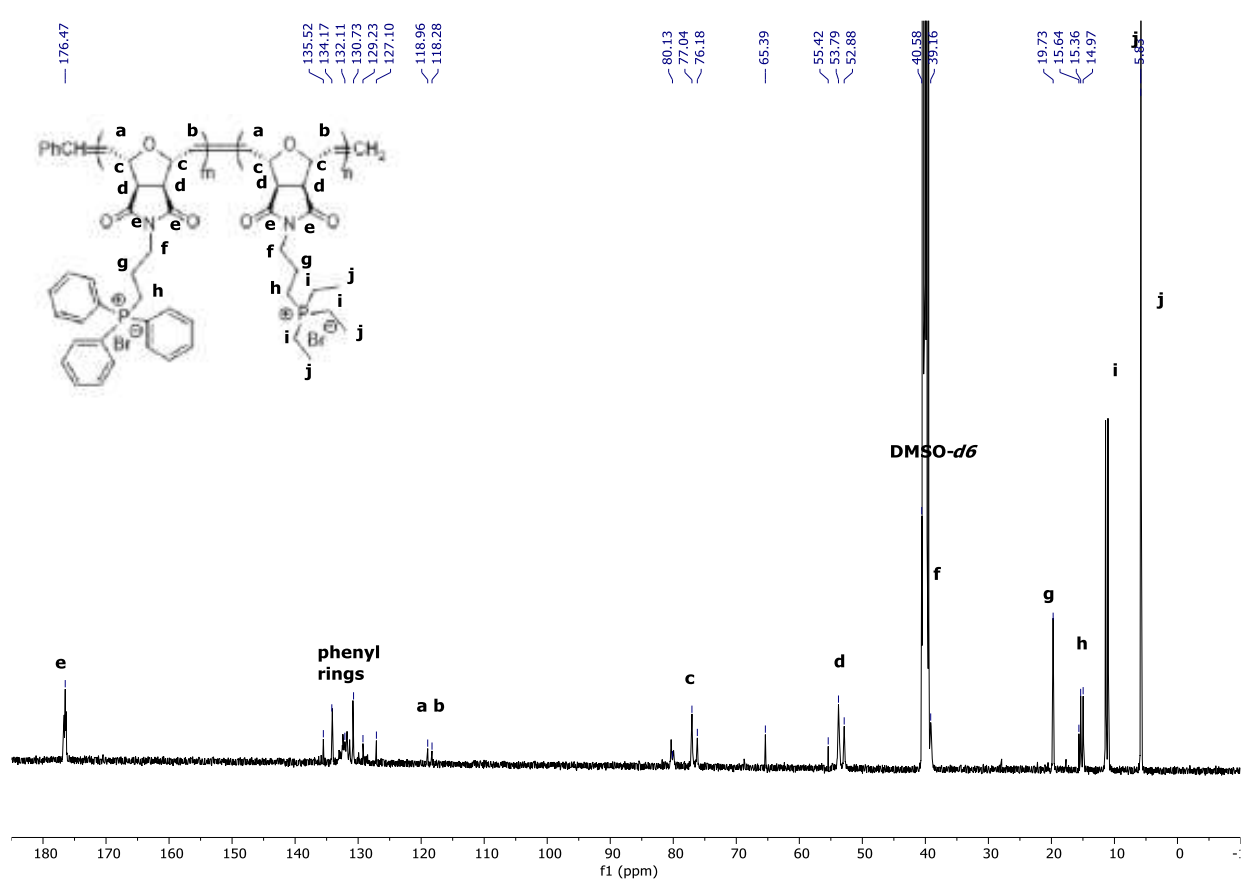

Figure S33. ${ }^{13} \mathrm{C}$ NMR spectrum of phenyl and ethyl based copolymer with a theoretical ratio m:n (1:9, by weight) in DMSO- $d_{6} .(5 a)$ 


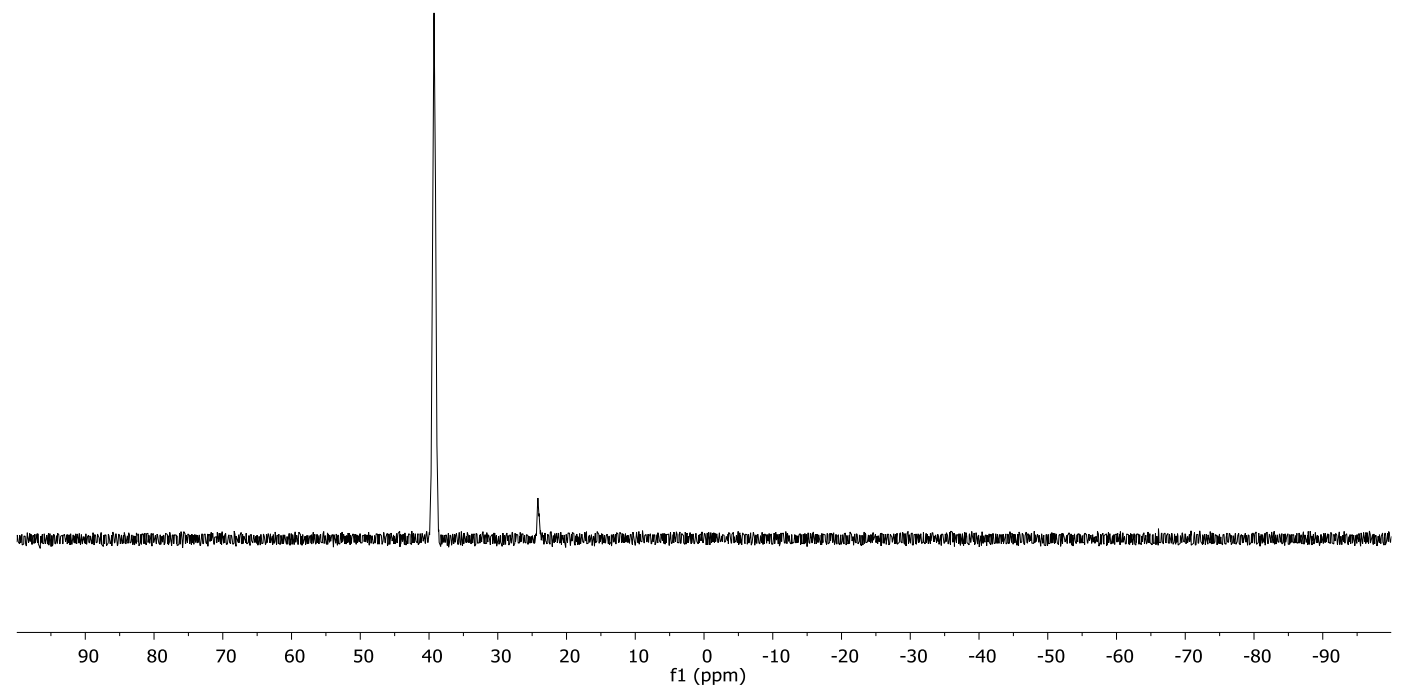

Figure S34. ${ }^{31} \mathrm{P}$ NMR spectrum of phenyl and ethyl based copolymer with a theoretical ratio m:n (1:9, by weight) in DMSO- $d_{6}$. (5a)

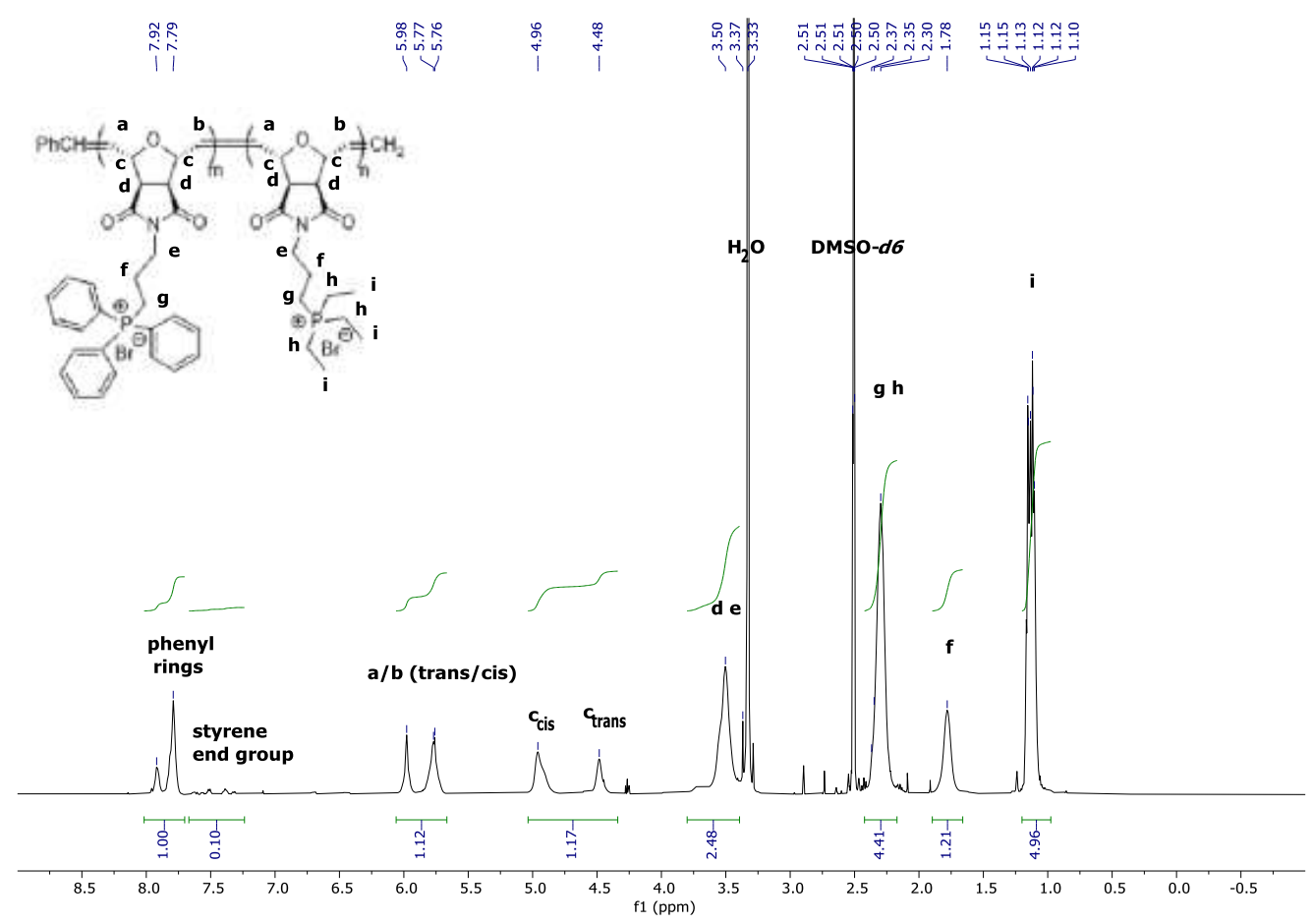

Figure S35. ${ }^{1} \mathrm{H}$ NMR spectrum of phenyl and ethyl based copolymer with a theoretical ratio m:n $(2: 8$, by weight $)$ in DMSO- $d_{6} .(\mathbf{5 b})$ 


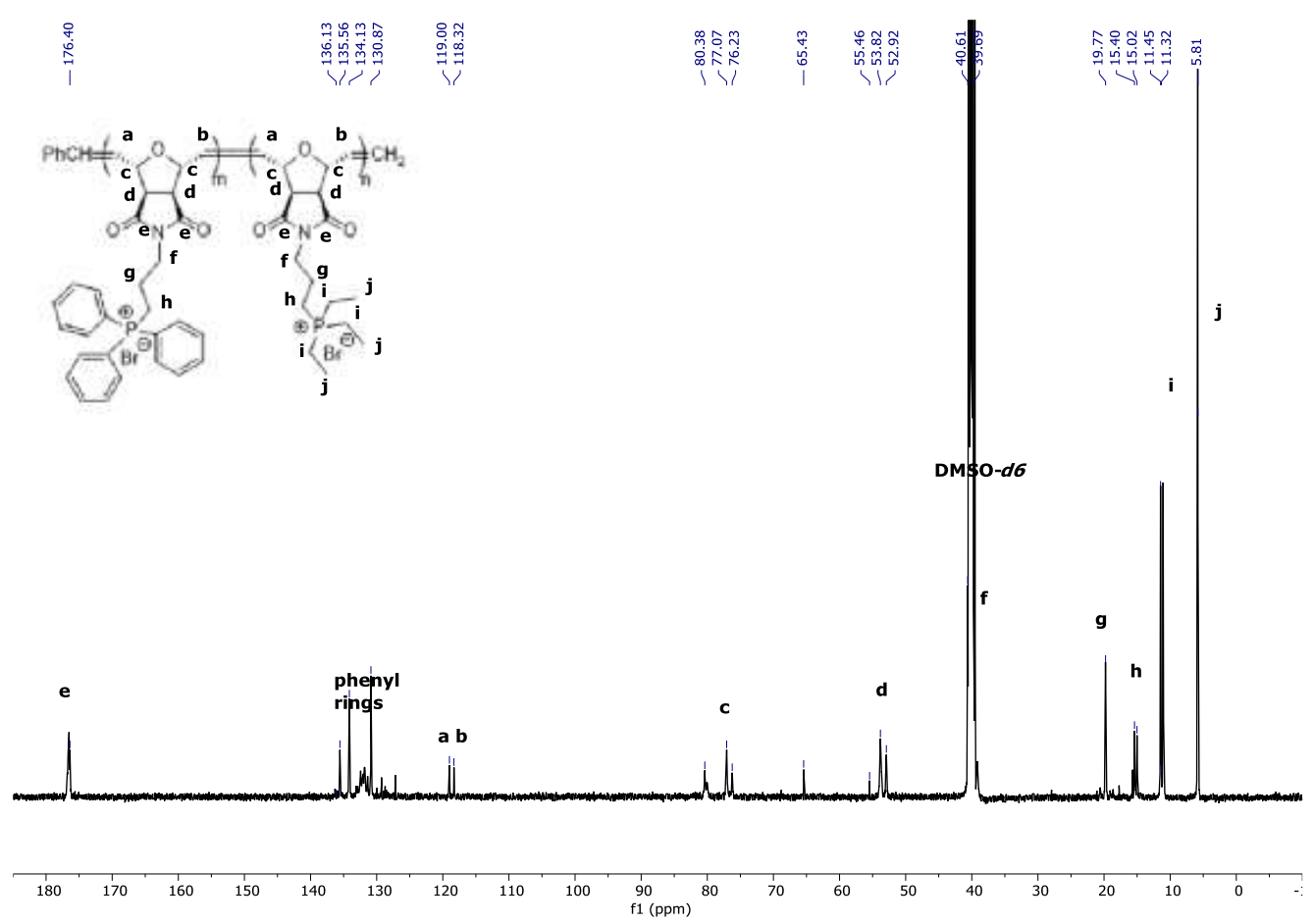

Figure S36. ${ }^{13} \mathrm{C}$ NMR spectrum of phenyl and ethyl based copolymer with a theoretical ratio m:n $\left(2: 8\right.$, by weight) in DMSO- $d_{6} .(\mathbf{5 b})$

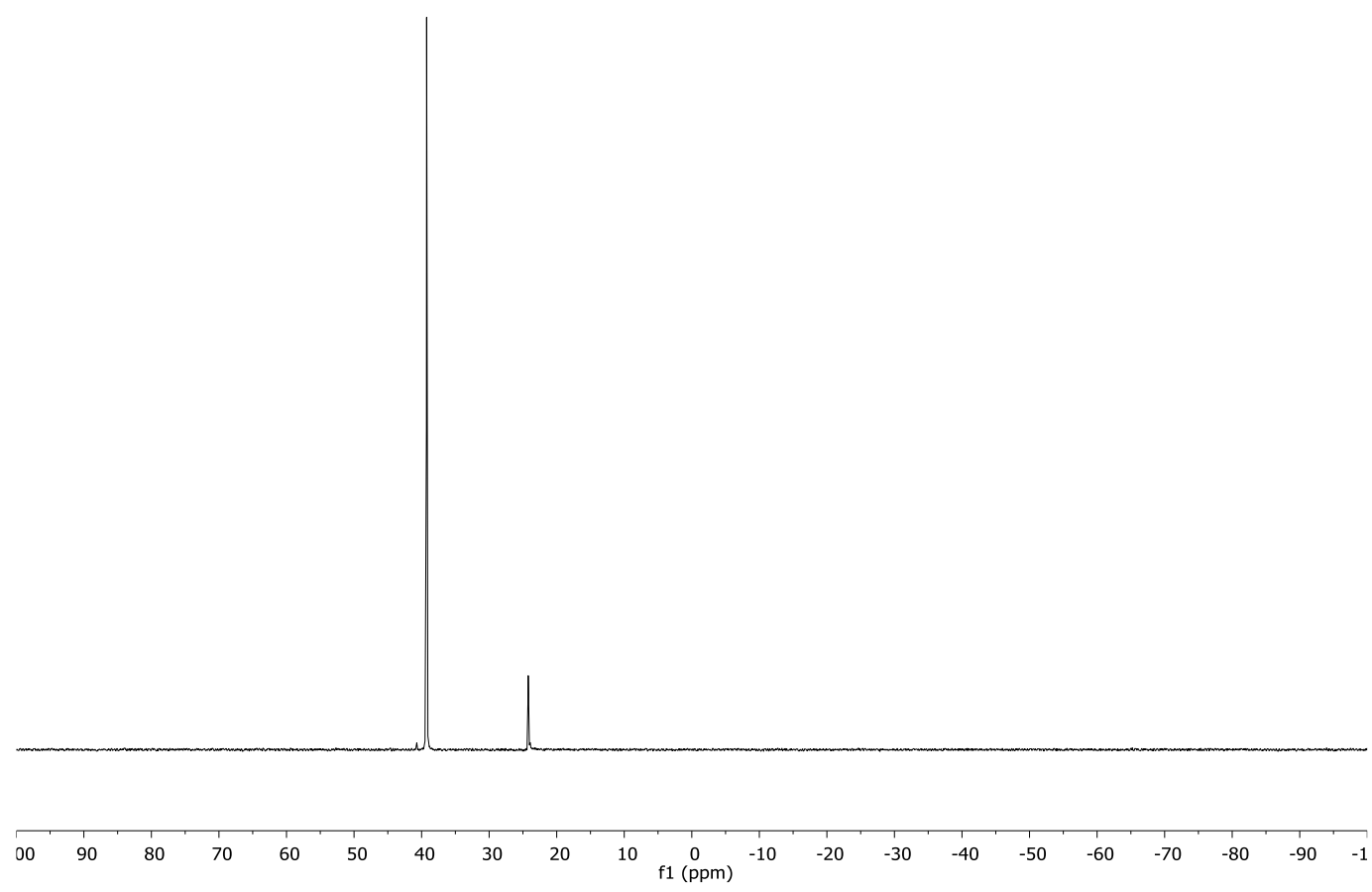

Figure S37. ${ }^{31} \mathrm{P}$ NMR spectrum of phenyl and ethyl based copolymer with a theoretical ratio m:n $(2: 8$, by weight $)$ in DMSO- $d_{6} .(\mathbf{5 b})$ 


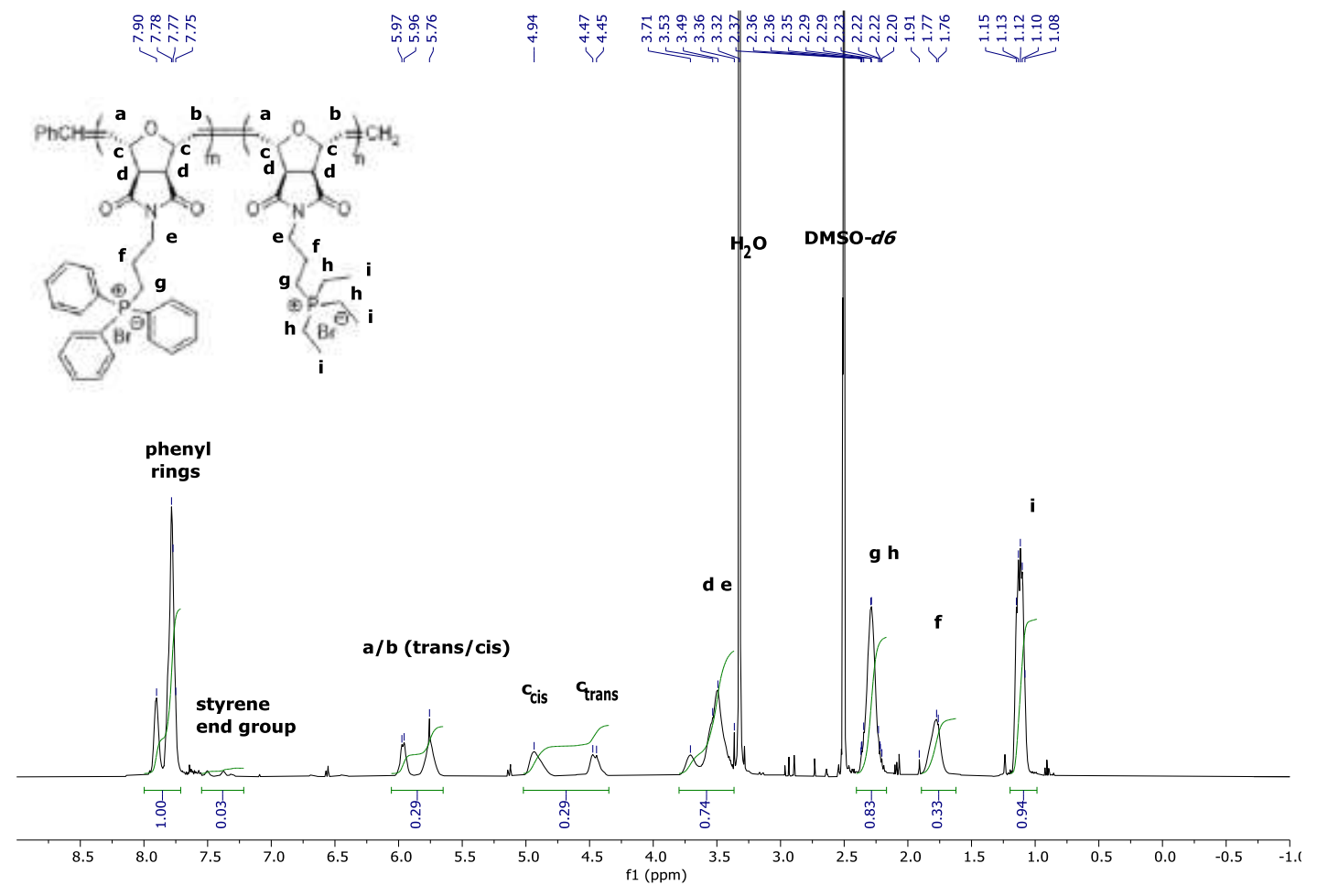

Figure S38. ${ }^{1} \mathrm{H}$ NMR spectrum of phenyl and ethyl based copolymer with a theoretical ratio m:n $\left(5: 5\right.$, by weight) in DMSO- $d_{6 .}(\mathbf{5 c})$
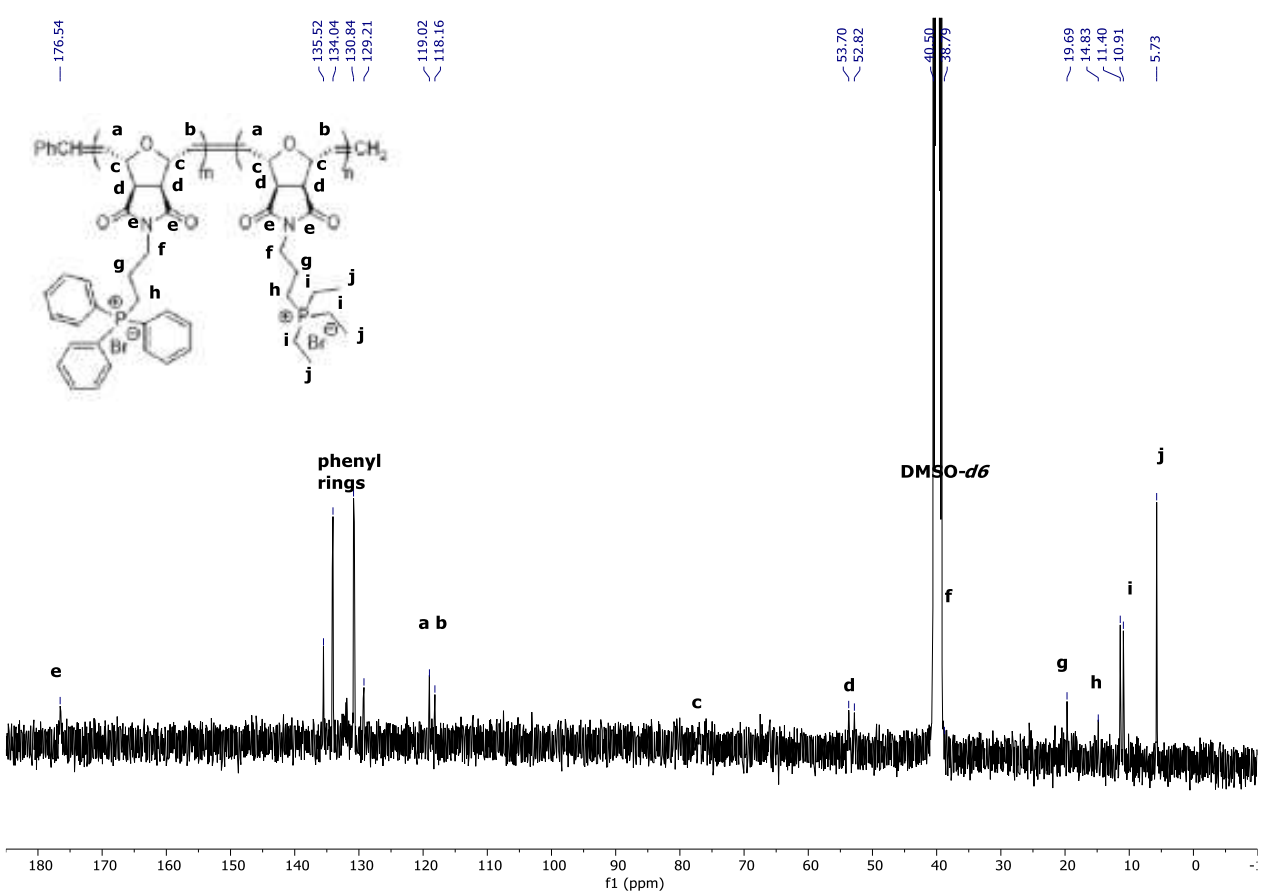

Figure S39. ${ }^{13} \mathrm{C}$ NMR spectrum of phenyl and ethyl based copolymer with a theoretical ratio m:n $(5: 5$, by weight $)$ in DMSO- $d_{6} .(\mathbf{5 c})$ 


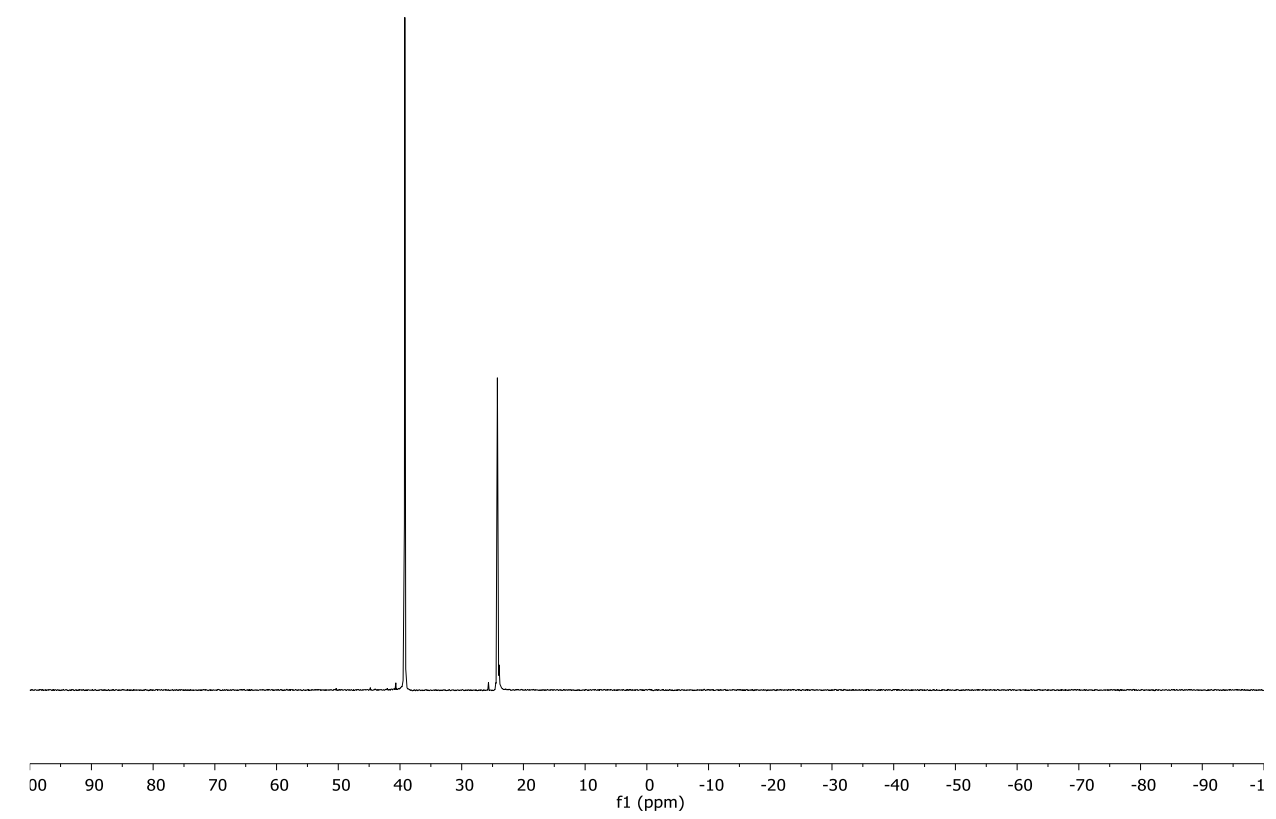

Figure S40. ${ }^{31} \mathrm{P}$ NMR spectrum of phenyl and ethyl based copolymer with a theoretical ratio m:n $(5: 5$, by weight $)$ in DMSO- $d_{6 .}(\mathbf{5 c})$

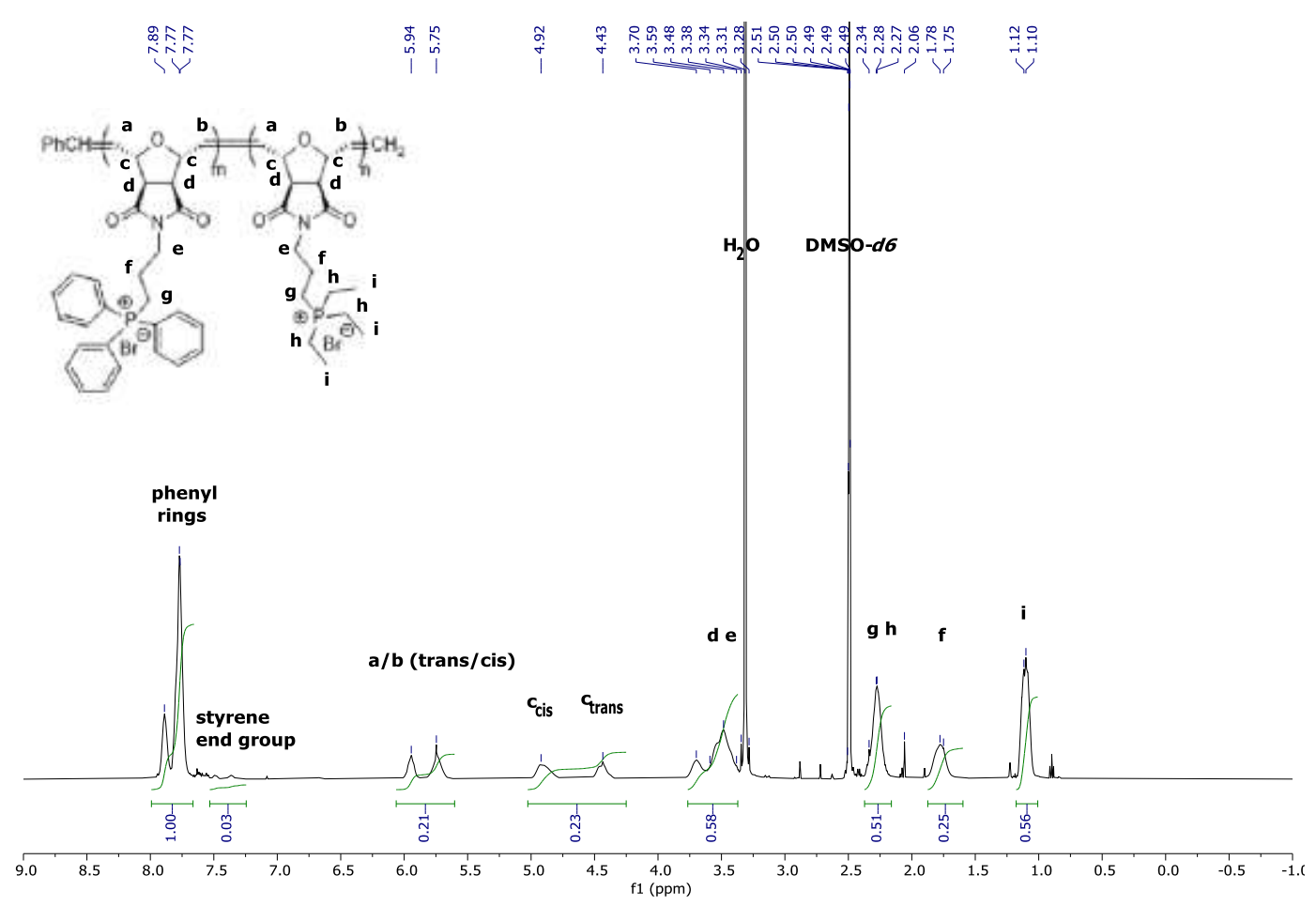

Figure S41. ${ }^{1} \mathrm{H}$ NMR spectrum of phenyl and ethyl based copolymer with a theoretical ratio m:n $(6: 4$, by weight $)$ in DMSO- $d_{6} .(\mathbf{5 d})$ 


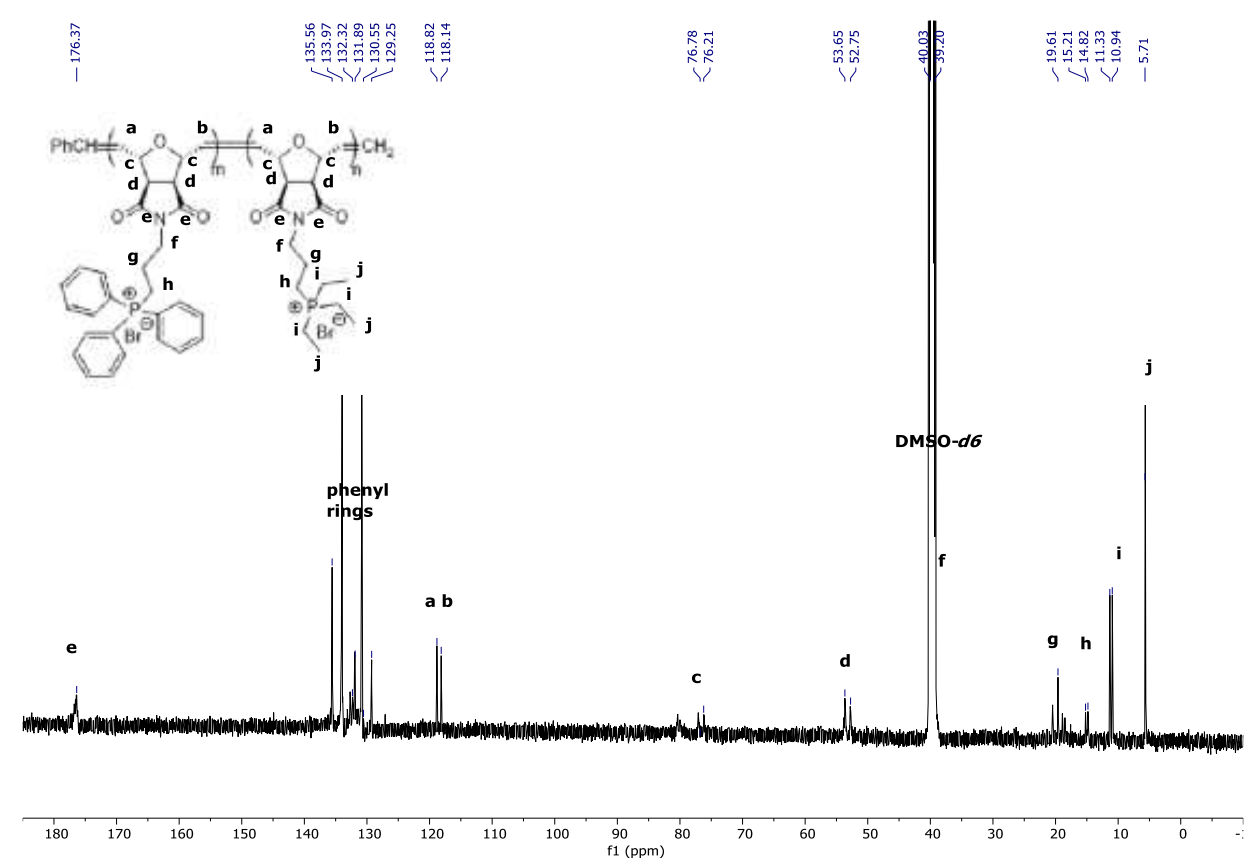

Figure S42. ${ }^{13} \mathrm{C}$ NMR spectrum of phenyl and ethyl based copolymer with a theoretical ratio m:n $(6: 4$, by weight $)$ in DMSO- $d_{6} .(\mathbf{5 d})$

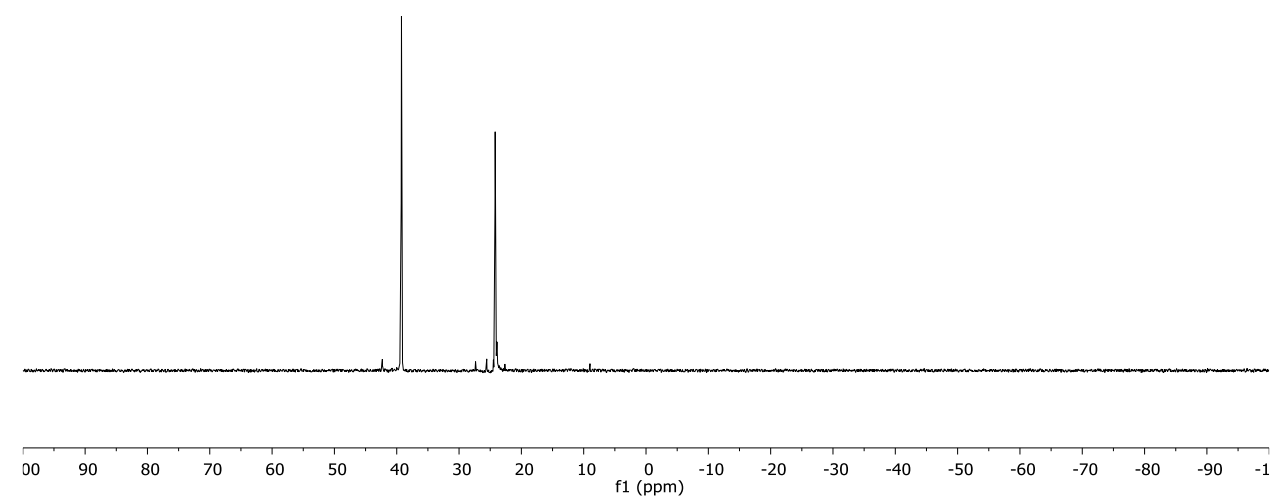

Figure S43. ${ }^{31} \mathrm{P}$ NMR spectrum of phenyl and ethyl based copolymer with a theoretical ratio m:n $(6: 4$, by weight $)$ in DMSO- $d_{6} .(\mathbf{5 d})$ 


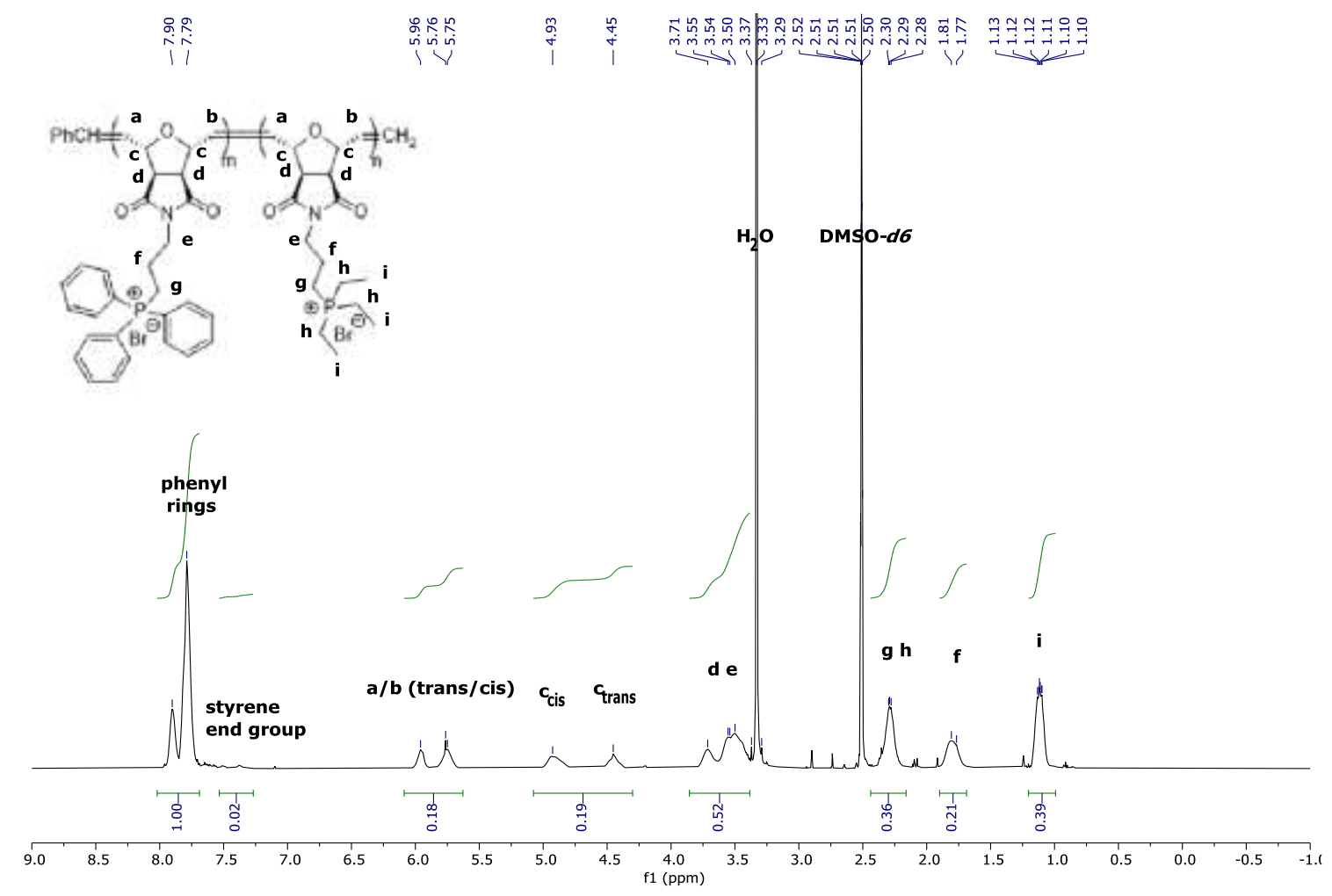

Figure S44. ${ }^{1} \mathrm{H}$ NMR spectrum of phenyl and ethyl based copolymer with a theoretical ratio m:n (7:3, by weight) in DMSO- $d_{6 .}(\mathbf{5 e})$

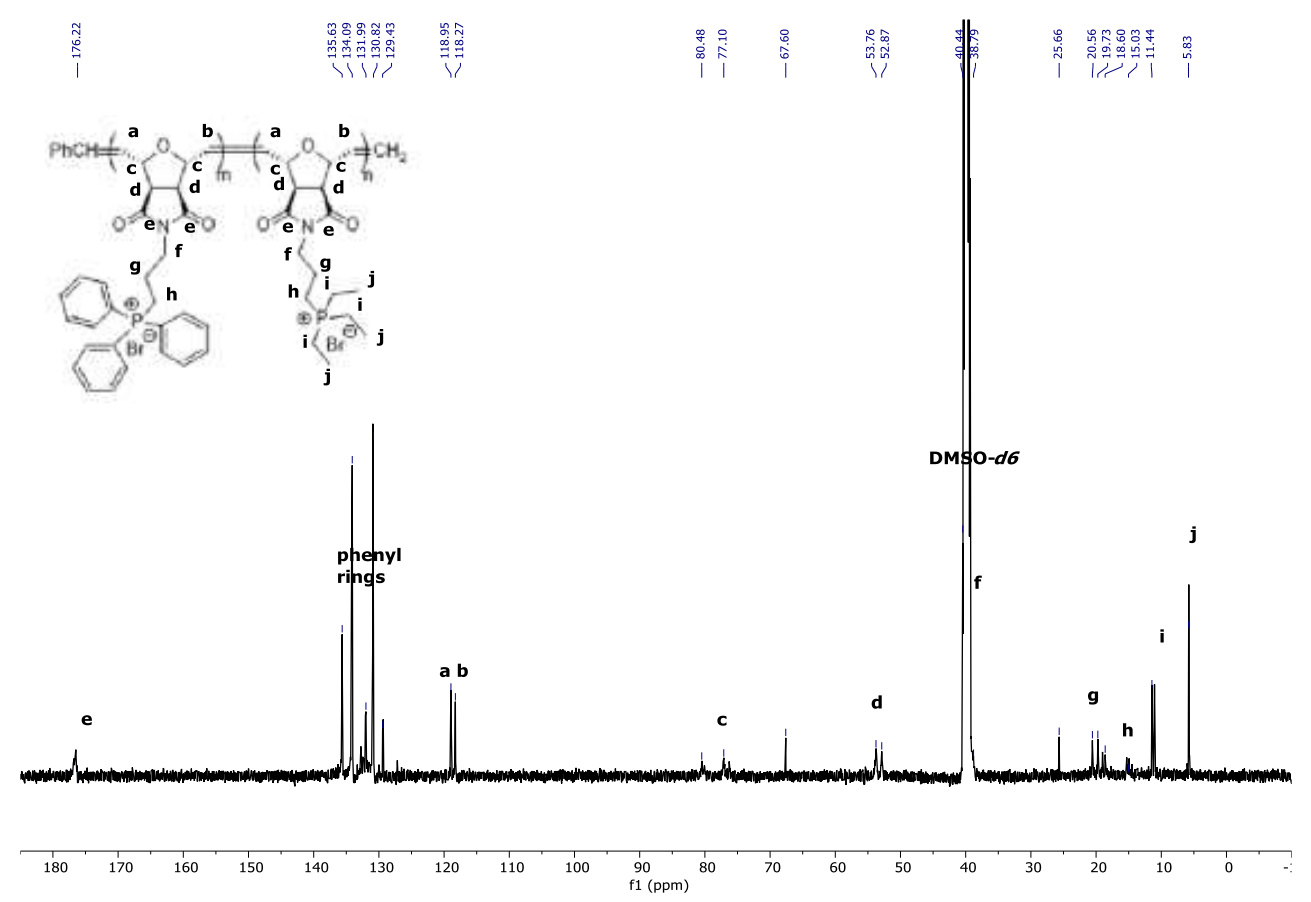

Figure S45. ${ }^{13} \mathrm{C}$ NMR spectrum of phenyl and ethyl based copolymer with a theoretical ratio m:n $(7: 3$, by weight $)$ in DMSO- $d_{6} .(5 e)$ 


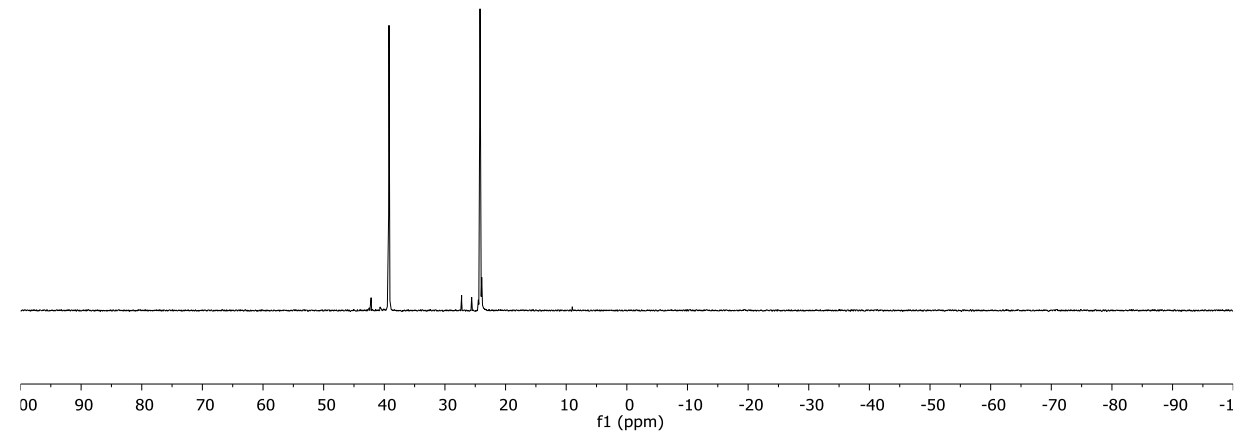

Figure S46. ${ }^{31} \mathrm{P}$ NMR spectrum of phenyl and ethyl based copolymer with a theoretical ratio m:n (7:3, by weight) in DMSO-d6. (5e)

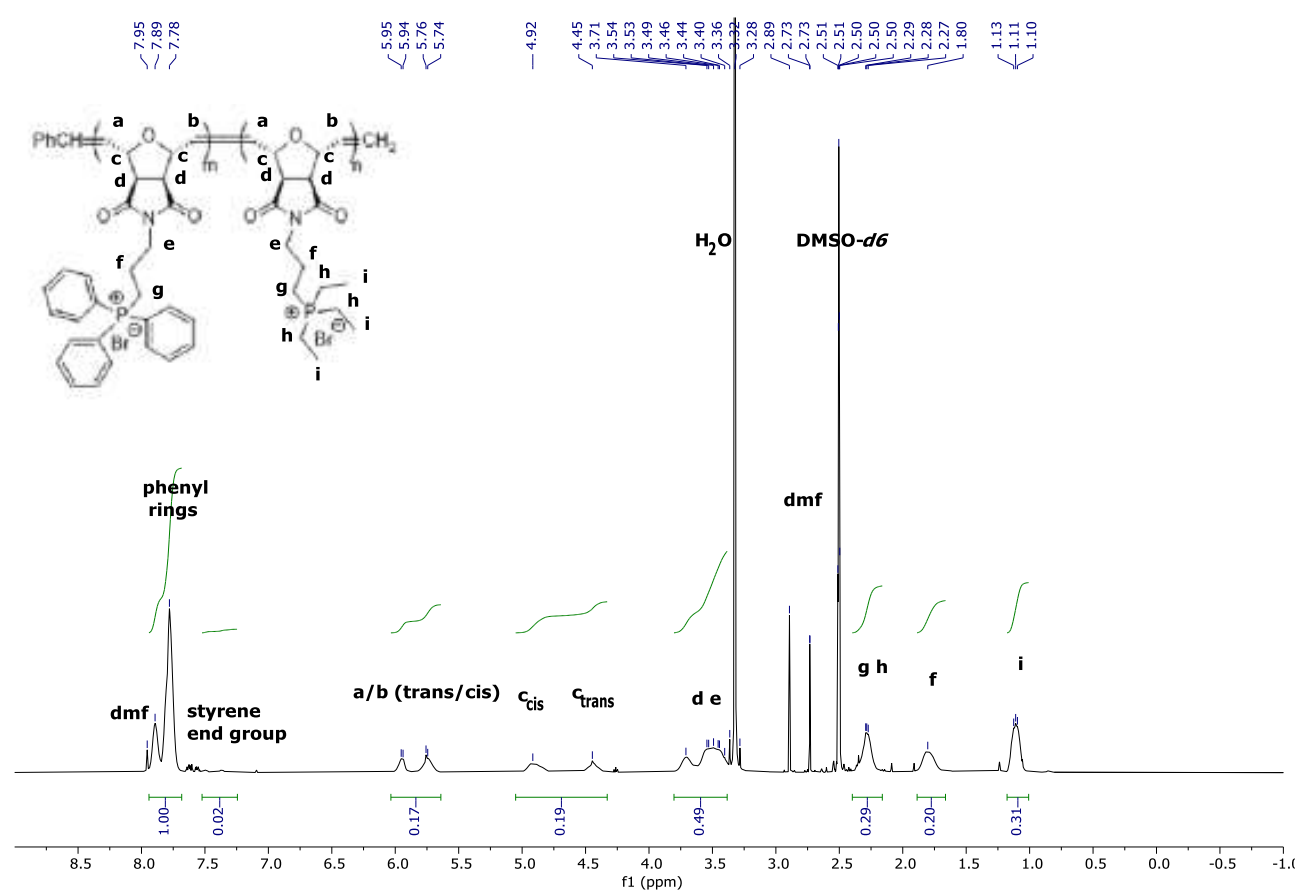

Figure S47. ${ }^{1} \mathrm{H}$ NMR spectrum of phenyl and ethyl based copolymer with a theoretical ratio m:n (8:2, by weight) in DMSO- $d_{6} .(\mathbf{5 f})$ 


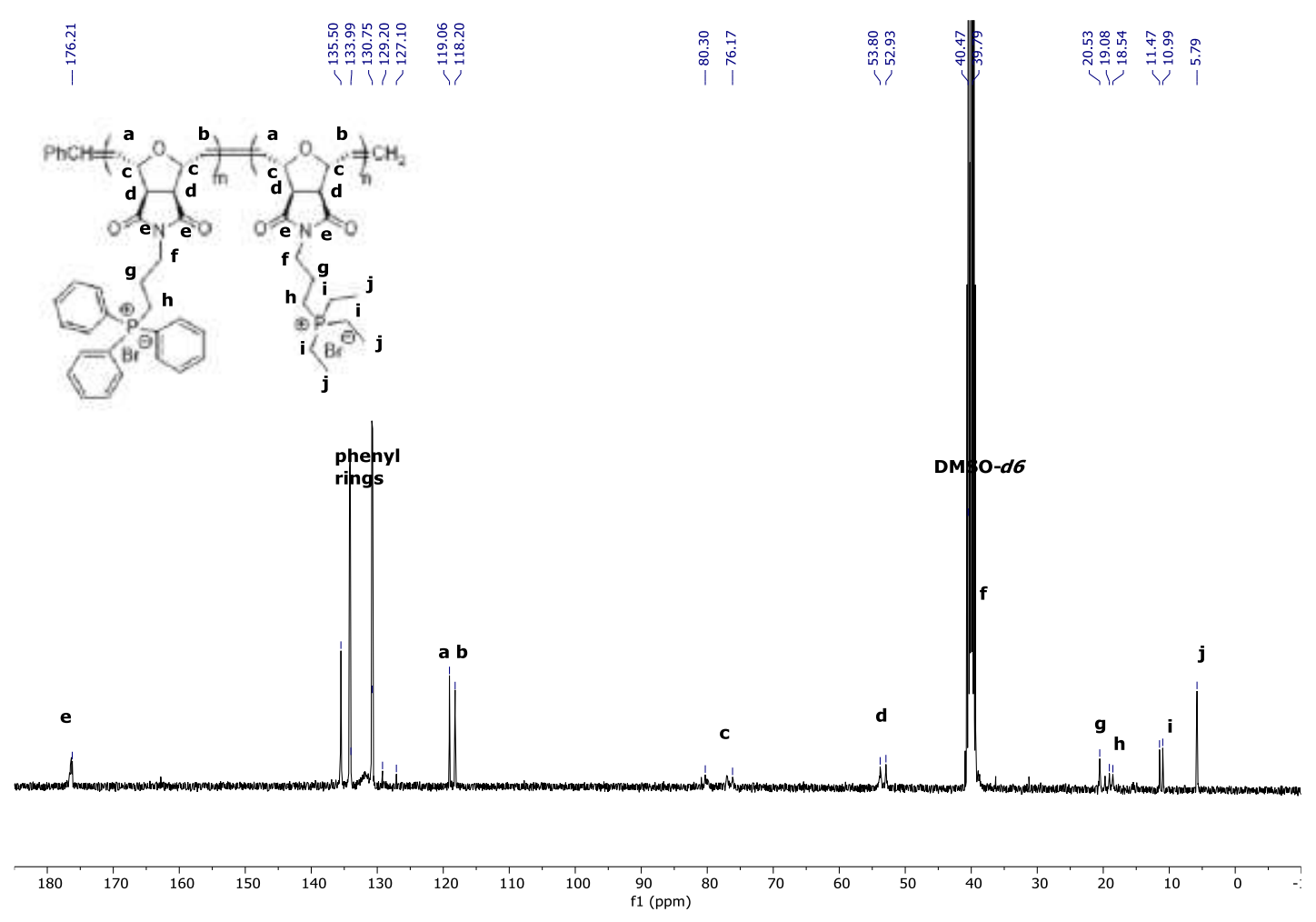

Figure S48. ${ }^{13} \mathrm{C}$ NMR spectrum of phenyl and ethyl based copolymer with a theoretical ratio $\mathrm{m}: \mathrm{n}\left(8: 2\right.$, by weight) in DMSO- $d_{6} . \mathbf{( 5 \mathbf { f } )}$

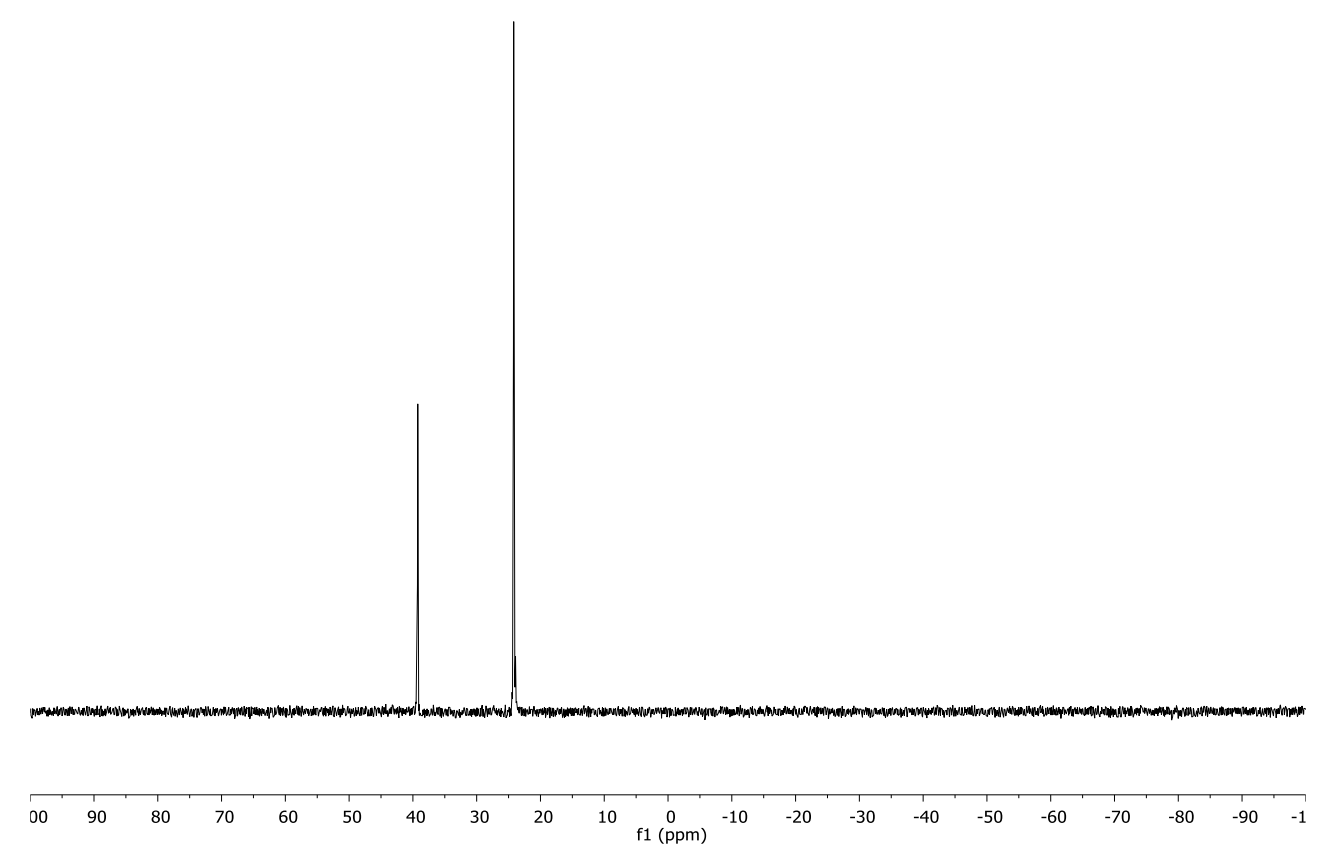

Figure S49. ${ }^{31} \mathrm{P}$ NMR spectrum of phenyl and ethyl based copolymer with a theoretical ratio m:n $\left(8: 2\right.$, by weight) in DMSO- $d_{6}$. (5f) 


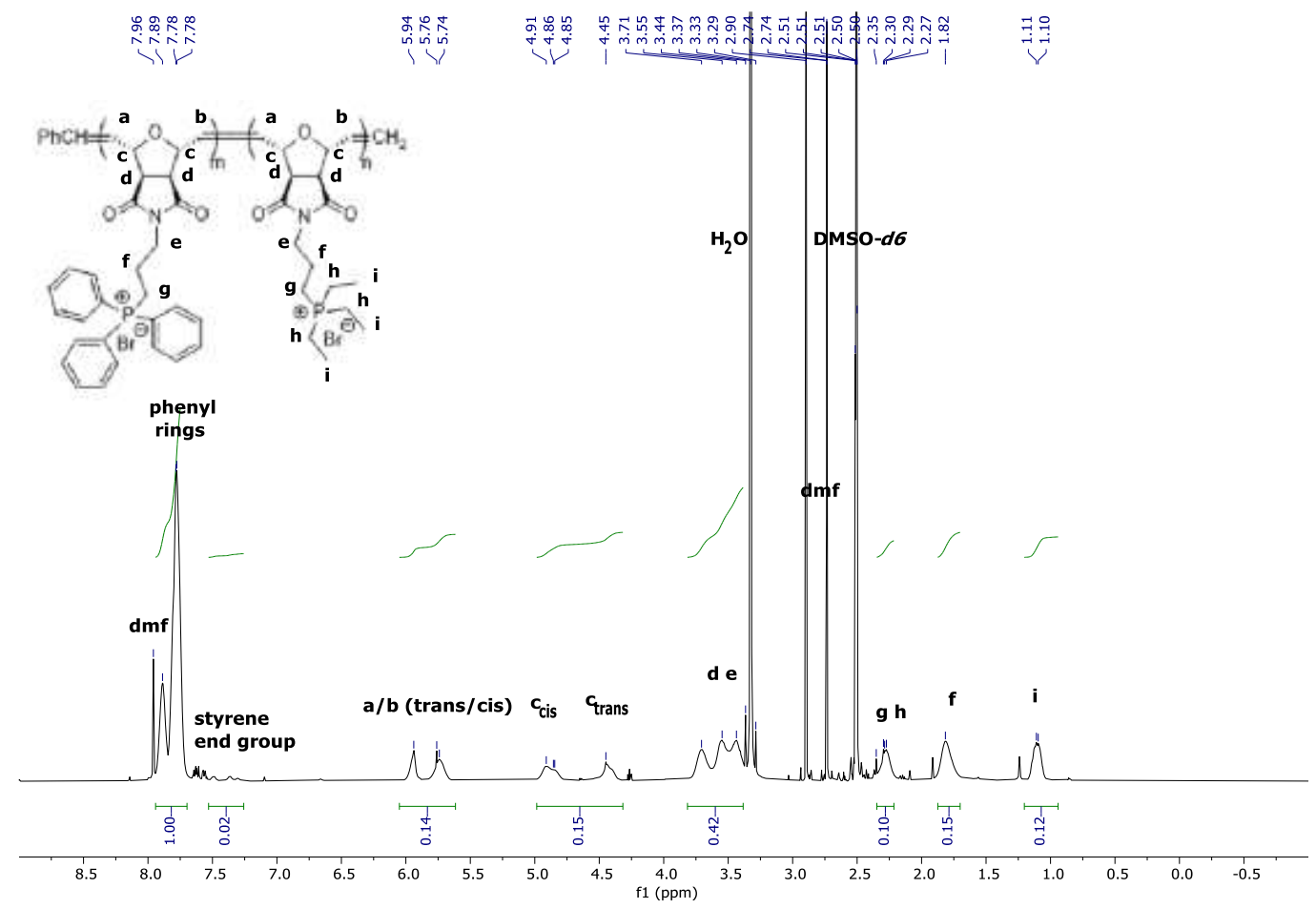

Figure S50. ${ }^{1} \mathrm{H}$ NMR spectrum of phenyl and ethyl based copolymer with a theoretical ratio m:n $(9: 1$, by weight $)$ in DMSO- $d_{6 .}(\mathbf{5 g})$

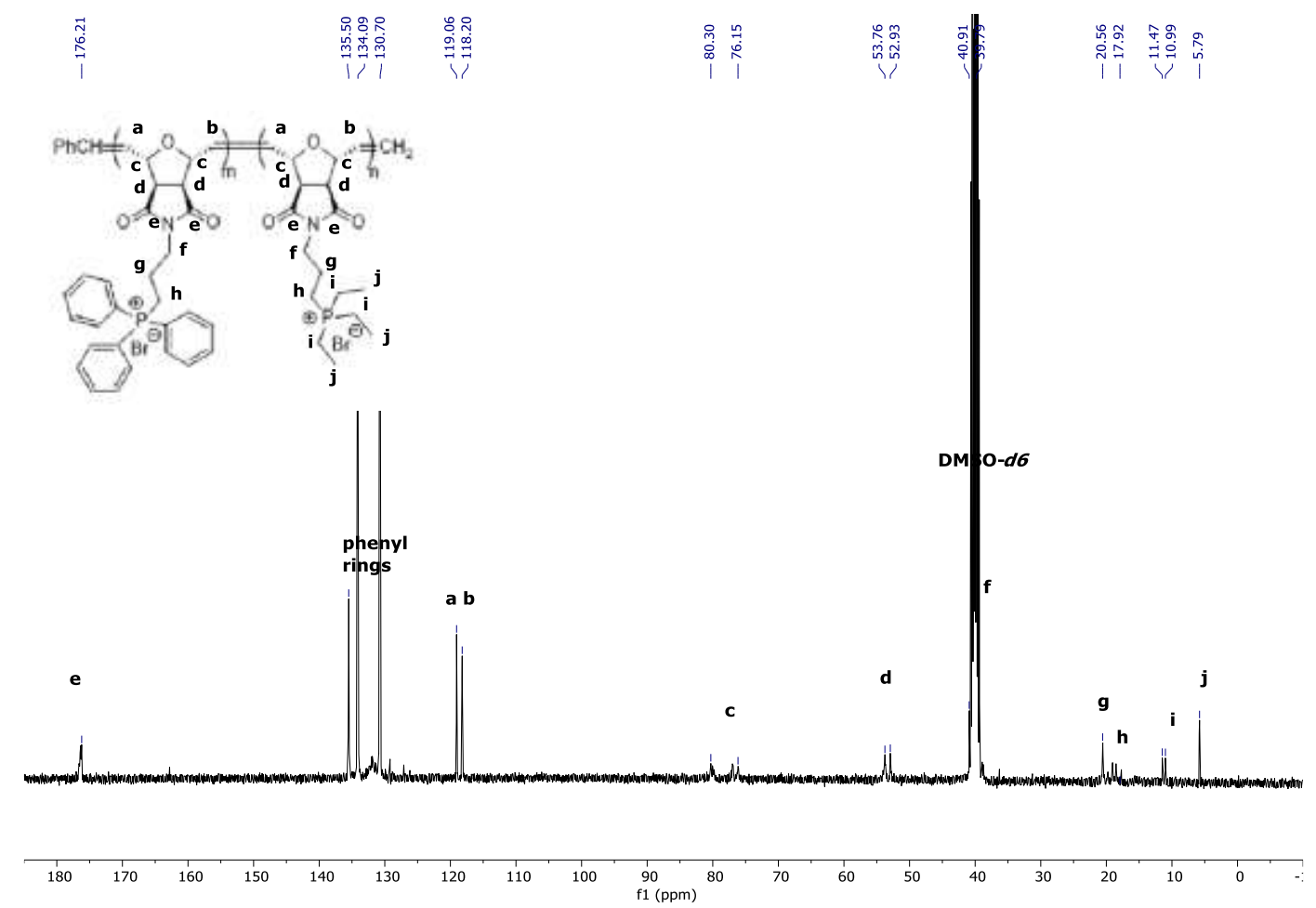

Figure S51. ${ }^{13} \mathrm{C}$ NMR spectrum of phenyl and ethyl based copolymer with a theoretical ratio m:n $\left(9: 1\right.$, by weight) in DMSO- $d_{6 .}(\mathbf{5 g})$ 


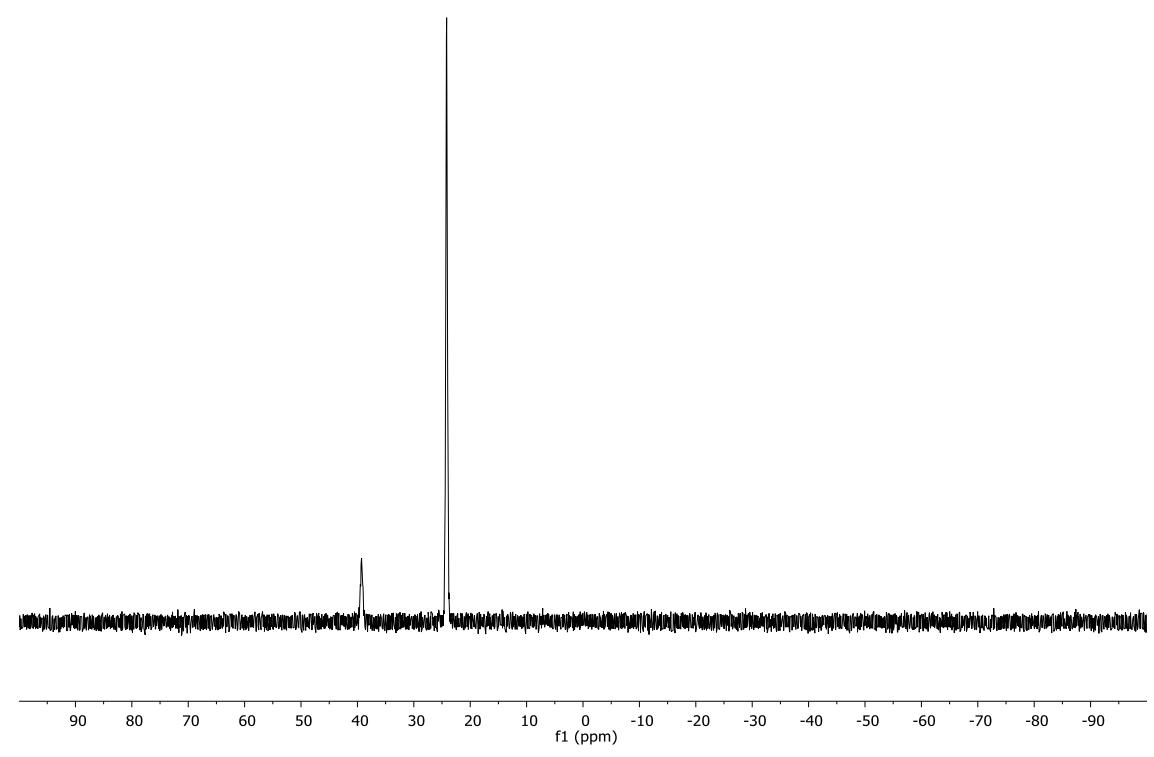

Figure S52. ${ }^{31} \mathrm{P}$ NMR spectrum of phenyl and ethyl based copolymer with a theoretical ratio m:n $\left(9: 1\right.$, by weight) in DMSO- $d_{6} .(\mathbf{5 g})$

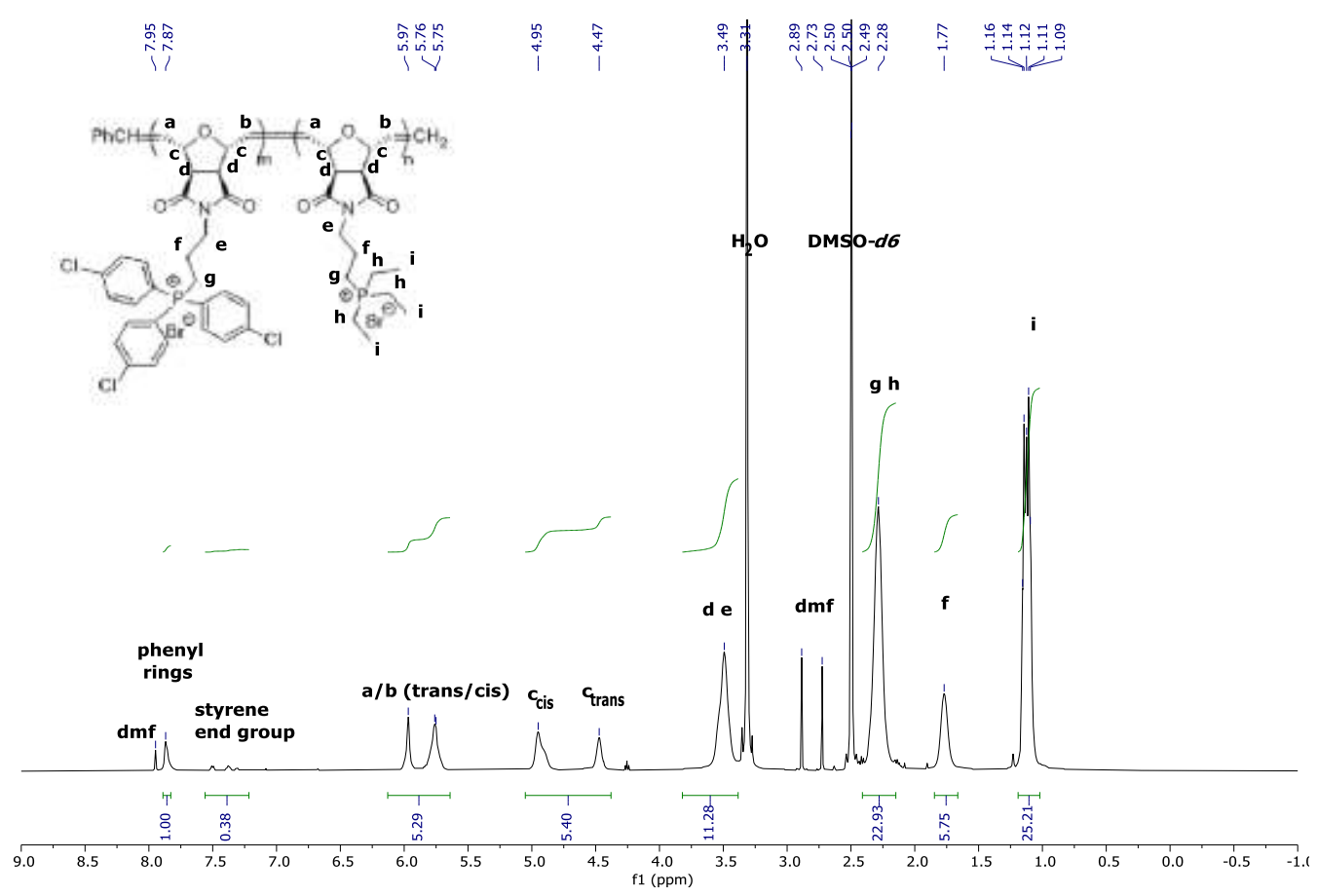

Figure S53. ${ }^{1}$ H NMR spectrum of chlorophenyl and ethyl based copolymer with a theoretical ratio m:n (1:9, by weight) in DMSO- $d_{6} .(\mathbf{5 h})$ 


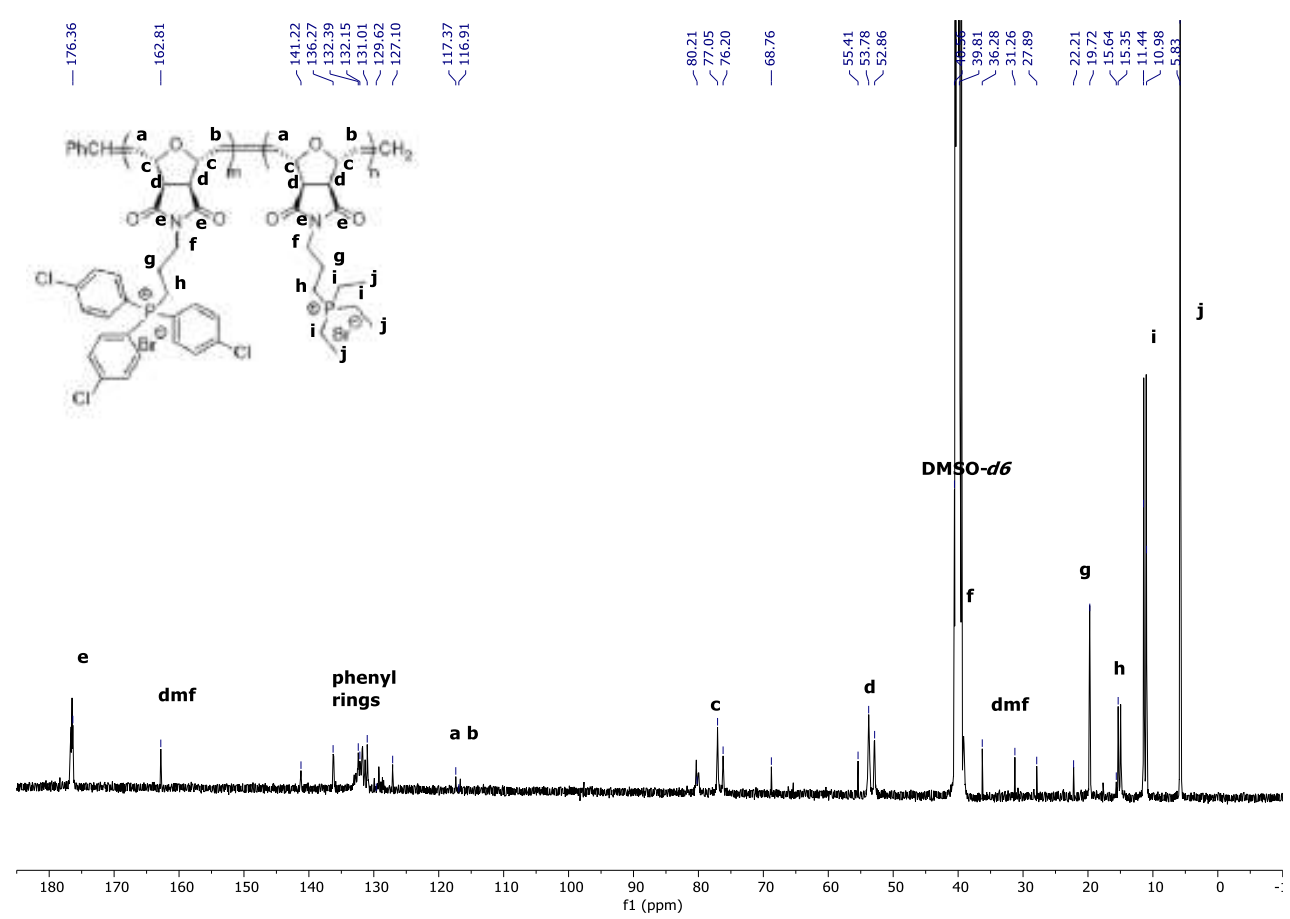

Figure S54. ${ }^{13} \mathrm{C}$ NMR spectrum of chlorophenyl and ethyl based copolymer with a theoretical ratio m:n (1:9, by weight) in DMSO- $d_{6}$. (5h)

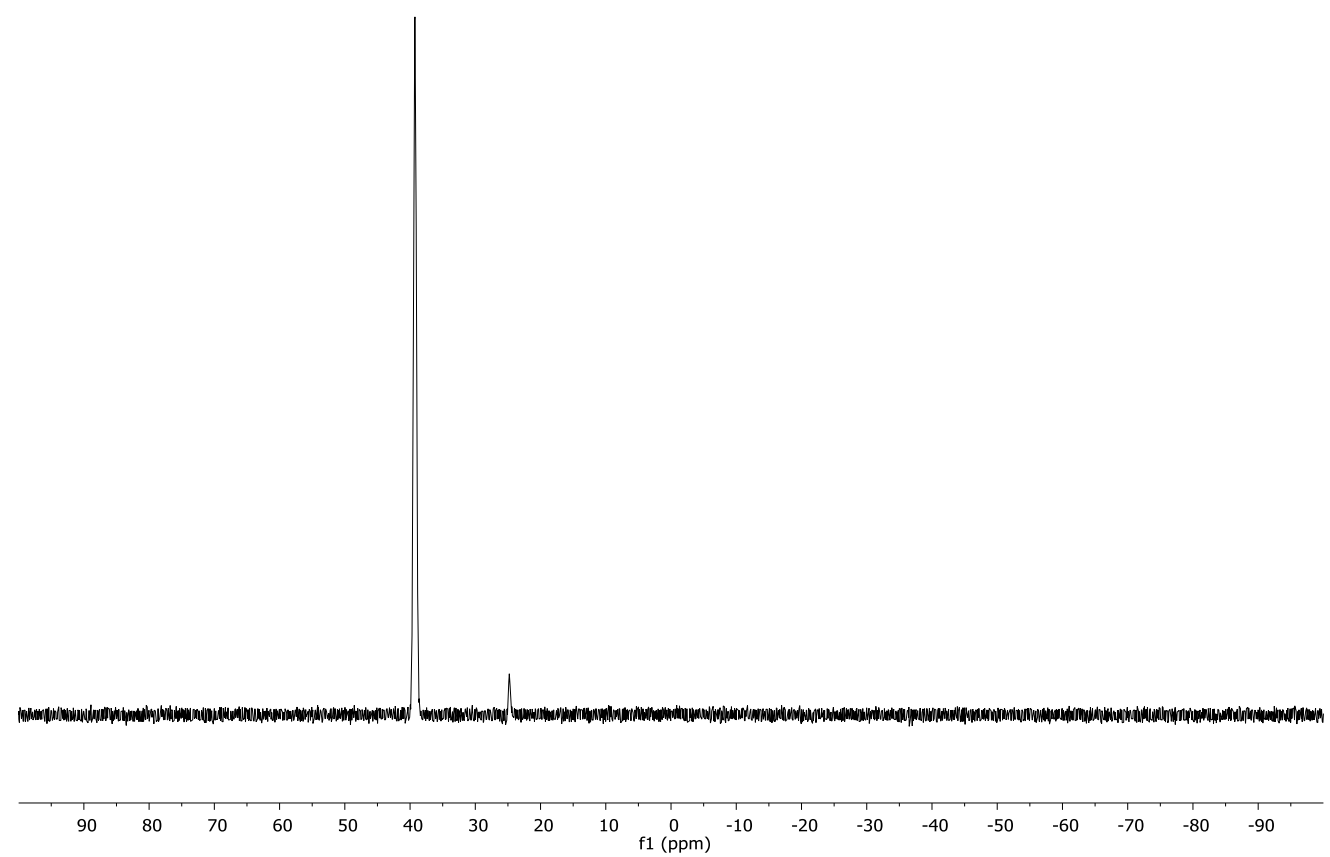

Figure S55. ${ }^{31} \mathrm{P}$ NMR spectrum of chlorophenyl and ethyl based copolymer with a theoretical ratio m:n (1:9, by weight) in DMSO- $d_{6} .(\mathbf{5 h})$ 


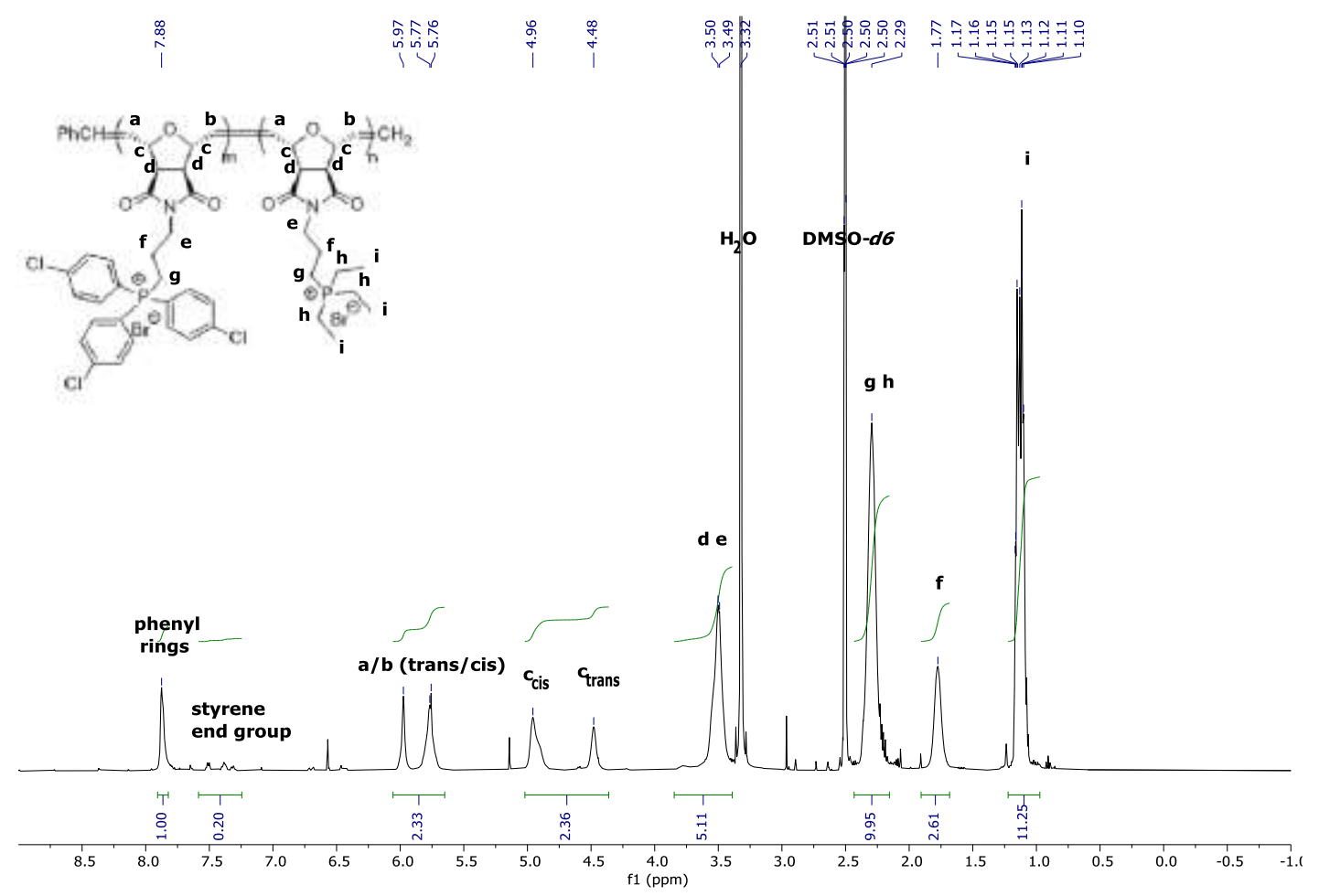

Figure S56. ${ }^{1} \mathrm{H}$ NMR spectrum of chlorophenyl and ethyl based copolymer with a theoretical ratio m:n $(2: 8$, by weight $)$ in DMSO- $d_{6 .}$ (5i)

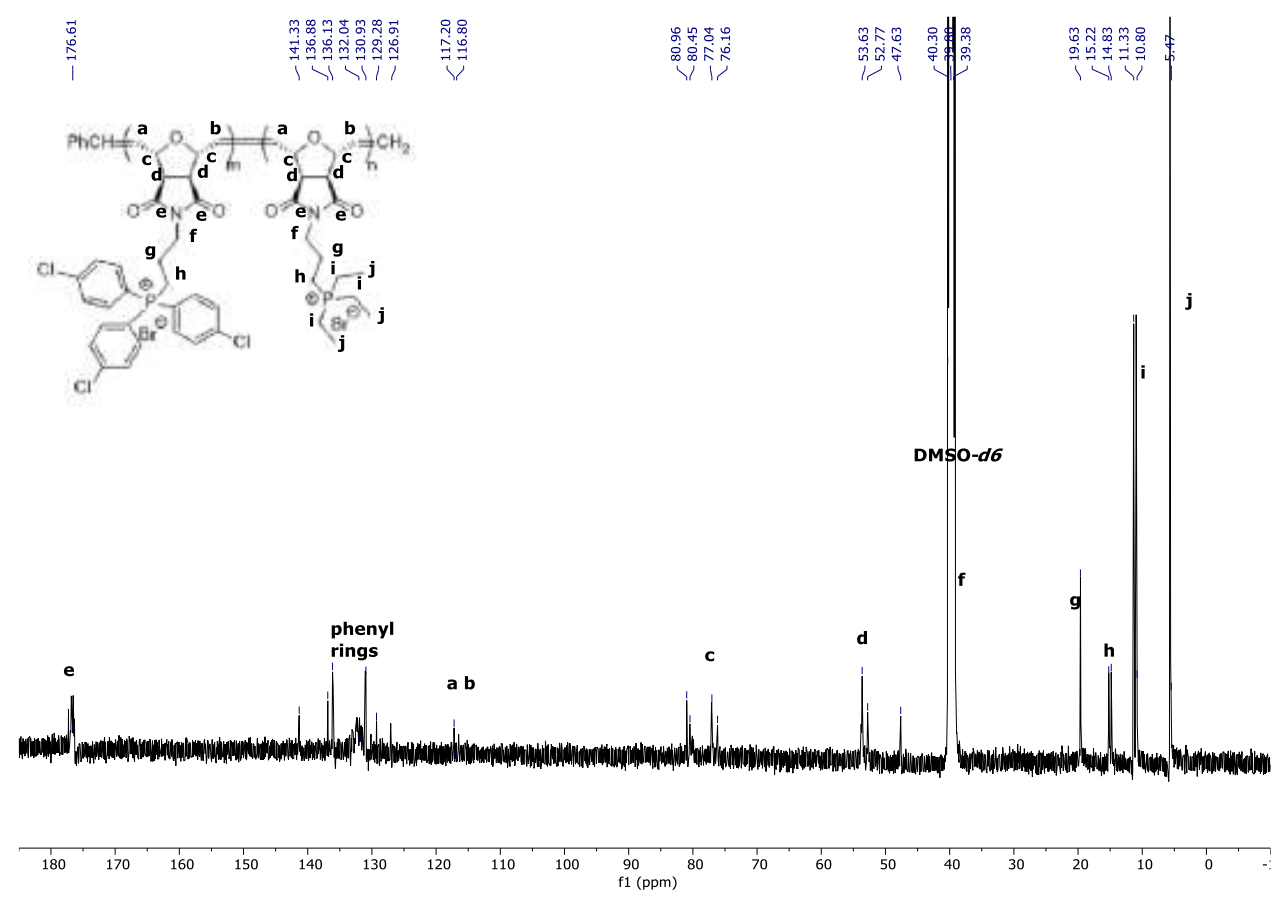

Figure S57. ${ }^{13} \mathrm{C}$ NMR spectrum of chlorophenyl and ethyl based copolymer with a theoretical ratio m:n $(2: 8$, by weight $)$ in DMSO- $d_{6} .(5 \mathbf{i})$ 


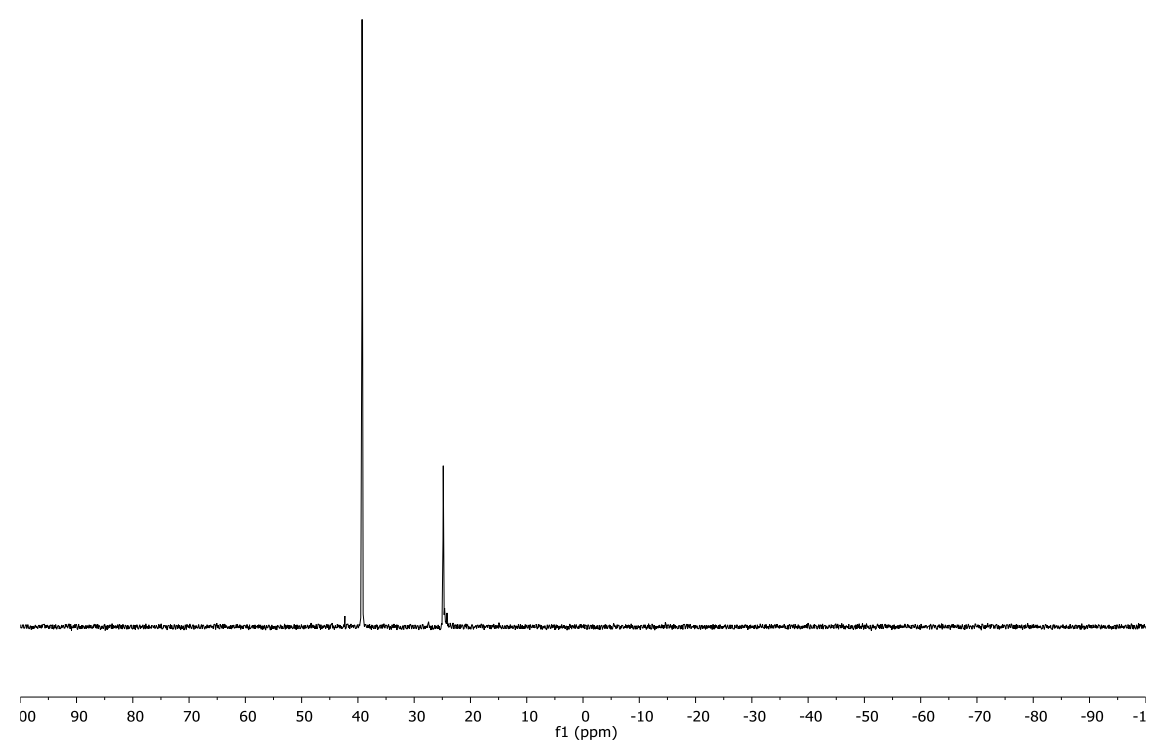

Figure S58. ${ }^{31} \mathrm{P}$ NMR spectrum of chlorophenyl and ethyl based copolymer with a theoretical ratio $m: n\left(2: 8\right.$, by weight) in DMSO- $d_{6 .}(\mathbf{5 i})$

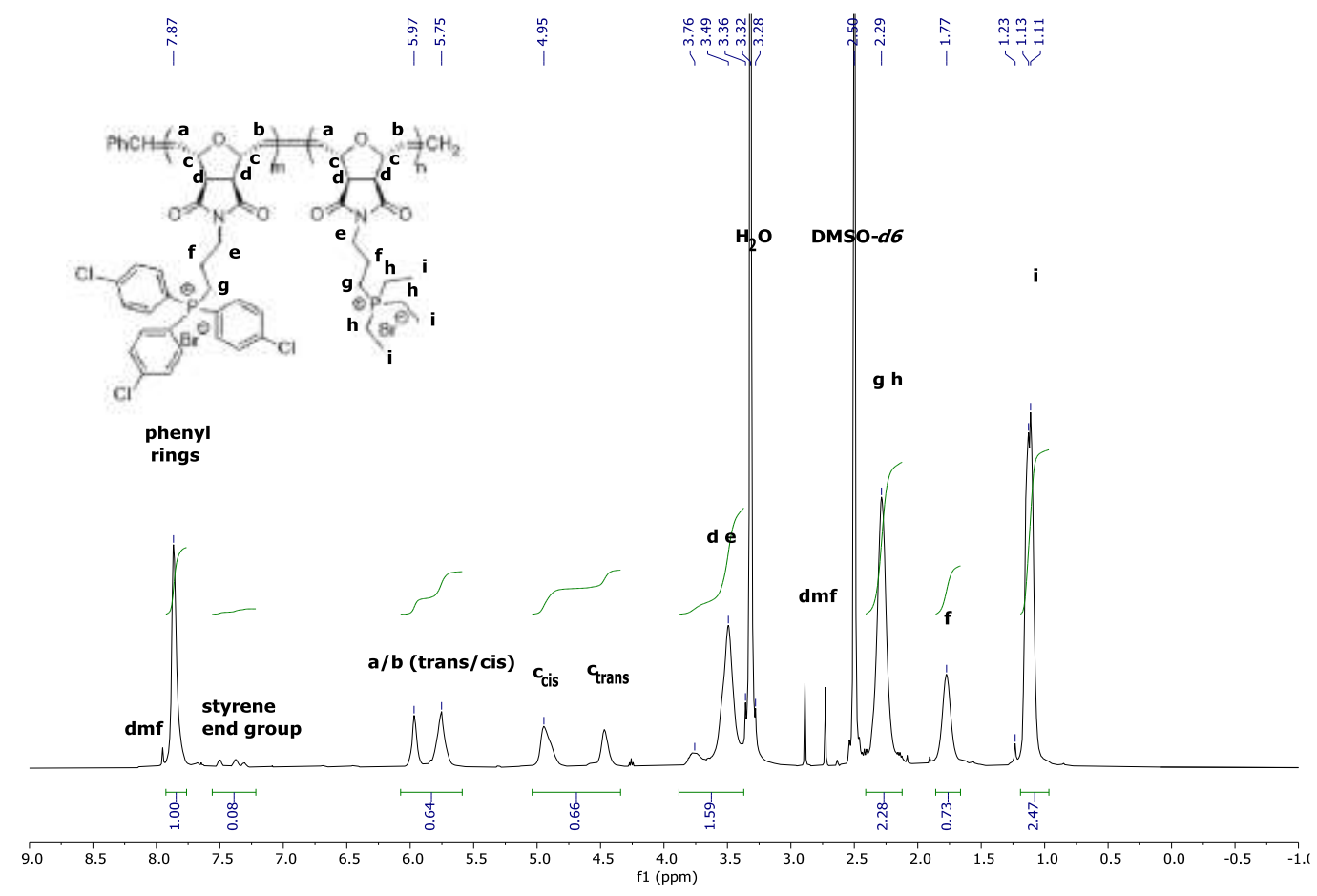

Figure S59. ${ }^{1} \mathrm{H}$ NMR spectrum of chlorophenyl and ethyl based copolymer with a theoretical ratio m:n (5:5, by weight) in DMSO- $d_{6} .(\mathbf{5 j})$ 


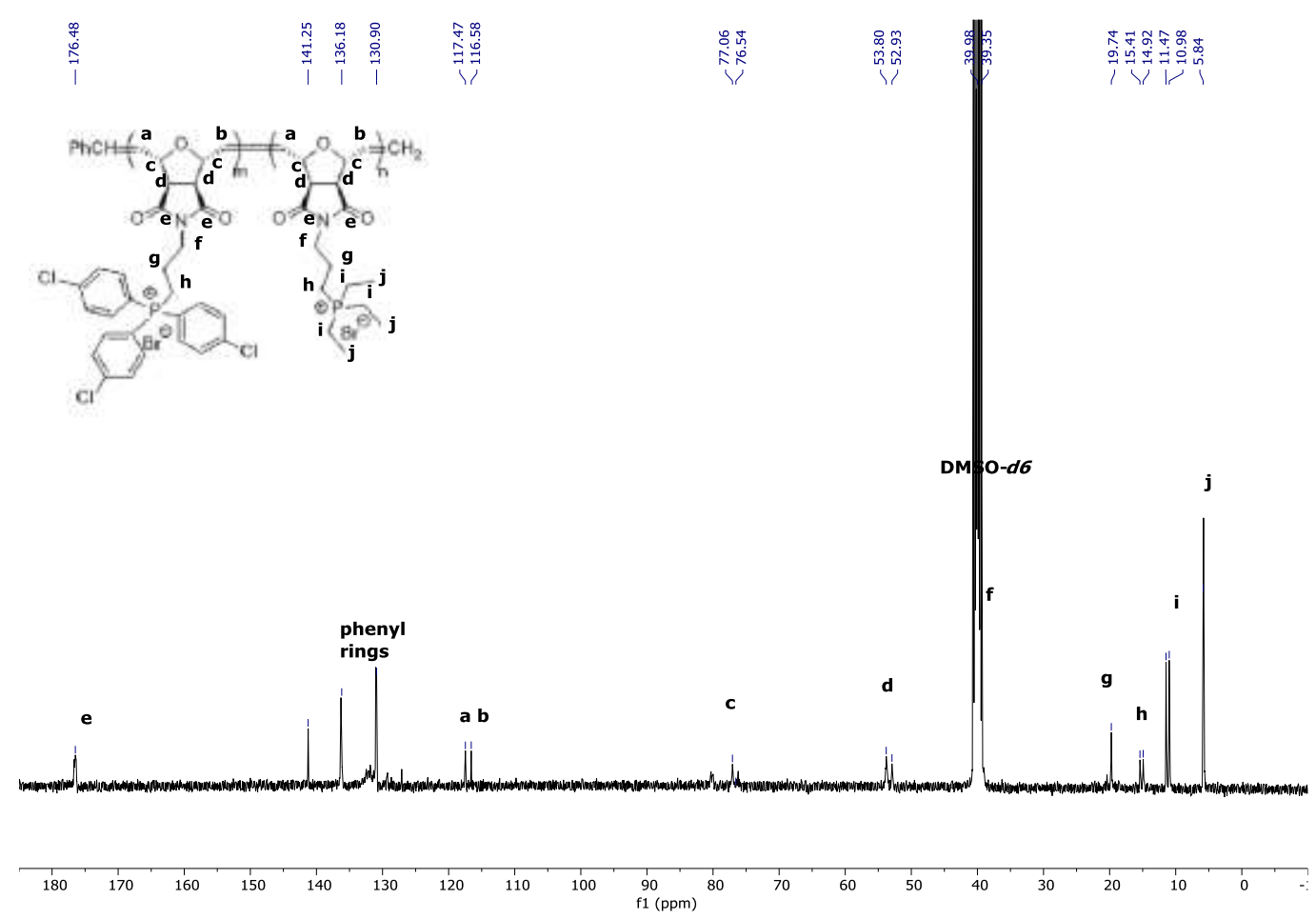

Figure S60. ${ }^{13} \mathrm{C}$ NMR spectrum of chlorophenyl and ethyl based copolymer with a theoretical ratio m:n $(5: 5$, by weight $)$ in DMSO- $d_{6} .(\mathbf{5 j})$

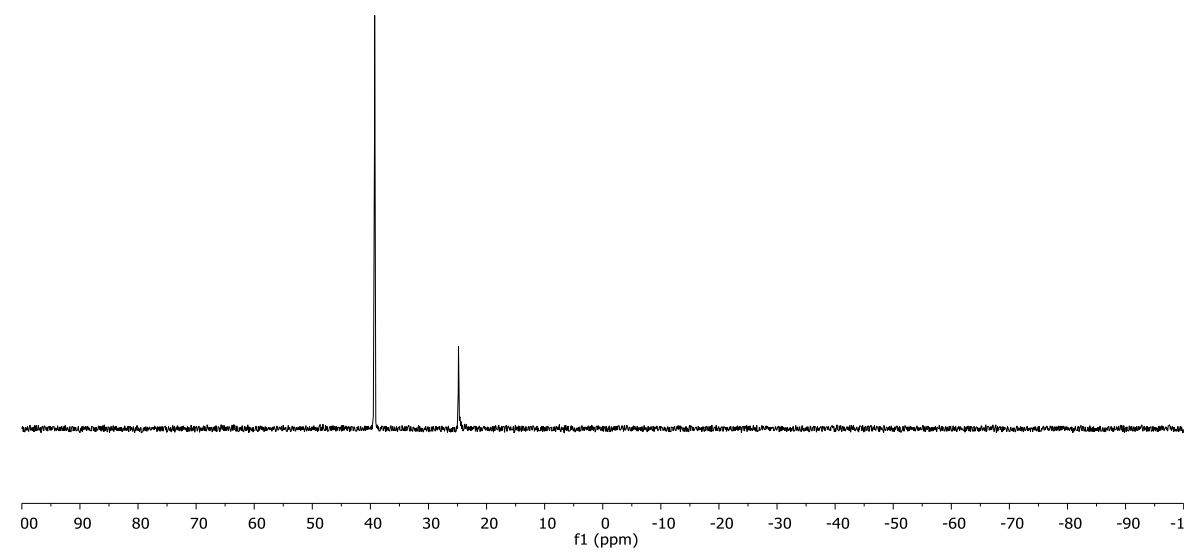

Figure S61. ${ }^{31} \mathrm{P}$ NMR spectrum of chlorophenyl and ethyl based copolymer with a theoretical ratio m:n (5:5, by weight) in DMSO- $d_{6} .(\mathbf{5 j})$ 


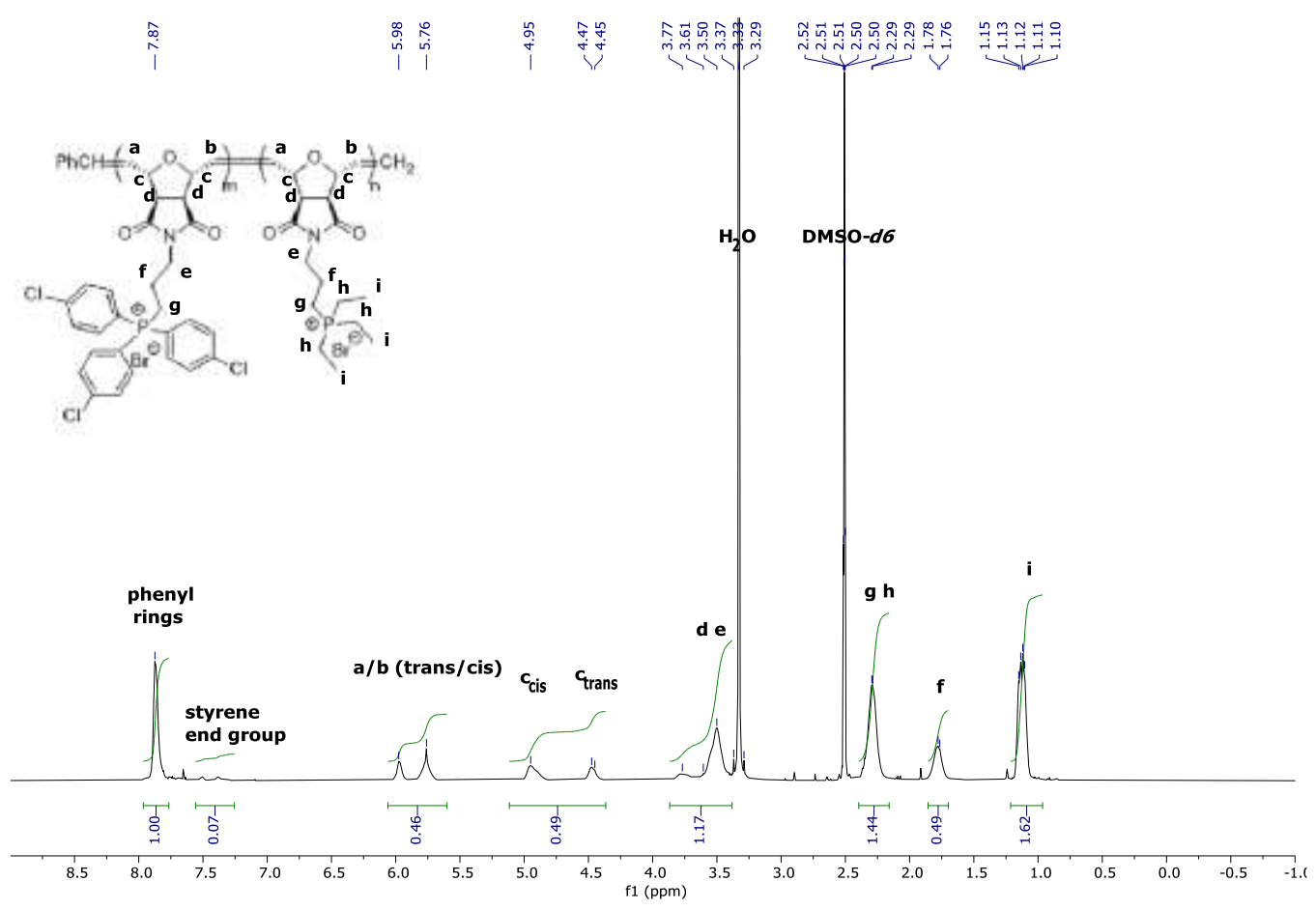

Figure S62. ${ }^{1}$ H NMR spectrum of chlorophenyl and ethyl based copolymer with a theoretical ratio m:n (6:4, by weight) in DMSO- $d_{6} .(5 \mathbf{k})$
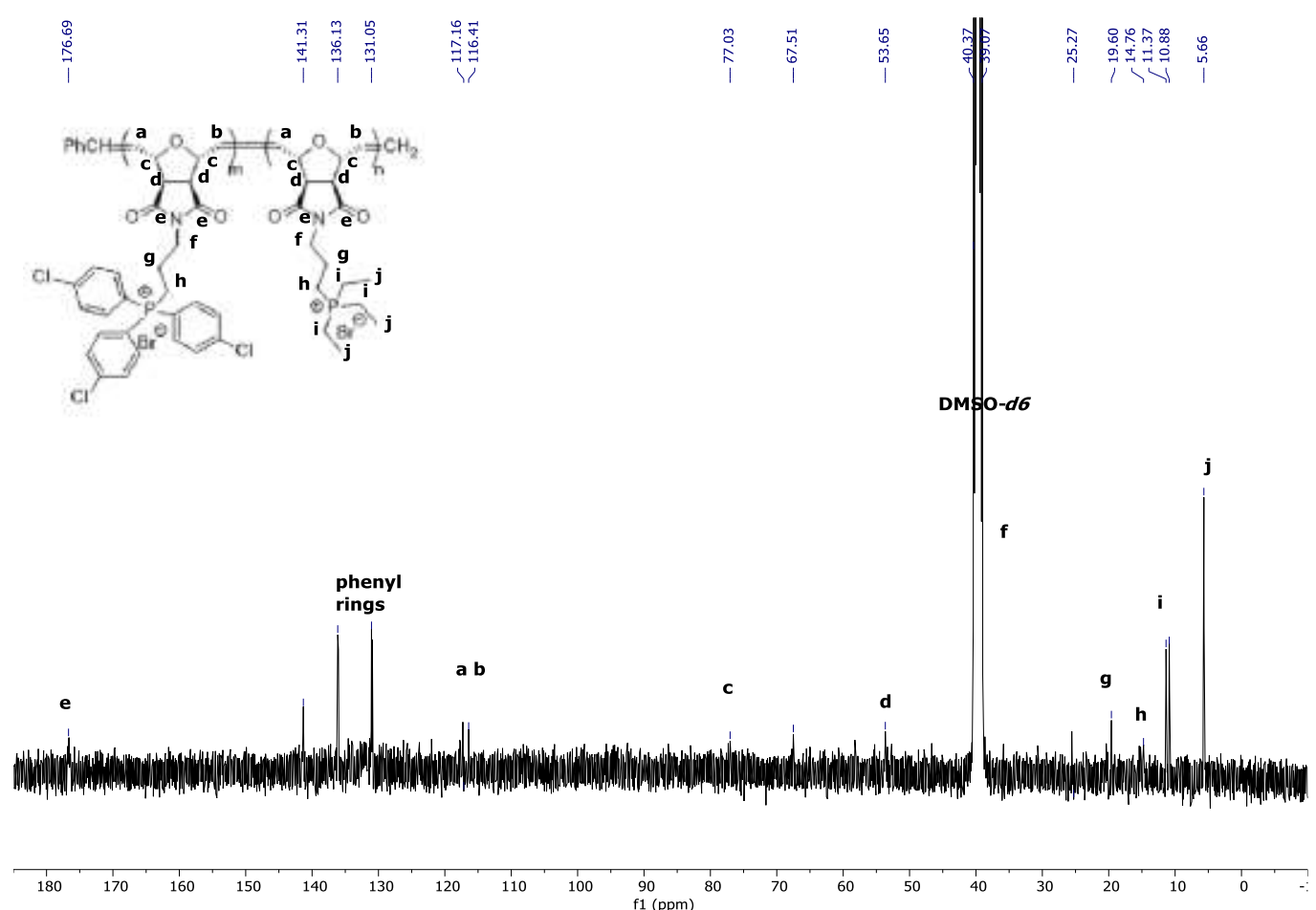

Figure S63. ${ }^{13} \mathrm{C}$ NMR spectrum of chlorophenyl and ethyl based copolymer with a theoretical ratio m:n $\left(6: 4\right.$, by weight) in DMSO- $d_{6} .(5 \mathbf{k})$ 


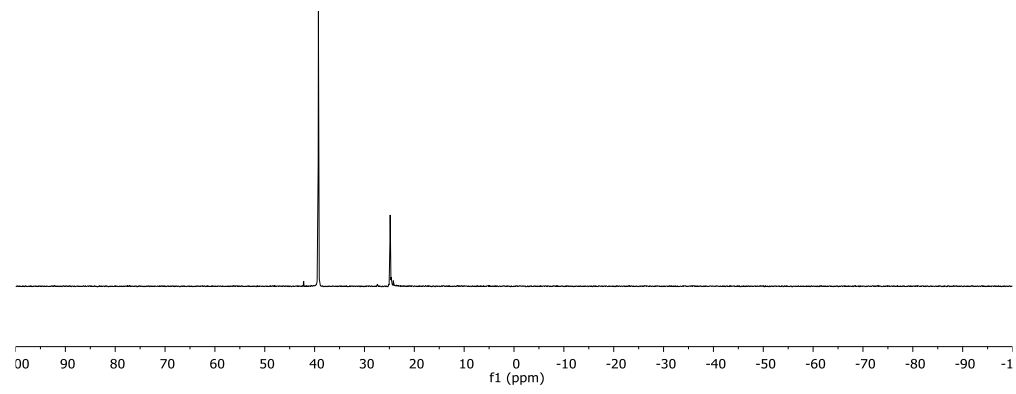

Figure S64. ${ }^{31} \mathrm{P}$ NMR spectrum of chlorophenyl and ethyl based copolymer with a theoretical ratio m:n $(6: 4$, by weight $)$ in DMSO- $d_{6} .(\mathbf{5 k})$

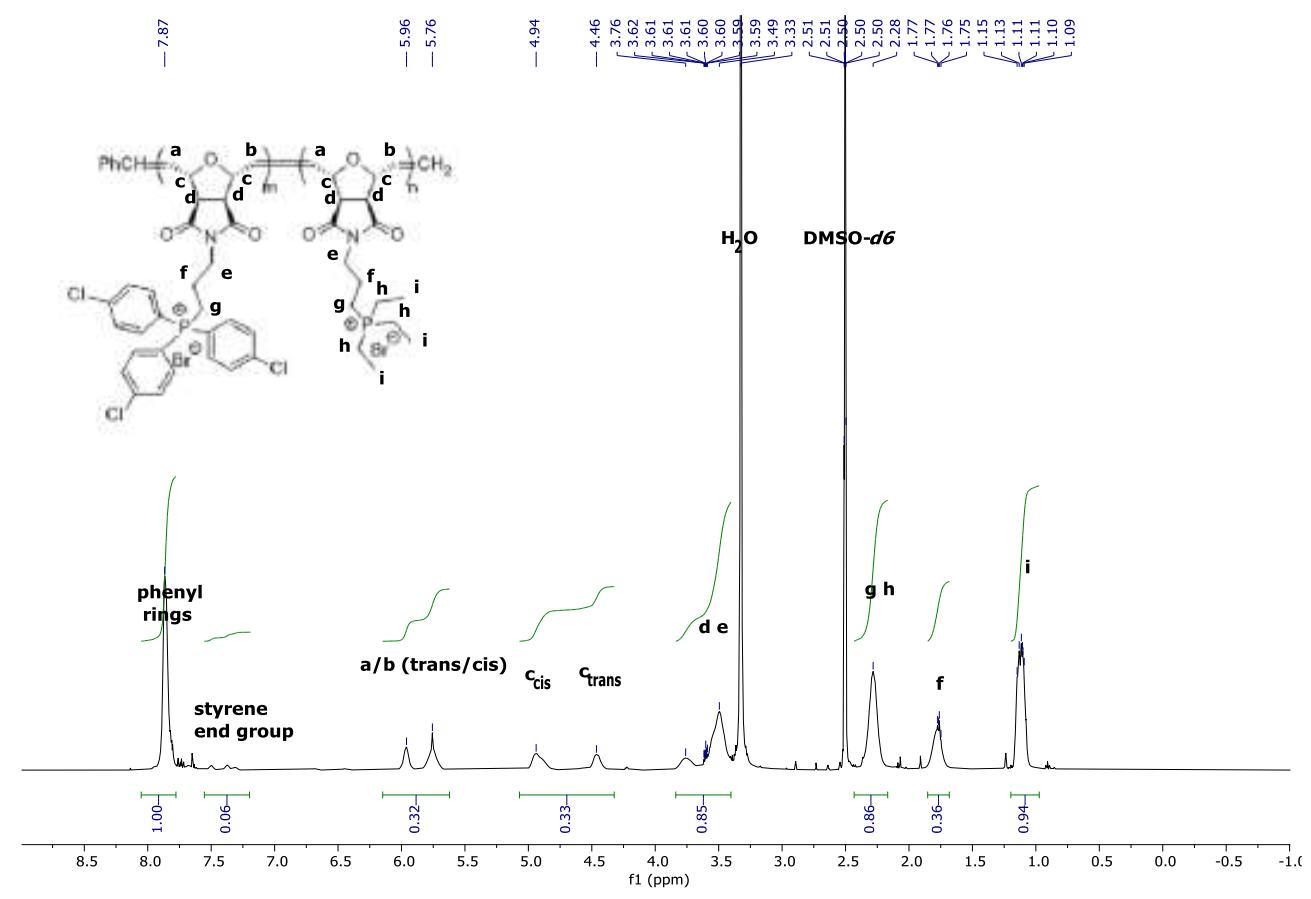

Figure S65. ${ }^{1} \mathrm{H}$ NMR spectrum of chlorophenyl and ethyl based copolymer with a theoretical ratio m:n (7:3, by weight) in DMSO- $d_{6} .(\mathbf{5 l})$ 


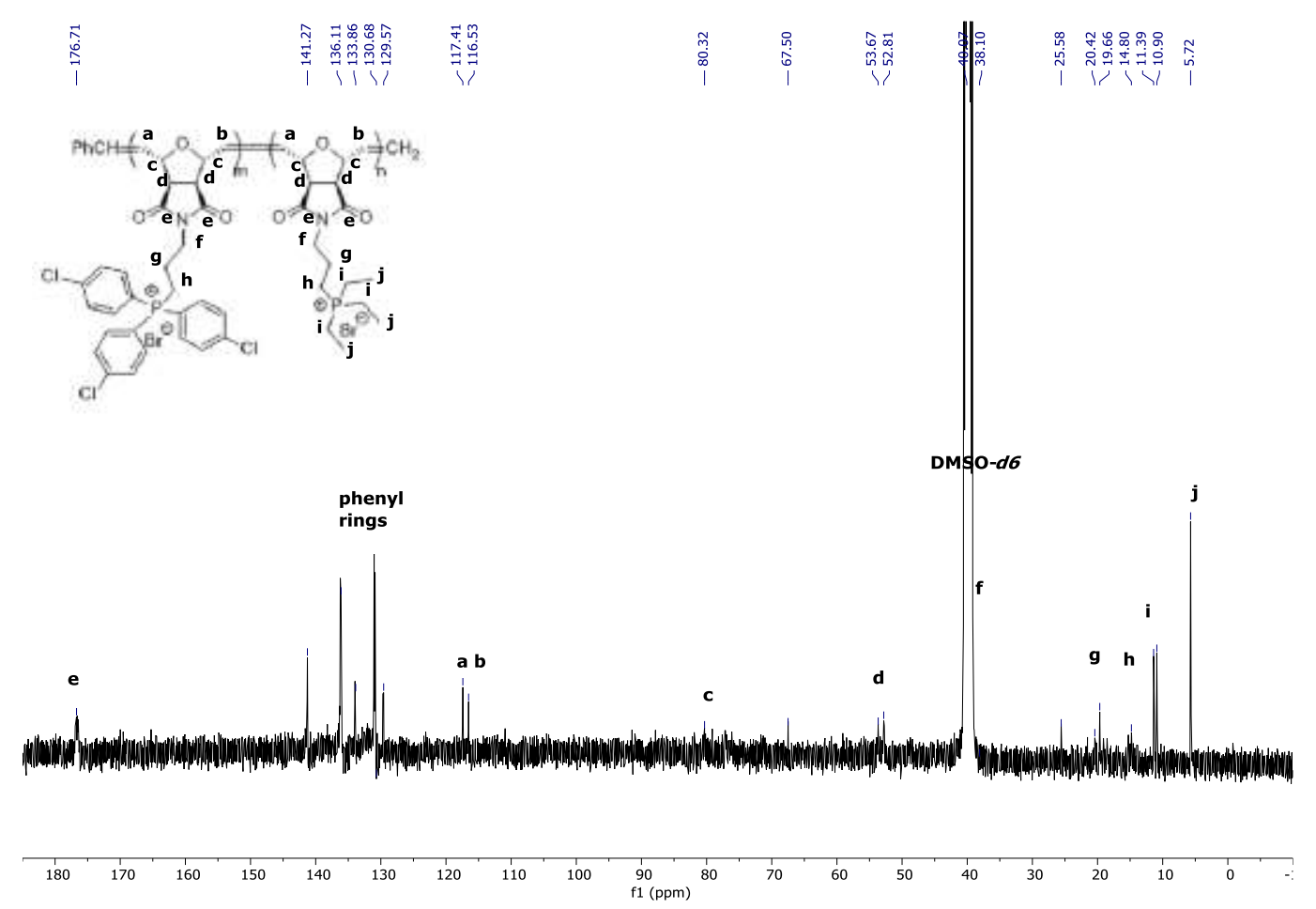

Figure S66. ${ }^{13} \mathrm{C}$ NMR spectrum of chlorophenyl and ethyl based copolymer with a theoretical ratio m:n (7:3, by weight) in DMSO- $d_{6} .(5 \mathbf{l})$

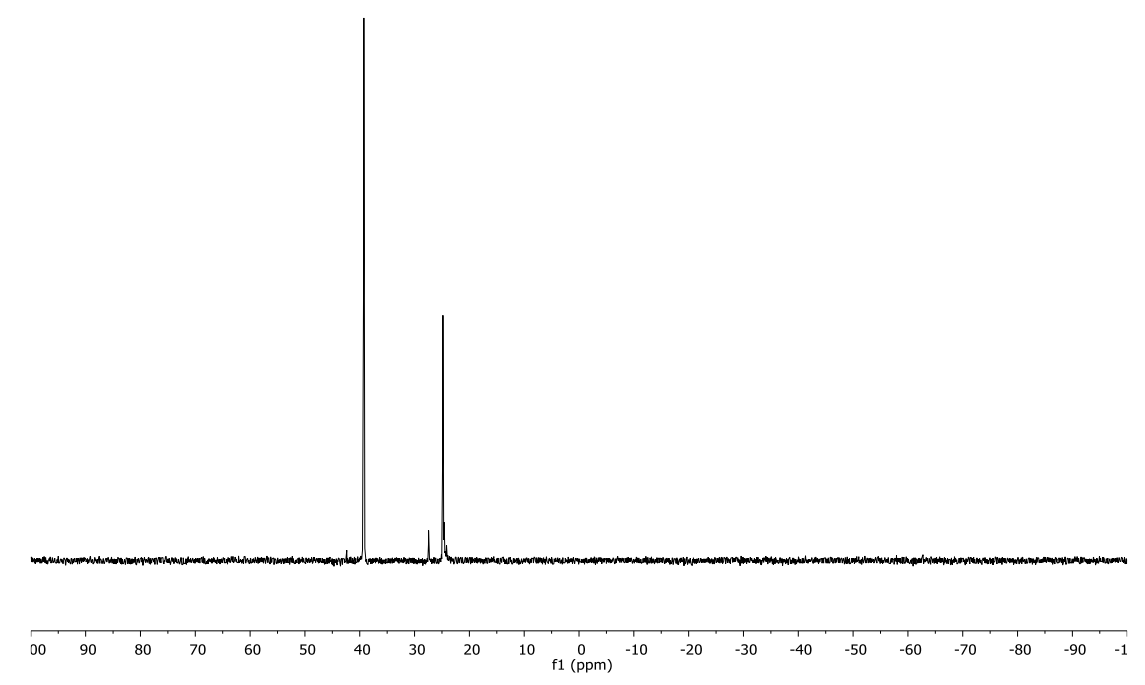

Figure S67. ${ }^{31} \mathrm{P}$ NMR spectrum of chlorophenyl and ethyl based copolymer with a theoretical ratio m:n (7:3, by weight) in DMSO- $d_{6} .(\mathbf{5 1})$ 


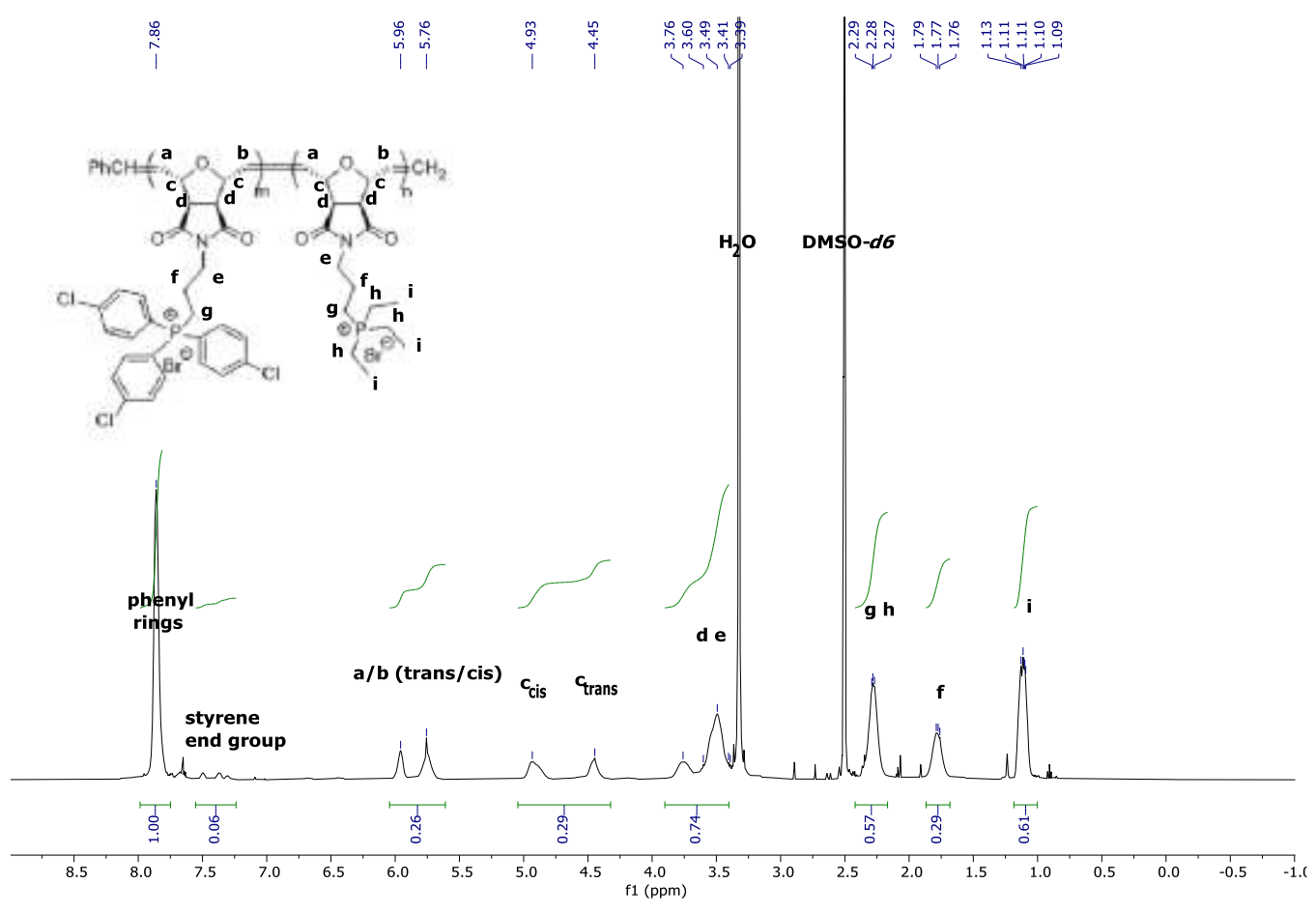

Figure S68. ${ }^{1} \mathrm{H}$ NMR spectrum of chlorophenyl and ethyl based copolymer with a theoretical ratio m:n $\left(8: 2\right.$, by weight) in DMSO- $d_{6} .(\mathbf{5 m})$

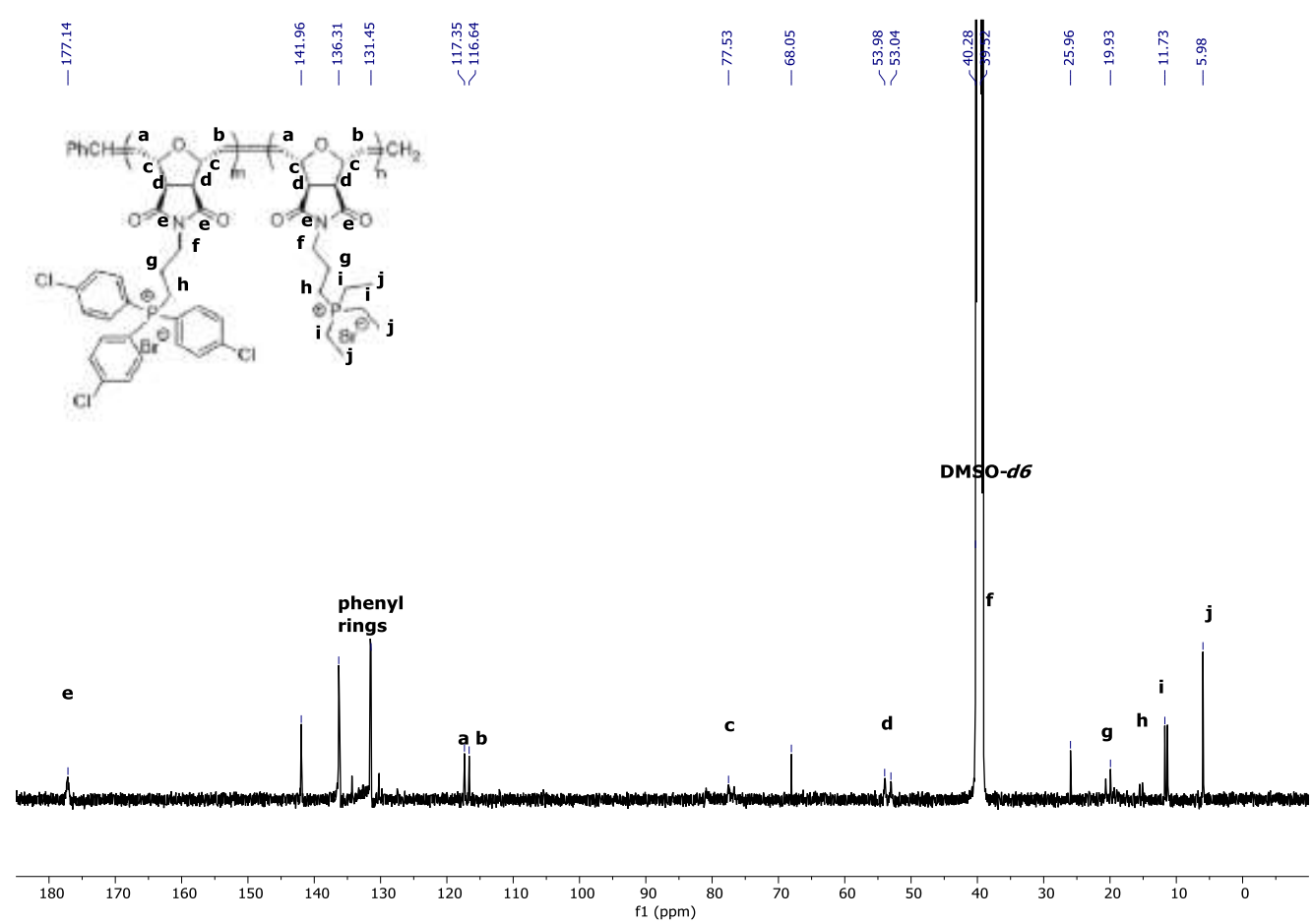

Figure S69. ${ }^{13} \mathrm{C}$ NMR spectrum of chlorophenyl and ethyl based copolymer with a theoretical ratio m:n $(8: 2$, by weight $)$ in $\mathrm{DMSO}-d_{6} .(\mathbf{5 m})$ 

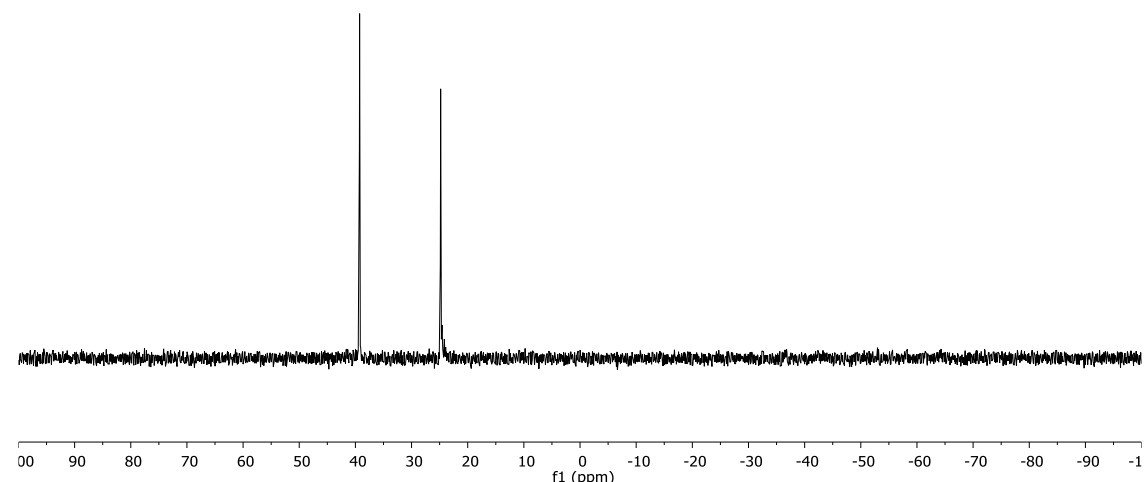

Figure S70. ${ }^{31} \mathrm{P}$ NMR spectrum of chlorophenyl and ethyl based copolymer with a theoretical ratio m:n (8:2, by weight) in DMSO- $d_{6} .(\mathbf{5 m})$

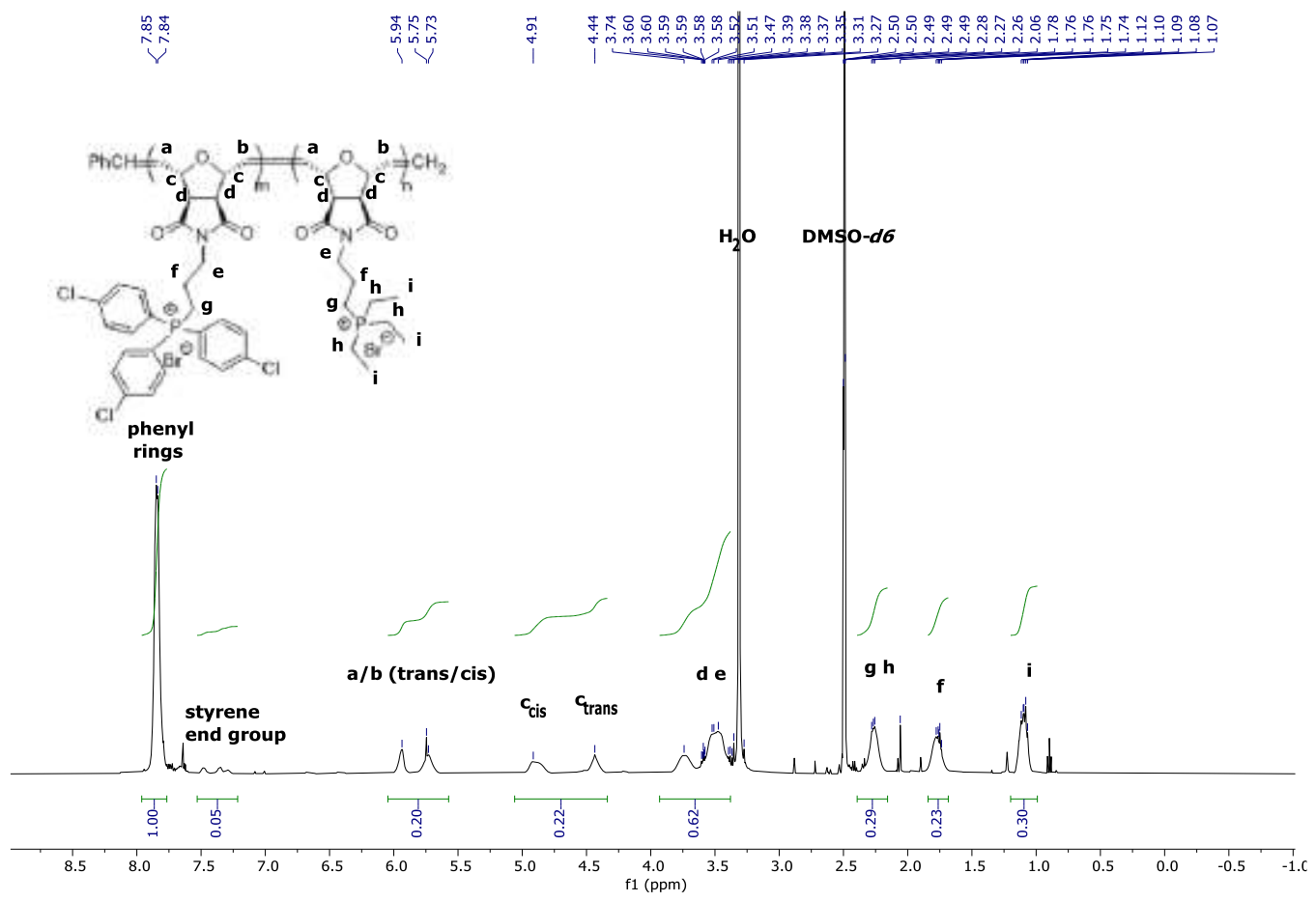

Figure S71. ${ }^{1} \mathrm{H}$ NMR spectrum of chlorophenyl and ethyl based copolymer with a theoretical ratio m:n $\left(9: 1\right.$, by weight) in DMSO- $d_{6} .(\mathbf{5 n})$ 


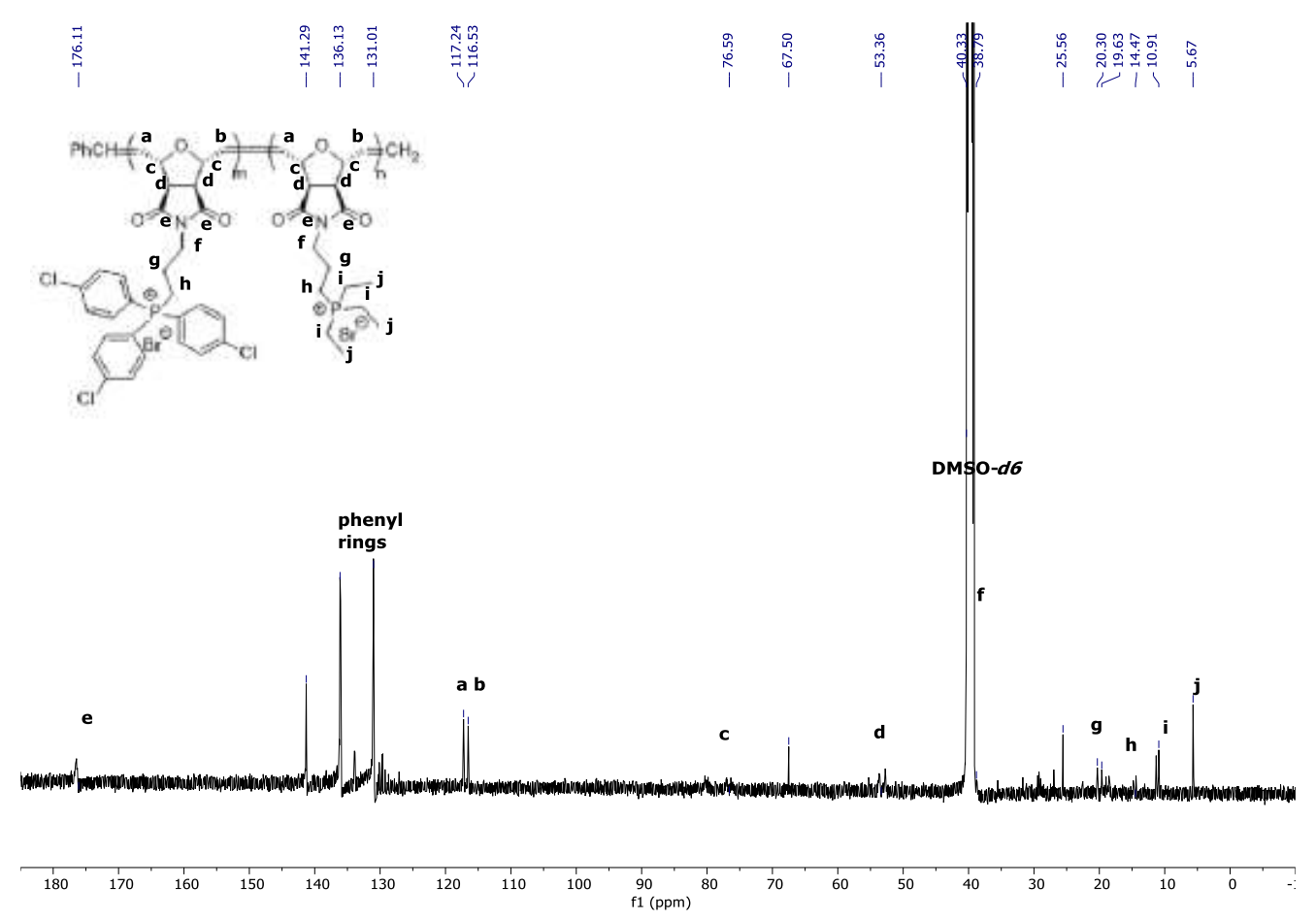

Figure S72. ${ }^{13} \mathrm{C}$ NMR spectrum of chlorophenyl and ethyl based copolymer with a theoretical ratio m:n (9:1, by weight) in DMSO- $d_{6} .(\mathbf{5 n})$

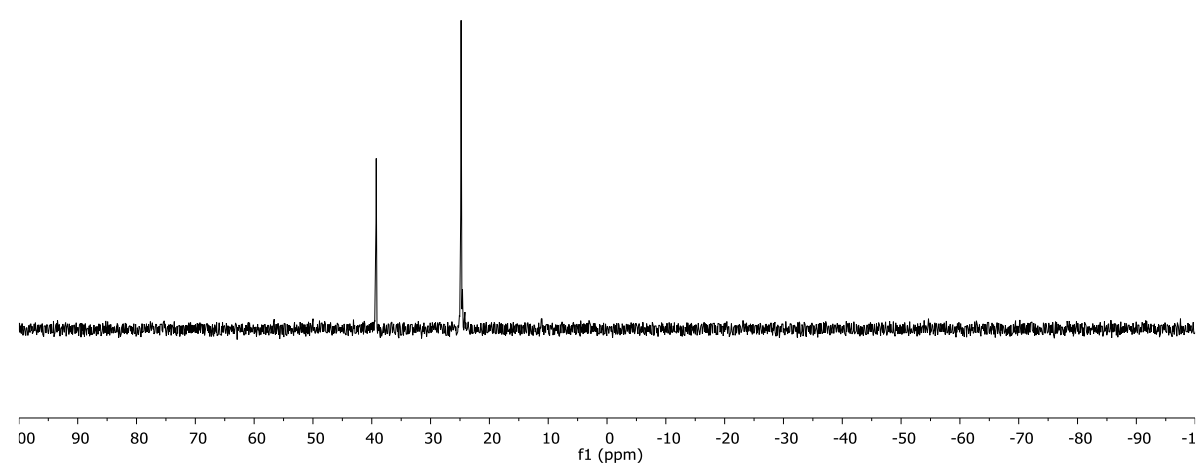

Figure S73. ${ }^{31} \mathrm{P}$ NMR spectrum of chlorophenyl and ethyl based copolymer with a theoretical ratio m:n (9:1, by weight) in DMSO- $d_{6} .(\mathbf{5 n})$ 


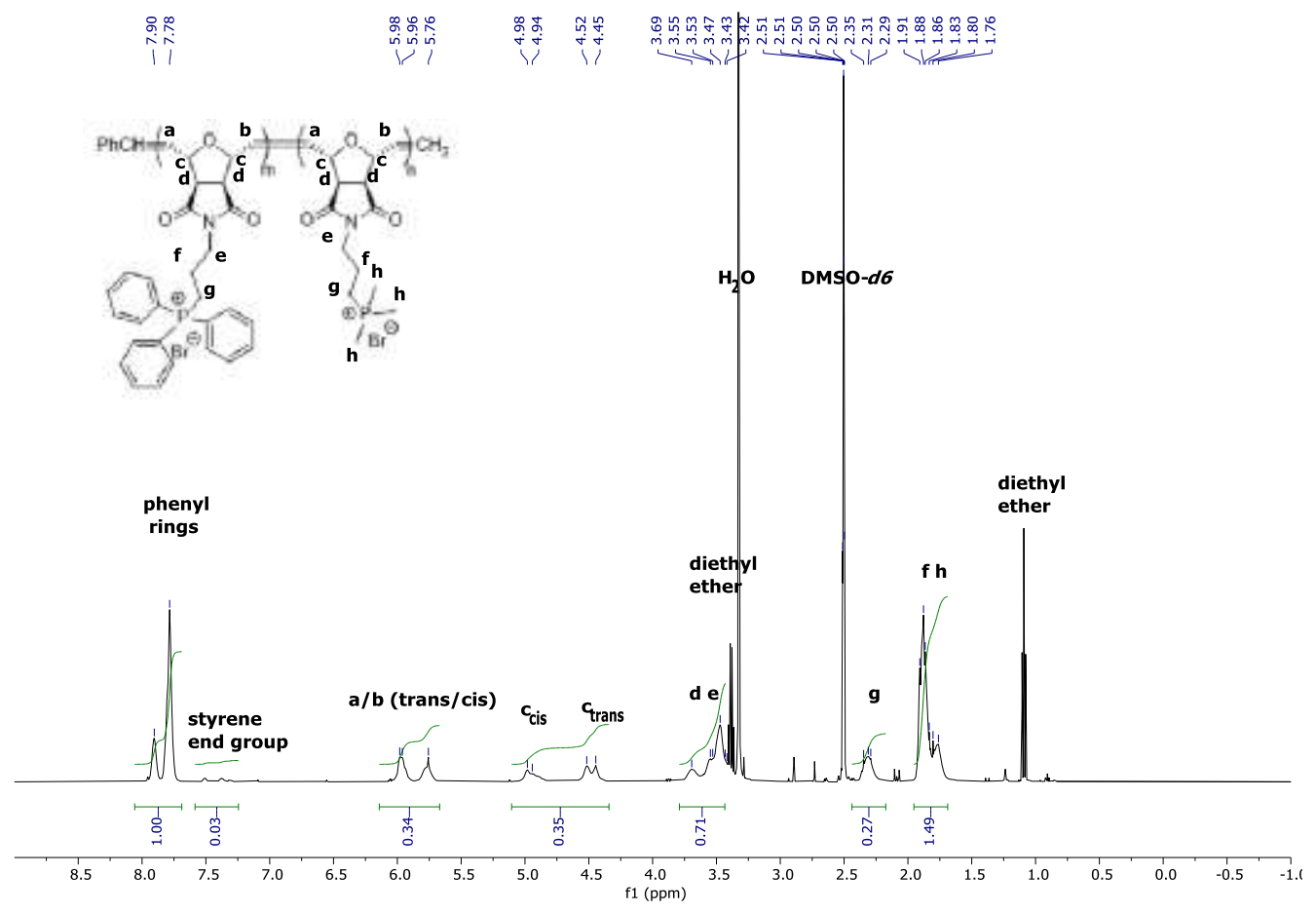

Figure S74. ${ }^{1}$ H NMR spectrum of phenyl and methyl based copolymer with a theoretical ratio m:n $\left(5: 5\right.$, by weight) in DMSO- $d_{6 .}(\mathbf{5 o})$
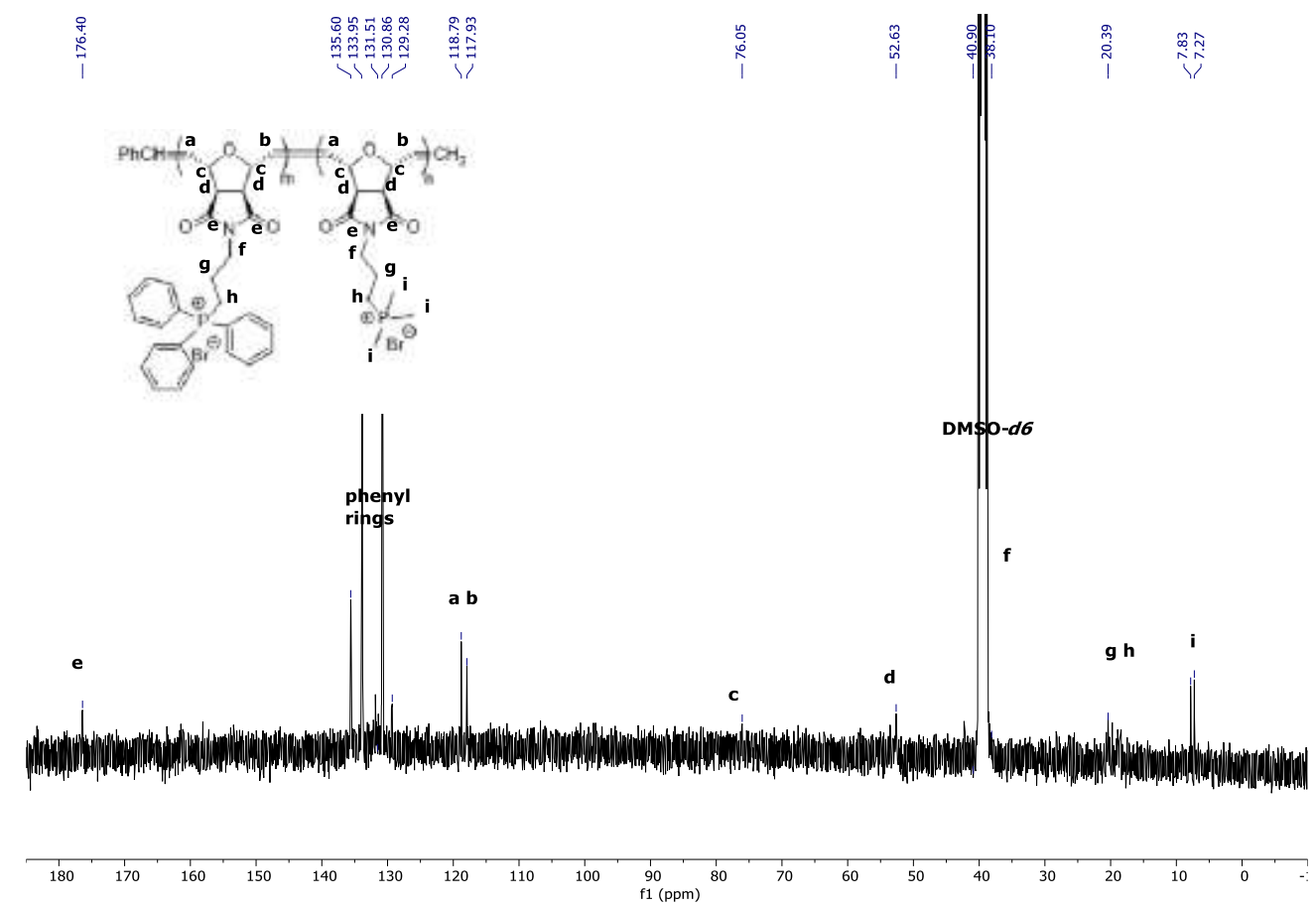

Figure S75. ${ }^{13} \mathrm{C}$ NMR spectrum of phenyl and methyl based copolymer with a theoretical ratio m:n (5:5, by weight) in DMSO- $d_{6}$. (5o) 


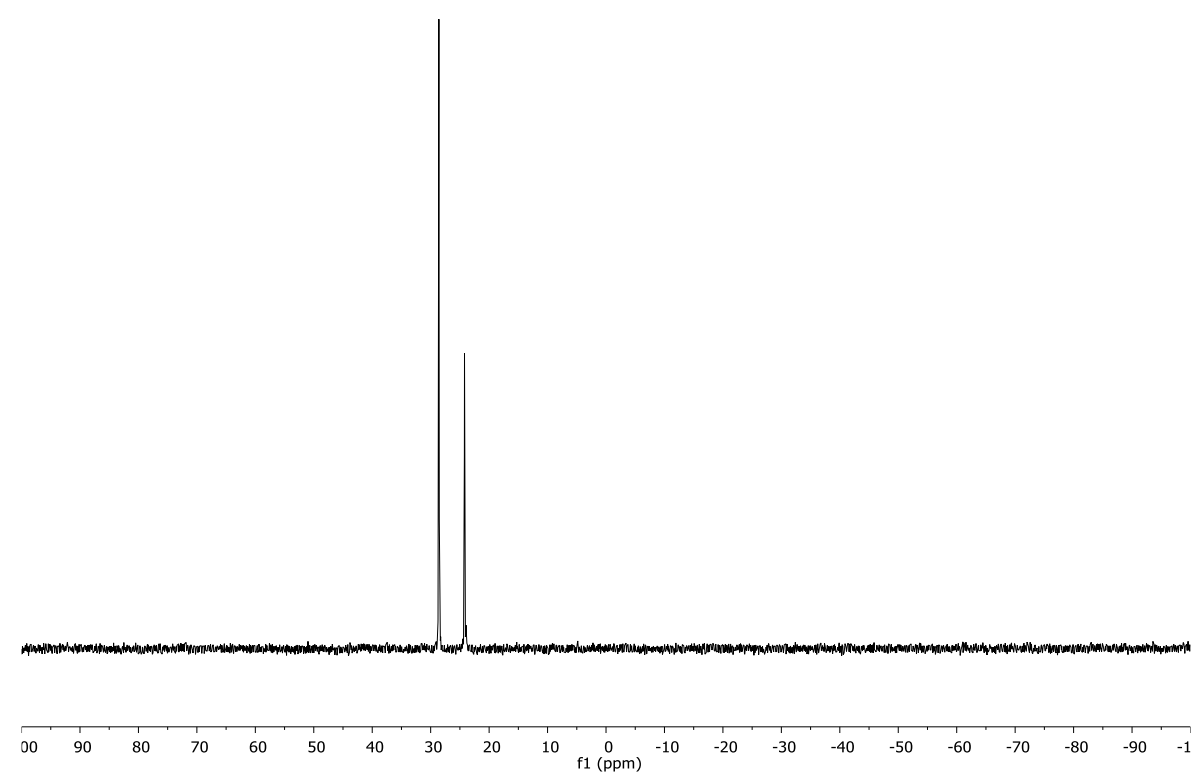

Figure S76. ${ }^{31} \mathrm{P}$ NMR spectrum of phenyl and methyl based copolymer with a theoretical ratio m:n (5:5, by weight) in DMSO- $d_{6}$. (5o)

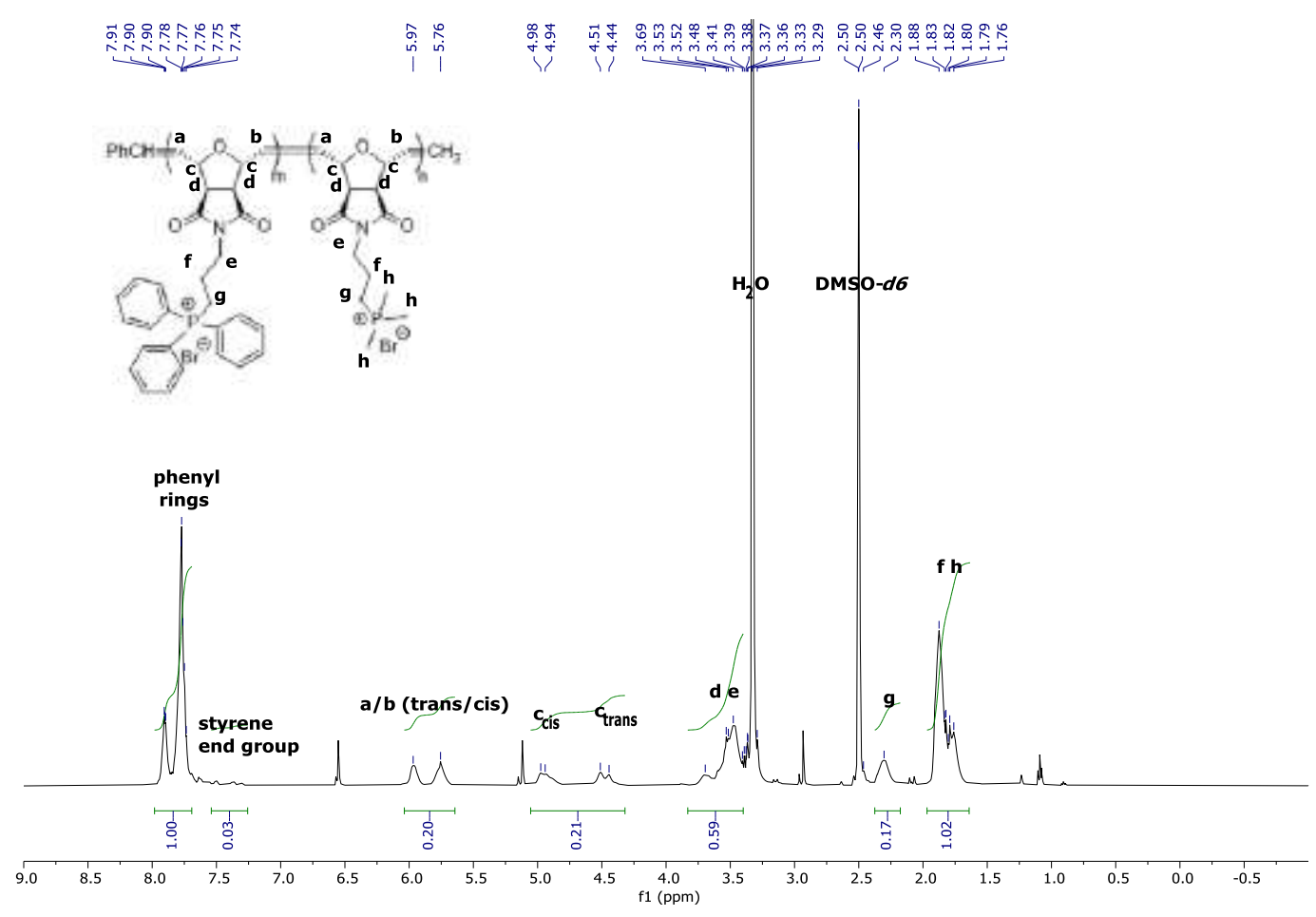

Figure S77. ${ }^{1}$ H NMR spectrum of phenyl and methyl based copolymer with a theoretical ratio m:n (6:4, by weight) in DMSO- $d_{6}(\mathbf{5 p})$. 


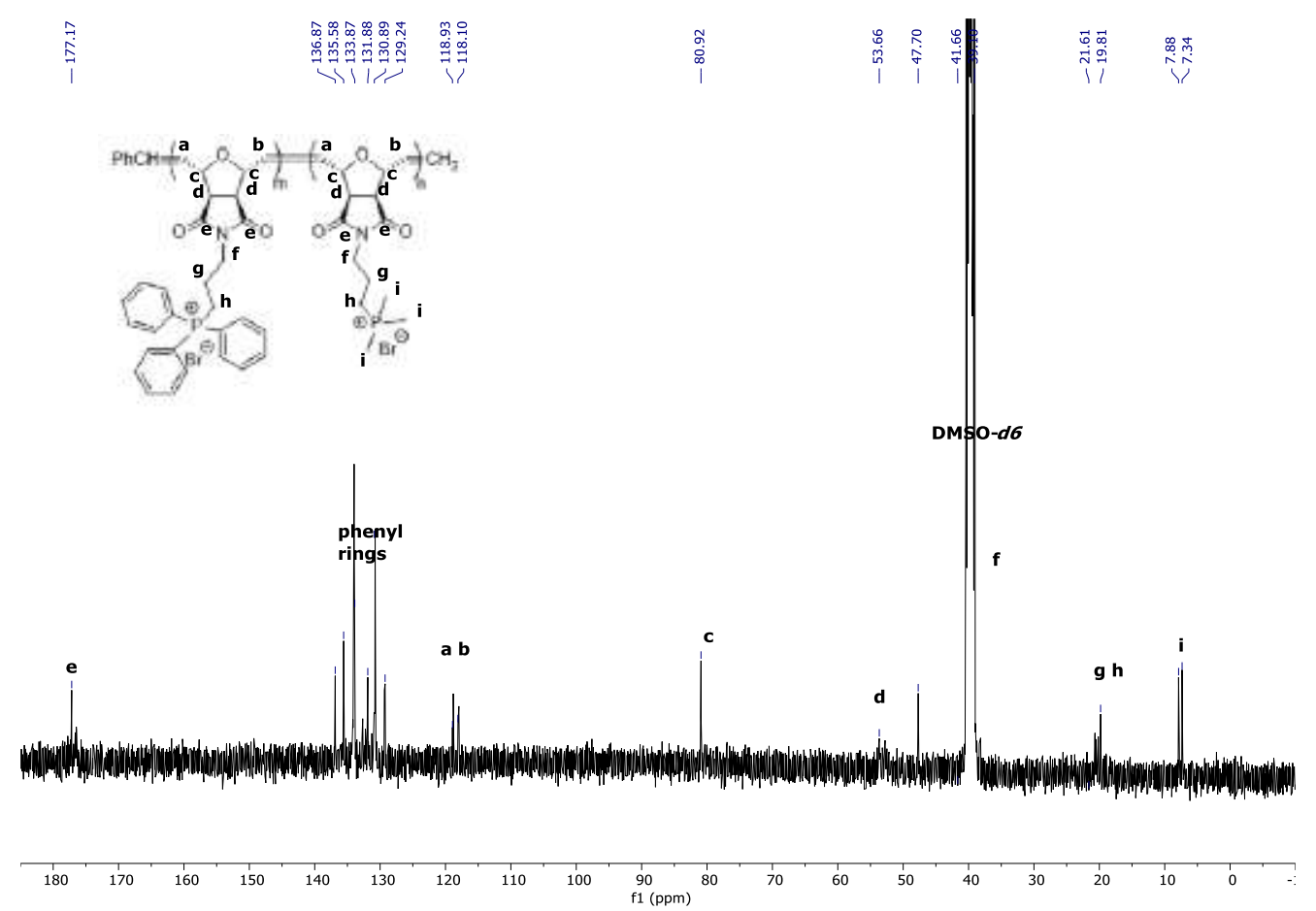

Figure S78. ${ }^{13} \mathrm{C}$ NMR spectrum of phenyl and methyl based copolymer with a theoretical ratio m:n (6:4, by weight) in DMSO- $d_{6}(\mathbf{5 p})$.

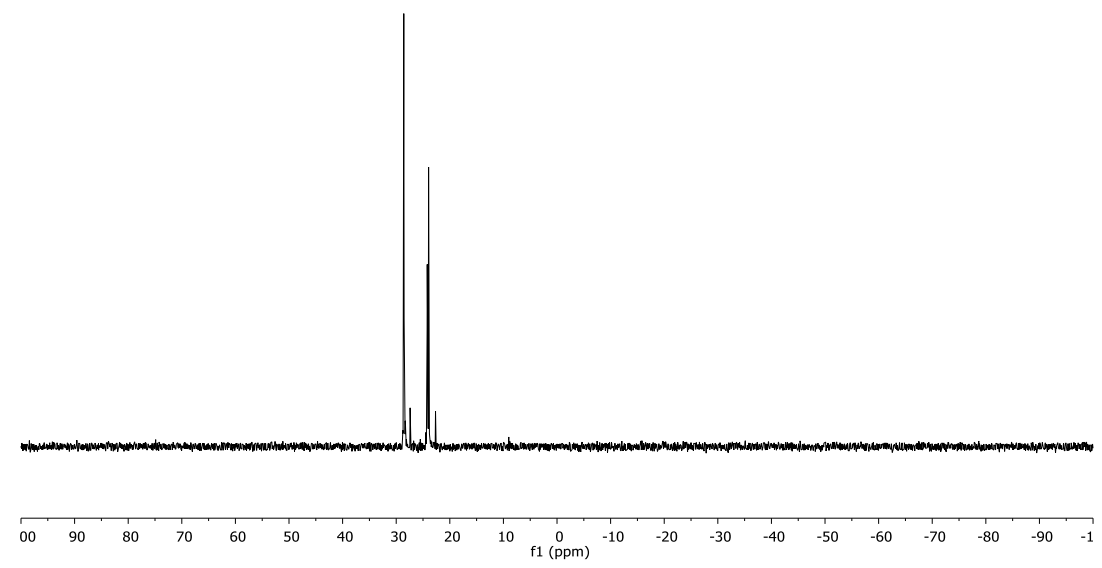

Figure S79. ${ }^{31} \mathrm{P}$ NMR spectrum of phenyl and methyl based copolymer with a theoretical ratio m:n (6:4, by weight) in DMSO- $d_{6}(\mathbf{5 p})$. 


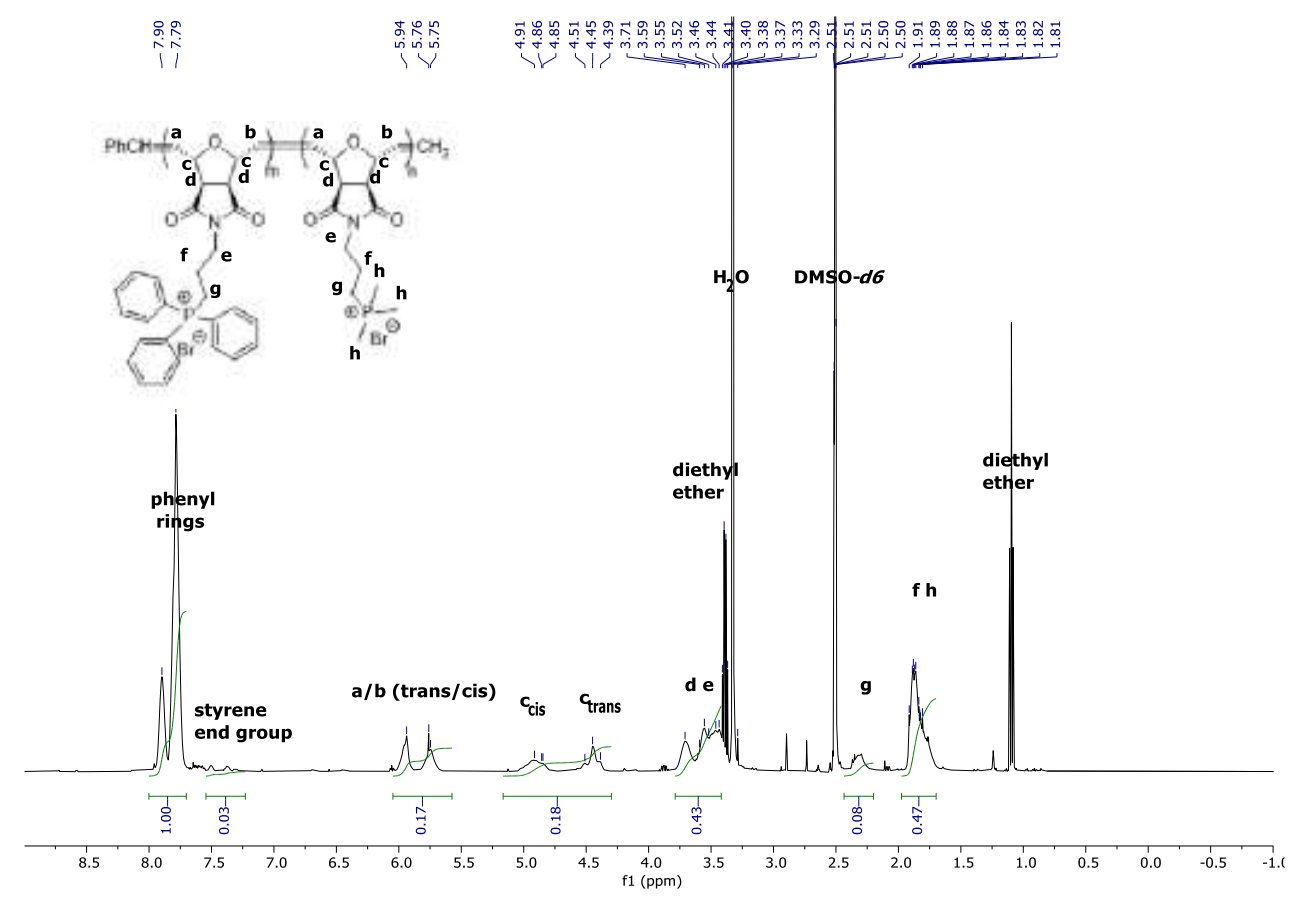

Figure S80. ${ }^{1} \mathrm{H}$ NMR spectrum of phenyl and methyl based copolymer with a theoretical ratio m:n $\left(8: 2\right.$, by weight) in DMSO- $d_{6 .}(\mathbf{5 q})$
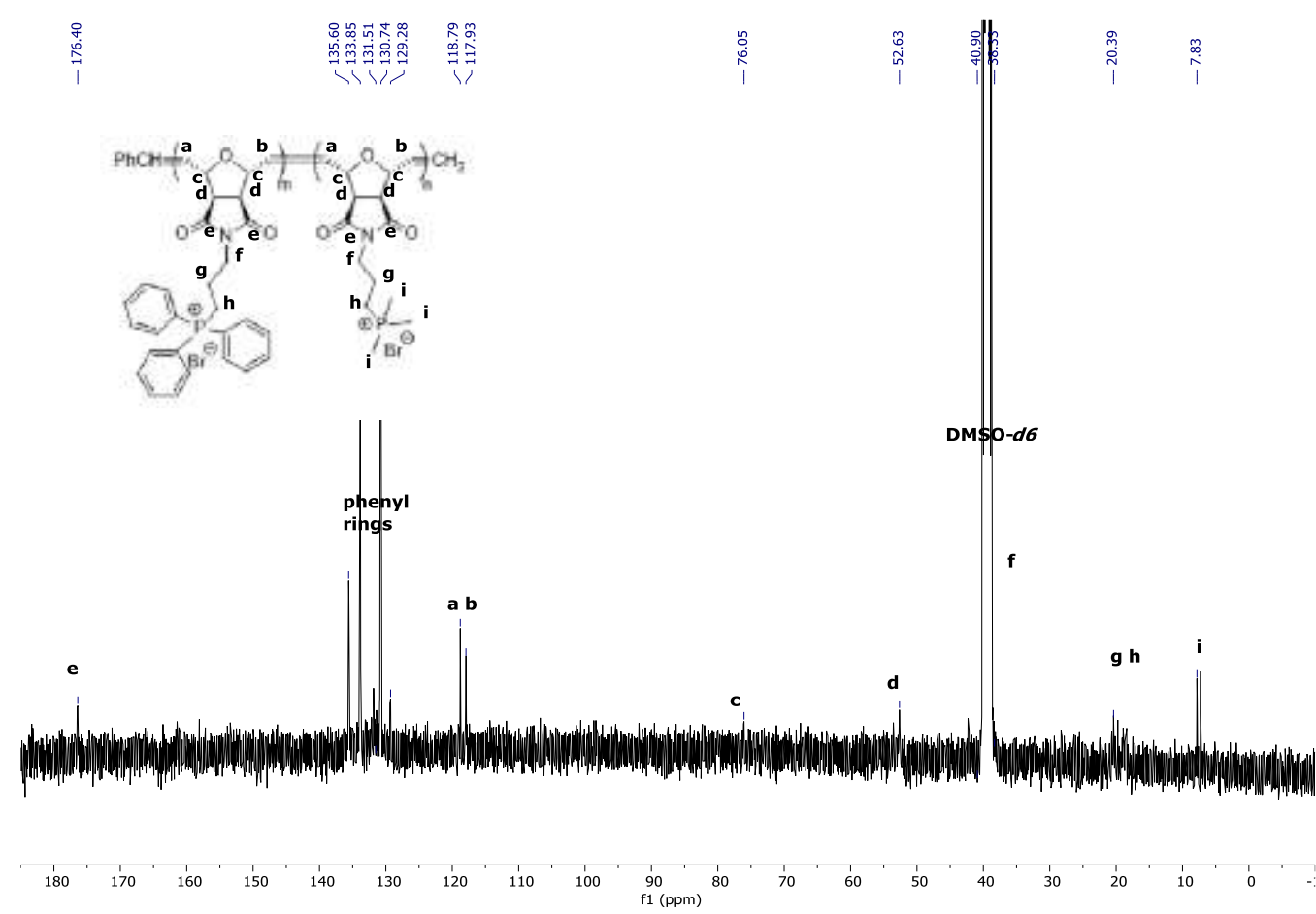

Figure S81. ${ }^{13} \mathrm{C}$ NMR spectrum of phenyl and methyl based copolymer with a theoretical ratio m:n (8:2, by weight) in DMSO- $d_{6 .}(\mathbf{5 q})$ 


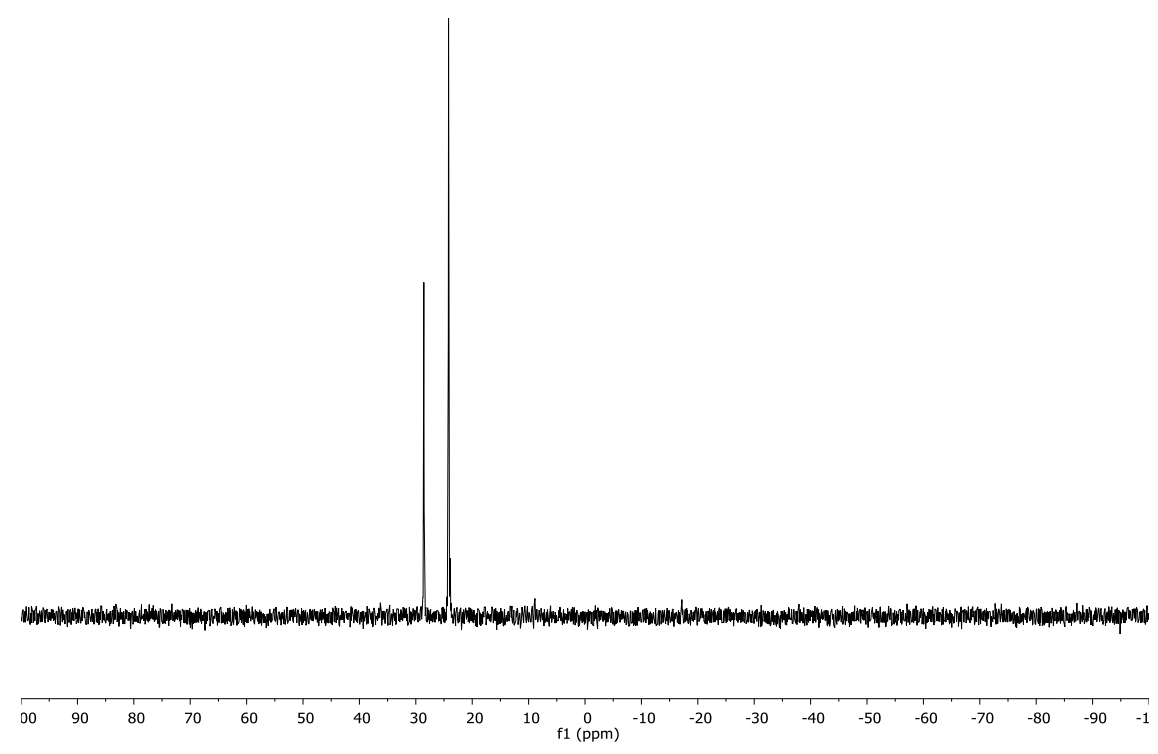

Figure S82. ${ }^{31} \mathrm{P}$ NMR spectrum of phenyl and methyl based copolymer with a theoretical ratio m:n $\left(8: 2\right.$, by weight) in DMSO- $d_{6 .}(\mathbf{5 q})$

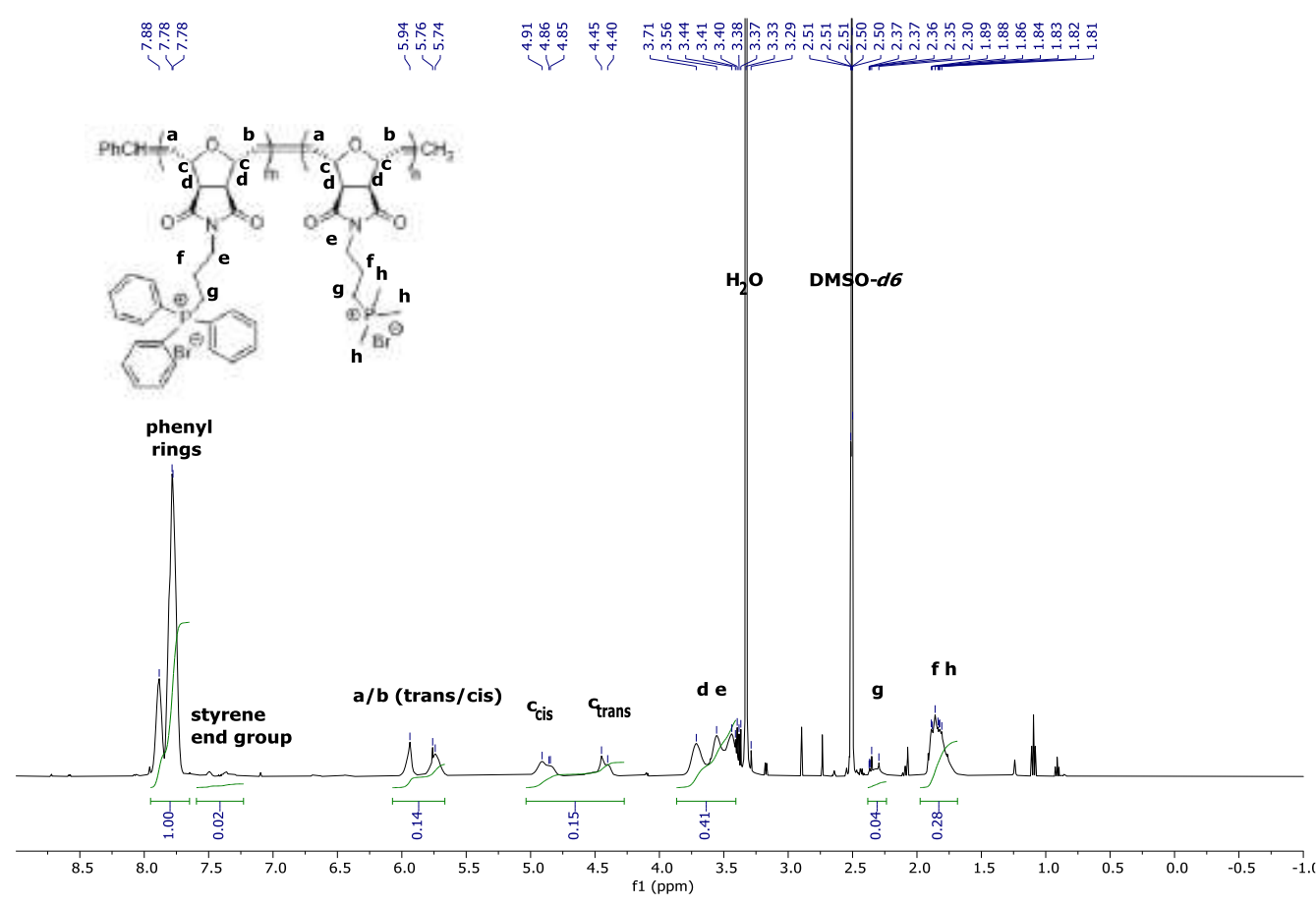

Figure S83. ${ }^{1}$ H NMR spectrum of phenyl and methyl based copolymer with a theoretical ratio m:n $\left(9: 1\right.$, by weight) in DMSO- $d_{6} .(5 \mathbf{r})$ 


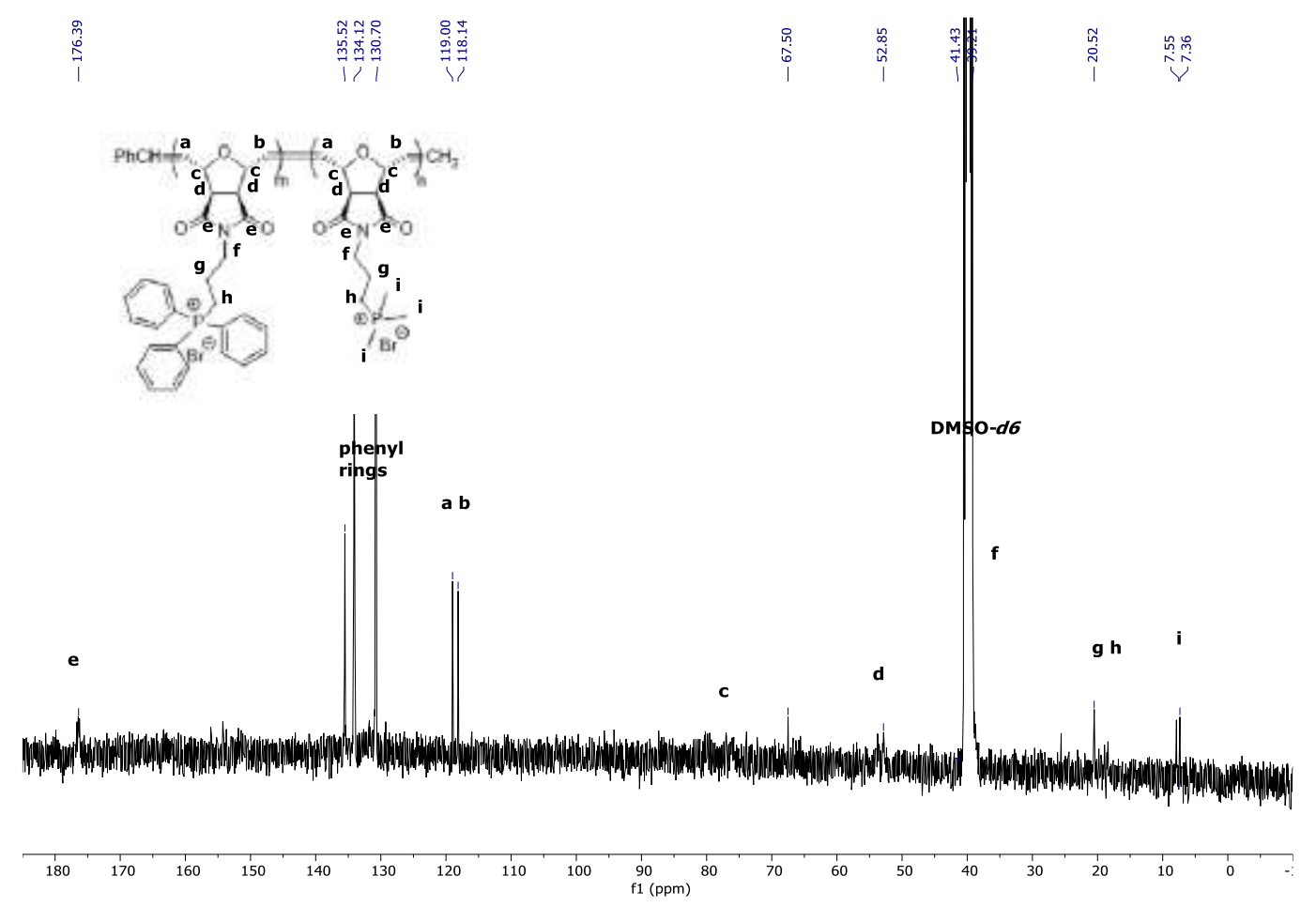

Figure S84. ${ }^{13} \mathrm{C}$ NMR spectrum of phenyl and methyl based copolymer with a theoretical ratio m:n $\left(9: 1\right.$, by weight) in DMSO- $d_{6} .(5 r)$

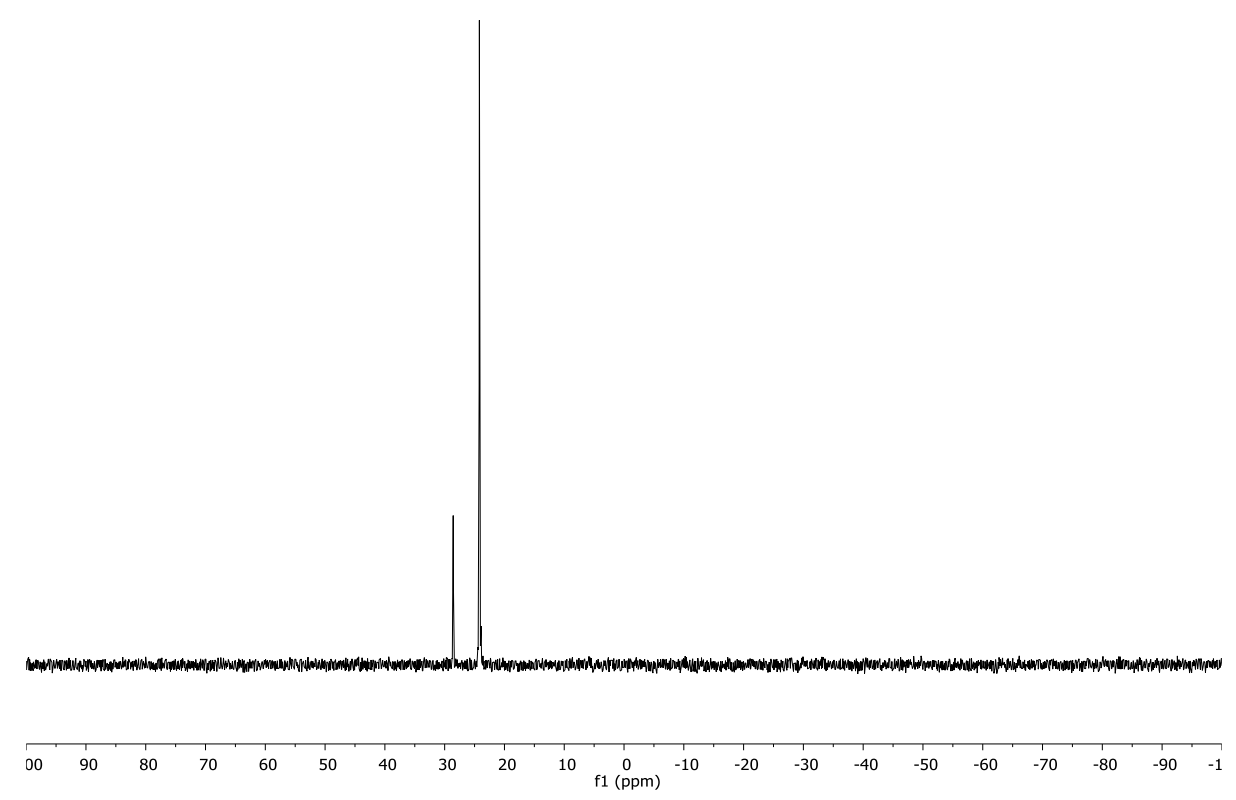

Figure S85. ${ }^{31} \mathrm{P}$ NMR spectrum of phenyl and methyl based copolymer with a theoretical ratio m:n (9:1, by weight) in DMSO- $d_{6}$. (5r) 


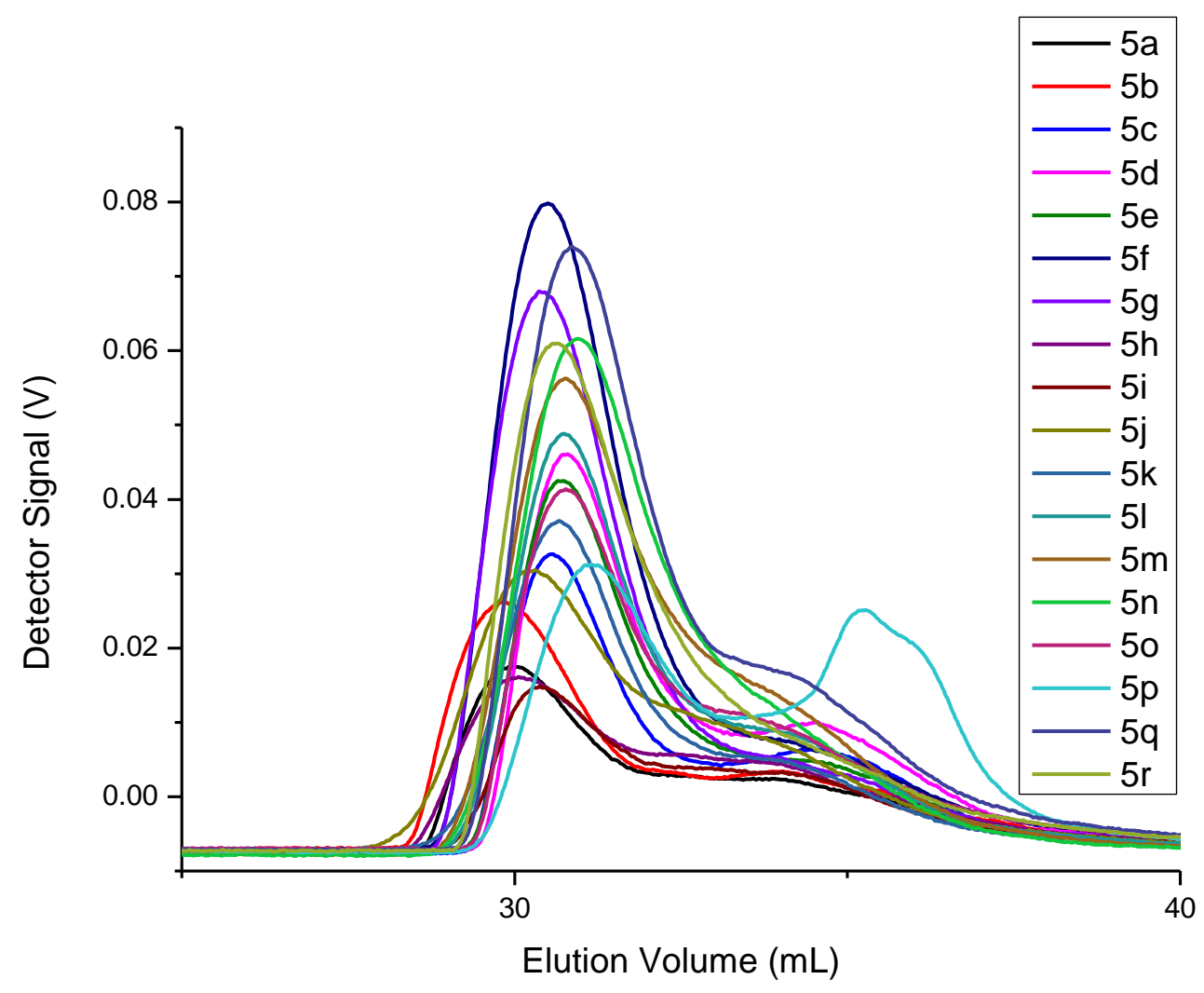

Figure S86. SEC spectra of copolymers (5a-5r) 
VI. Antibacterial and Hemolytic Activity of the Copolymers

Table S3. The antibacterial and hemolytic activities of the copolymers

\begin{tabular}{|c|c|c|c|c|c|c|}
\hline \multirow[t]{2}{*}{$\begin{array}{c}\text { Polyme } \\
\text { rs }\end{array}$} & \multirow[t]{2}{*}{ Feeding Ratios } & \multicolumn{2}{|c|}{$\operatorname{MIC}\left(\mu \mathrm{g} \mathrm{mL}^{-1}\right)$} & \multirow[t]{2}{*}{ 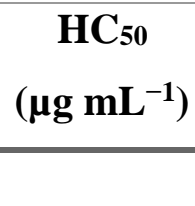 } & \multicolumn{2}{|c|}{$\begin{array}{c}\text { SI } \\
\left(\text { HC }_{50} / \mathrm{MIC}\right)\end{array}$} \\
\hline & & S. aureus & E. coli & & S. aureus & E. coli \\
\hline $4 a-10 k$ & Phenyl & 16 & 32 & $<512$ & $<32$ & $<16$ \\
\hline $4 c-10 k$ & $\mathrm{Cl}$-Phenyl & 128 & 512 & $<1$ & $<1$ & $<1$ \\
\hline $4 \mathrm{f}-10 \mathrm{k}$ & Methyl & 512 & 512 & $>512$ & $>1$ & $>1$ \\
\hline $4 g-10 k$ & Ethyl & $>512$ & $>512$ & $>512$ & $>1$ & $>1$ \\
\hline $5 a$ & Phenyl : Ethyl (1:9) & 512 & $>512$ & $>2048$ & $>4$ & $>4$ \\
\hline $5 b$ & Phenyl : Ethyl (2:8) & 512 & $>512$ & $>2048$ & $>4$ & $>4$ \\
\hline $5 c$ & Phenyl : Ethyl (5:5) & 32 & 128 & 2048 & 64 & 16 \\
\hline $5 d$ & Phenyl : Ethyl (6:4) & 8 & 32 & 128 & 16 & 4 \\
\hline $5 e$ & Phenyl : Ethyl (7:3) & 8 & 8 & 128 & 16 & 16 \\
\hline $5 f$ & Phenyl : Ethyl (8:2) & 8 & 8 & 32 & 4 & 4 \\
\hline $5 g$ & Phenyl : Ethyl (9:1) & 8 & 16 & 4 & $<1$ & $<1$ \\
\hline $5 \mathrm{~h}$ & Cl-Phenyl : Ethyl (1:9) & 512 & $>512$ & $>2048$ & $>4$ & $>4$ \\
\hline $5 \mathrm{i}$ & Cl-Phenyl : Ethyl (2:8) & 128 & $>512$ & $>2048$ & 16 & $>4$ \\
\hline $5 \mathrm{j}$ & Cl-Phenyl : Ethyl (5:5) & 32 & 128 & 128 & 4 & 1 \\
\hline $5 \mathrm{k}$ & Cl-Phenyl : Ethyl (6:4) & 8 & 64 & 16 & 2 & $<1$ \\
\hline 51 & Cl-Phenyl : Ethyl (7:3) & 16 & 32 & 8 & $<1$ & $<1$ \\
\hline $5 \mathrm{~m}$ & Cl-Phenyl : Ethyl (8:2) & 8 & 32 & 4 & $<1$ & $<1$ \\
\hline $5 n$ & Cl-Phenyl : Ethyl (9:1) & 16 & 32 & 4 & $<1$ & $<1$ \\
\hline 50 & Phenyl : Methyl (5:5) & 16 & 256 & 2048 & 128 & 8 \\
\hline $5 p$ & Phenyl : Methyl (6:4) & 32 & 256 & 1024 & 32 & 4 \\
\hline $5 q$ & Phenyl : Methyl (8:2) & 8 & 16 & 64 & 8 & 4 \\
\hline $5 r$ & Phenyl : Methyl (9:1) & 8 & 16 & 4 & $<1$ & $<1$ \\
\hline
\end{tabular}

